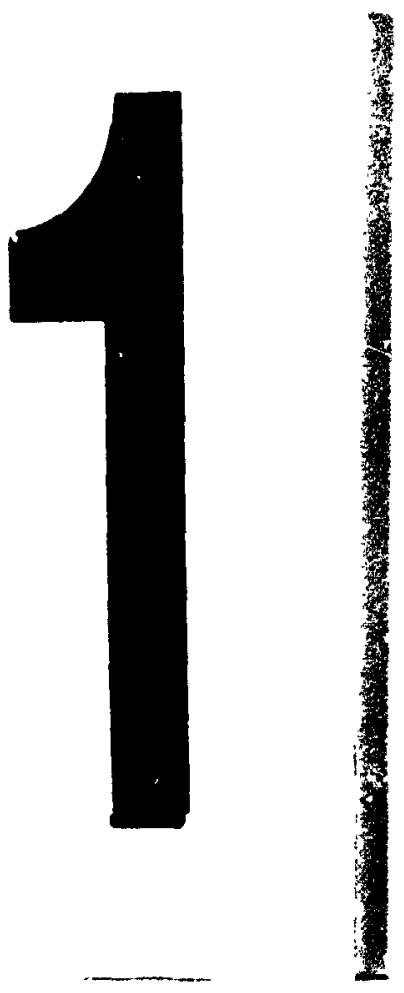

PM-1 31/2"X4" PHOTOGRAPHIC MICROCOPY TARGET NBS 1010 ANSI/ISO "2 EOUIVALENT

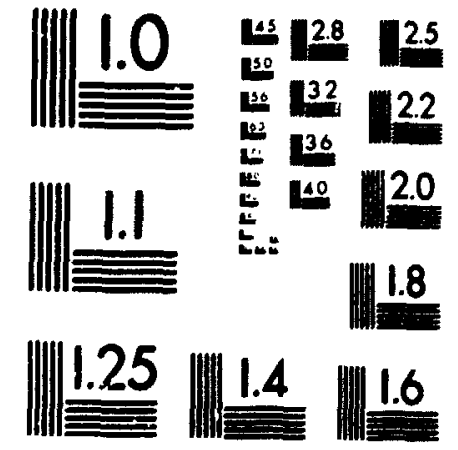

PRECISIONEM RESOLUTION TARGETS

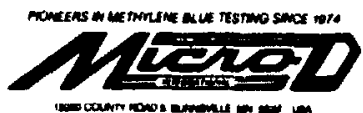


Nationa! Library

of Canada

Acquisitions and

Bibliographic Services Branch

395 Wellingion Street

Ottawa, Ontario

KIA ON4
Bibliotheque nationale

du Canada

Direction des acquisitions et

des services bibliographiques

395, rue Wellington

Ottawa (Ontario)

KIA ON4

\section{NOTICE}

AVIS

La qualité de cette microforme dépend grandement de la qualité de la thèse soumise au microfilmage. Nous avons tout fait pour assurer une qualité supérieure de reproduction.

S'il manque des pages, veuillez communiquer avec l'université qui a conféré le grade.

La qualité d'impression de certaines pages peut laisser à désirer, surtout si les pages originales ont été dactylographiées à l'aide d'un ruban usé ou si l'université nous a fait parvenir une photocopie de qualité inférieure.

La reproduction, même partielle, de cette microforme est soumise à la Loi canadienne sur le droit d'auteur, SRC 1970, c. C-30, et ses amendements subséquents.
Reproduction in full or in part of this microform is governed by the Canadian Copyright Act, R.S.C. 1970, C. C-30, and subsequent amendments.
The quality of this microform is Some pages may have indistinct print especially if the original pages were typed with a poor typewriter ribbon or if the university sent us an inferior photocopy.

If pages are missing, contact the university which granted the degree. for microfilming. ensure the highest quality of reproduction possible. 


\title{
CUSTOMER SATISFACTION WITH THE INDUSTRIAL TELEMARKETING OF COMPUTER SOFTWARE PRODUCTS AND SUPPORT SERVICES
}

\author{
by
}

John K. Barton, B Comm. (Honours)

\begin{abstract}
A thesis submitted to
the Faculty of Graduate Studies and Research

in partial fulfilment of

the requirements for the degree of
\end{abstract}

Master of Management Studies

School of Business

Carleton University

July, 1991 
National Library

of Canada

Acquisitions and

Bibliographic Services Branch

395 Wellington Street

Ottawa. Ontario

KIA ON4
Bıblıothèque natıonale

du Canada

Direction des acquisitions et

des services bibliographiques

395. rue Wellington

Ottawa (Ontario)

KIAON4
The author has granted an irrevocable non-exclusive licence allowing the National Library of Canada to reproduce, loan, distribute or sell copies of his/her thesis by any means and in any form or format, making this thesis available to interested persons.
L'auteur a accordé une licence irrévocable et non exclusive permettant à la Bibliothèque nationale du Canada de reproduire, prêter, distribuer ou vendre des copies de sa thèse de quelque manière et sous quelque forme que ce soit pour mettre des exemplaires de cette thèse à la disposition des personnes intéressées.

L'auteur connserve la propriété du droit d'auteur qui protège sa thèse. Ni la thèse ni des extraits substantiels de celle-ci ne doivent être imprimés ou autrement reproduits sans son autorisation. 
Thesis Acceptance Form

M.M.S. CANDIDATE

The undersigned recommend to the Faculty of Graduate Studies and Research acceptance of the thesis

\section{CUSTOMER SATISFACTION WITH THE INDUSTRIAL TELEMARKETING OF COMPUTER SOFTWARE PRODUCTS AND SUPPORT SERVICES}

submitted by John K. Barton, B.Comm (Honours)

in partial fulfilment of the requirements for

the degree of Master of Management Studies

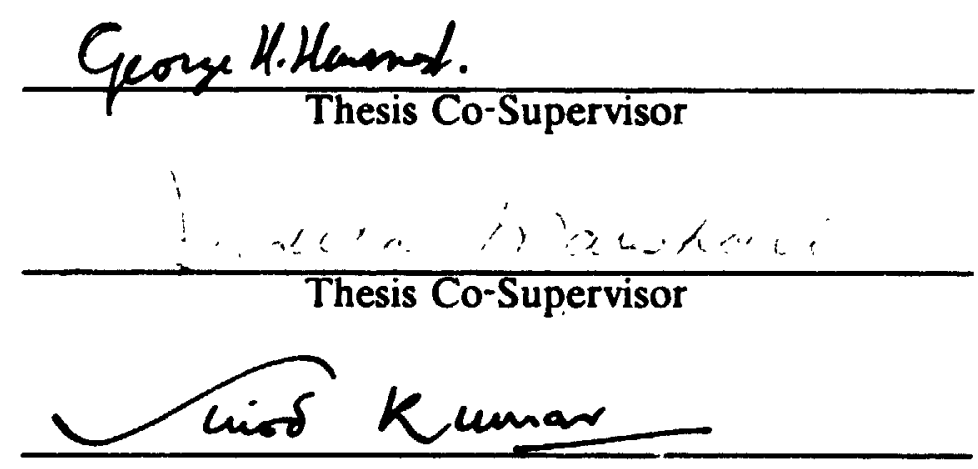

Chair, School of Business

School of Business

Carleton University

August 12, 1991 


\begin{abstract}
Customer satisfaction with a telemarketing operation that specializes in the corporate sales of computer software products and support services is studied. The purpose of the research is (1) to document customer satisfaction/ dissatisfaction (CS/D) with industrial telemarketing and determine what factors are related to this satisfaction/dissatisfaction and (2) to collect customer perceptions regarding the appropriate usage of industrial telemarketing. Various service and and usage factors, customer characteristics as well as CS/D measures were identified and examined in order to achieve these objectives. Telephone interviews were conducted with industrial telemarketing customers from across Canada to collect the study's data.
\end{abstract}

The research findings indicated that customers are generally satisfied with the sponsoring company's telemarketing department. Three of the seventeen service factors measured were found to be associated highly with this satisfaction and important to customers. These service factors have to do with the telemarketer's speed of filling requests, knowledge of company products and ability to answer questions. Customer characteristics also seem to be partially related to $C S / D$. Each of the characteristics examined (i.e. experience using telemarketing, age of the customer and company size) were significantly related to two of the four satisfaction measures. However, because the effect sizes were small and the unexplained variation was high for each characteristic, no trait 
emerged as a more reliable indicator of CS/D.

Customer acceptance of industrial telemarketing for software products and services is high, as $\mathbf{8 4}$ percent of customers have purchased or stated they would consider purchasing these products over the telephone. Based on the requirement for product demonstrations, a strong consensus was shown among customers regarding the purchase circumstances the use of industrial telemarketing is most appropriate. For first-time purchases, the use of telemarketing is most appropriate for services while for subsequent purchases, all product types can be purchased in this manner. However, based on product/service price, a weak consensus was shown among customers regarding the appropriateness of telemarketing for these same purchase circumstances. Generally, it was found that the existence of a relationship established through a previous purchase or product demonstration is the primary reason affecting customer usage of industrial telemarketing.

The information collected in this study also led to the identification of other factors which may have influenced the CS/D ratings and usage perceptions. These additional findings show that accounting for and measuring the many factors which influence CS/D is difficult to achieve with precision. Continuing research in this area will increase in importance as companies rely more on telemarketing to perform the dual roles of generating sales while simultaneously maintaining high levels of customer satisfaction. 


\section{ACKNOWLEDGEMENTS}

There are a number of people in the academic and private sector community whose contribution to this thesis should be recognized. First, I would like to thank my co-supervisors, Drs. Judith Marshall and George Haines, for their willingness to meet and lend their expertise to the project whenever necessary. I would also like to extend my gratitude to Professors Louise Heslop and ian Lee who provided helpful insights in a number of instances.

Second, I would like to acknowledge the generous support of the sponsoring organization, without which this thesis would not have been possible. I especially wish to thank the Manager, Canadian Marketing Operations and the Telemarketing representatives for their contributions throughoul the entire process.

I would also like to take this time to thank some special people in my life. This includes my parents, who have given me constant encouragement in my graduate work and in everything I have ever done and my fiancée, Liana, who from the beginning of my M.M.S. studies has provided me unlimited patience and support. 


\section{TABLE OF CONTENTS}

Page

Acceptance Sheet

Abstract

Acknowledgements

Table of Contents

List of Tables

List of Figures

List of Appendices

CHAPTER 1

INTRODUCTION

1.1 Research Problem 2

1.2 Research Objectives and Organization of the Thesis 3

CHAPTER 2

LITERATURE REVIEW

2.1 Customer Satisfaction / Dissatisfaction (CS/D) 6

2.1.1 Definition of CS/D 6

2.1.2 Conceptualization of CS/D 7

2.1.3 Importance of CS/D to Business $\quad 12$

2.1.4 Measurement of CS/D 16

2.2 Telemarketing 20

2.2.1 Definition of Telemarketing 21

2.2.2 History and Growth of Telemarketing 22

2.2.3 Consumer vs. Industrial Telemarketing 29

2.2.4 Telemarketing of Computer Software Products 31

2.2.5 Literature Review Summary 32 
TABLE OF CONTENTS (cont...)

Page

CHAPTER 3

RESEARCH QUESTIONS AND HYPOTHESES

3.1 Level of CS/D

3.2 Factors Related to CS/D with Telemarketing 37

3.2.1 Service Factors

37

3.2.2 Customer Characteristics

39

3.3 Factors Related to Telemarketing Usage 42

3.3.1 Requirement for Product Demonstrations 44

3.3.2 Product / Service Price $\quad 52$

\section{CHAPTER 4}

RESEARCH METHODOLOGY

4.1 Research Design 55

4.2 Data Collection / Survey Development 57

4.2.1 Mail Questionnaire 58

4.2.2 Pretest Results $\quad 58$

4.2.3 Telephone Survey $\quad 60$

4.3 Sampling Methodology 61

4.4 Operational Procedures $\quad 63$

4.5 Data Analysis 66 
TABLE OP CONTENTS (cont...)

Page

CHAPTER 5

RESEARCH FINDINGS AND INTERPRETATION 69

5.1 Response Rate 69

5.2 Description of Sample $\quad 72$

5.3 Level of CS/D 77

5.4 Factors Related to CS/D with Telemarketing 85

5.4.1 Service Factors $\quad 85$

$\begin{array}{ll}\text { 5.4.2 Customer Characteristics } & 97\end{array}$

5.5 Factors Related to Telemarketing Usage 105

5.5.1 Requirement for Pruduct Demonstrations 109

5.5.2 Product / Service Price 125

5.6 Other Findings 131

5.6.1 Barriers to Telemarketing Controlled by 132 the Seller

5.6.2 Barriers to Telemarketing Not Controlled by 136 the Seller

\section{CHAPTER 6}

CONCLUSIONS AND RECOMMENDATIONS 140

6.1 Summary 140

6.2 Limitations of the Research 144

6.3 Benefits and Strategic Implications of the Research 148

6.4 Future Research 156

$\begin{array}{ll}\text { BIBLIOGRAPHY } & 158\end{array}$

$\begin{array}{ll}\text { APPENDICES } & 167\end{array}$ 


\section{LIST OF TABLES}

Table 1: Growth of Telemarketing in the U.S.

Table 2: $\quad$ Dollar Value of Products Sold through

Telemarketing

Table 3: Regional Breakdowns of Customer Organizations

Table 4: Response Rate Data by Region

Table 5: Reasons for Customer Non-response

Table 6: Nature of Business by Region

Table 7: $\quad$ Range of Customer Companies' 1990 Gross Dollar Revenue

Table 8: Number of Employees at the Customer Companies

Table 9: Functional Positions of the Respondents

Table 10: Number of Years in the Workforce Fulltime

Table 11: Time of Last Contact with the Sponsoring Company's

Telemarketing Department

Table 12: Number of Telephone Purchases Made in the Last Year

Table 13: Satisfaction Using Telemarketing to Purchase

Computer Software Products (Prodsat)

Table 14: Satisfaction Using Telemarketing to Purchase

Support Services (Servsat)

Table 15: Satisfaction with the Telemarketing Service

Compared to Expectations (Expect)

Table 16: Willingness to Recommend the Telemarketing

Service to Business Associates (Willing)

Table 17: Pearson Correlations between the CS/D Measures

Table 18: Pearson Correlations between the Telemarketing

Service Factors and the CS/D Measures 


\section{LIST OF TABLES (cont.)}

page

Table 19: Telemarketing Service Factors Most Important 90

Table 20: CS/D with the Sponsoring Company's Performance 92 on the Telemarketing Service Factors

Table 21: Preferred Frequency of Telemarketing Contact versus Frequency of Last Telemarketing Contact

Table 22: Relation of Company Size, Age and Amount of Experience using Telemarketing to Satisfaction using Telemarketing for Purchasing Computer Software Products (Prodsat)

Table 23: Relation of Company Size, Age and Amount of Experience using Telemarketing to Satisfaction using Telemarketing for Purchasing Computer Software Services (Servsat)

Table 24: Relation of Company Size, Age and Amount of Experience using Telemarketing to Satisfaction with the Telemarketing Service Compared to Expectations (Expect)

Table 25: Relation of Company Size, Age and Amount of Experience using Telemarketing to Willingness to Recommend the Service to Business Associates (Willing)

Table 26: Summary of the Customer Characteristic Effect Sizes on the CS/D Measures

Table 27: Customer Acceptance of Telemarketing 106

Table 28: Most Important Reasons for Using Telemarketing 107 for Purchasing Computer Software Products and Services

Table 29: Most Important Reasons for Not Using Telemarketing for Purchasing Computer Software Products and Services

Table 30: Purchase Frequency by Product Type 


\section{LIST OF TABLES (cont.)}

page

Table 31: Purchase involvement by Product Type

Table 32: Crosstabulations of Purchase Type by Purchase

Table 33: Spearman Rank Order Correlations of

Telemarketing Appropriateness and Demonstration Importance by Product and Purchase Type

Table 34: Crosstabulations of Telemarketing Appropriateness and Demonstration Importance for First-Time Purchases of Mainline Products (FT/M)

Table 35: Crosstabulations of Telemarketing Appropriateness and Demonstration Importance for First-Time Purchases of Complementary Products (FT/C)

Table 36: Crosstabulations of Telemarketing Appropriateness and Demonstration Importance for First-Time Purchases of Service Products (FT/S)

Table 37: Crosstabulations of Telemarketing Appropriateness and Demonstration Importance for Subsequent Purchases of Mainline Products (S/M)

Table 38: Crosstabulations of Telemarketing Appropriateness and Demonstration Importance for Subsequent Purchases of Complementary Products (S/C)

Table 39: Crosstabulations of Telemarketing Appropriateness and Demonstration Importance for Subsequent Purchases of Service Products (S/S)

Table 40: Frequencies of Dollar Limits on Telemarketing

Purchases by Purchase Type

Table 41: Number of Customers Placing Conditions on the Dollar Limits by Purchase Type

Table 42: Conditions which Influence the Dollar Limits by Purchase Type 
LIST OF FIGURES

Figure 1: Expected Median Values of the Demonstration Importance ansi the Telemarketing Appropriateness Ratings by Purchase Circumstance

Figure 2: Actual Median Values of the Demonstration Importance and the Telemarketing Appropriateness Ratings by Purchase Circumstance page

50

117

xii 


\section{LIST OF APPENDICES}

A. Advantages / Uses of Telemarketing

B. Disadvantages / Limitations of Telemarketing

C. Description of Recent Technological Developments Impacting the Telemarketing Industry

D. Differences Between Consumer and Industrial Telemarketing

E. Sample Mail Questionnaire

G. Linkage of Research Questions, Telephone Survey and

Data Analysis

H. Sample Coleman Analysis Calculations 
CHAPTER 1

INTRODUCTION

Telemarketing has gained respectability as an industrial marketing tool during the past decade (Bailey, 1988). Traditionally, it has been primarily used in the sales of consumer goods and services to individual households (Wingis, 1981). Currently, businesses are discovering the benefits of using telemarketing for selling to their corporate clients as well. Industrial telemarketing generated an estimated one billion dollars in sales across Canada in 1988 (Esterhuizen and Poirier, 1989). This performance is evidence that the use of business-to-business telemarketing is being accepted in the marketplace.

Sales is one measure of success with telemarketing, however, another measure of success is customer satisfaction with telemarketing. Many explanations have been proposed in the literature regarding the causes of CS/D with telemarketing (Domine, 1989; AT\&T, 1989a; Perruzza and Bischoff, 1988; Webster, 1980), however, few of these have been empirically tested. The information that does exist pertains primarily to consumer telemarketing and may not be appropriate to explain CS/D with industrial telemarketing because of inherent differences in these buying situations (Moller and Wilson, 1988; Pope, 1981; Howard and Sheth, 1969; Domine, 1989; Wingis, 1981; Raymond, 1976). Consequently, knowledge acquired through reseaich on this topic may help industrial telemarketers improve customer satisfaction and ensure continued patronage of their most important resource, the customer. 


\subsection{RESEARCH PROBLEM}

Literature in the area of CS/D with industrial telemarketing is almost nonexistent. With the exception of Marshall (1986), Marshall and Vredenburg (1988), and Shipp (1989), the information which does exist (Telecom Canada, 1989; AT\&T, 1989b; Smyth, 1986; Noble, 1986; Webster, 1980) tends to be prescriptive in nature and not substantiated by empirical research. Specifically, this prescriptive literature implies customer satisfaction with industrial telemarketing is automatic as long as recommended service guidelines are followed. These service guidelines tend to be user-defined (i.e. determined by the telemarketing company), not prioritized, nor product-specific.

Consequently, four deficiencies in the literature can be identified which support the need for further research in this area:

1) It is not known if business-to-business customers are satisfied/dissatisfied with the use of industrial telemarketing to sell products and services because their views have not been documented.

2) The literature is very general with respect to prescribed telemarketing services. This makes it difficult for individual companies to customize telemarketing service strategies for their individual product or service offerings to achieve customer satisfaction. 
3) The effects that customer characteristics have on CS/D with industrial telemarketing have not been addressed in previous research. It is unknown if it is possible to determine a customer's satisfaction level and receptiveness to the use of industrial telemarketing based on the traits they possess.

4) There has been a lack of research examining issues which may influence customer usage of industrial telemarketing (i.e. requirement for product demonstrations and product/service price). Knowledge regarding these issues is quite significant because, depending on how companies choose to use this tool, telemarketing can either positively or negatively affect customer satisfaction (i.e. may be seen by custcmers as cutting or providing more service). In addition, such information may reveal the purchase circumstances under which telemarketing's use is most appropriate, define the most effective roles of inside and field sales representatives and uncover opportunities for use never before anticipated.

\subsection{RESEARCH OBJECTIVES AND ORGANIZATION OF THE THESIS}

The specific objectives of the research are (1) to document CS/D with industrial telemarketing and determine what factors are related to this satisfaction/dissatisfaction and (2) to collect customer perceptions regarding the appropriate usage of industrial telemarketing. 
The products under consideration for this research include computer software products and related support services. These products were chosen because they are currently being sold via industrial telemarketing centres (Noble, 1986), thereby making such a study possible. In addition, this area deserves research attention given the lack of available service information and the controversy that exists with respect to the telemarketing of products/services that are of a technical nature (Bailey, 1988; Wingis, 1981; Hunt, 1977a; Moncrief et al., 1988).

Five chapters comprise the remainder of this study. The next chapter reviews literature on CS/D and industrial (business-to-business) telemarketing. Following the literature review, chapters three, four and five detail the research questions, methodology, findings and their interpretation respectively. Chapter six summarizes the conclusions and presents recommendations through a disclission of the research's limitations, benefits and strategic implications and future direction. Finally, references and appendices which complement the literature and/or further explain other details of the research conclude the report. 
Currently, no product specific studies exist in the literature which examine CS/D with industrial telemarketing from the receiver's (customer's) perspective. This lack of CS/D literature may be due to the focus of previous research on sellers' viewpoints instead of customer perceptions of telemarketing (Angus Reid Associates, 1988; Marshall, 1986; Marshall and Vredenburg, 1988; Bailey, 1988; Domine, 1989), telemarketing's recent expansion into industrial applications, and/or companies not making information from their own proprietary studies publicly available.

This chapter reviews CS/D and industrial (business-to-business) telemarketing literature in two sections. Specifically, the first section examines present knowledge with respect to CS/D's definition, conceptualization, importance to business, and measurement. The second section summarizes telemarketing's definition, history and growth, distinguishes between consumer and industrial telemarketing and discusses its use with technology-based products such as computer software. 


\subsection{CUSTOMER SATISFACTION / DISSATISFACTION (CSID)}

CS/D literature is plentiful because it has been studied by many disciplines over a long period of time. As a result, numerous theories have been proposed regarding its definition, conceptualization, importance to business and measurement. Still, relatively little has been concluded about how customers arrive at feelings of satisfaction or dissatisfaction. The purpose of this section will be to examine some of the issucs associated with this subject area.

\subsubsection{Definition of CS/D}

It appears from the literature that no universally accepted definition of CS/D exists. It has been referred to as "the buyer's cognitive state of being adequately or inadequately rewarded in a buying situation for a sacrifice undergone" (Howard and Sheth, 1969), "the favourableness or unfavourableness of an individual's subjective evaluation of various outcomes and experiences" (Westbrook, 1980), and as "an evaluation of the surprise inherent in a product acquisition and/or consumption experience" (Oliver, 1981).

Day (1984) suggests that CS/D may be "a kind of attitude" or emotion. He believes that CS/D could be an attitude in the sense that it can be evaluated and measured but does not completely fit the definition because it cannot be preconceived (i.e. CS/D cannot happen before the event occurs) nor is it 
necessarily stable over time. As an emotion, CS/D could be a state of arousal manifested in conscious feelings, expressions, and behaviours which could disappear if the stimulus or situation changes.

Hunt (1977a) summarized these and a number of other thoughts by concluding that CS/D is "an evaluation rendered that an experience was at least as good as it was supposed to be". Given the previous definitions, this study considers CS/D to be the positive or negative feelings customers experience after consciously evaluating a consumption outcome with their own subjective criteria.

\subsubsection{Conceptualization of CS/D}

Hunt (1977a) reviewed most theories on CS/D in an effort to make researchers aware of each other's works and to expedite the slow empirical development in this area. His summary suggests that CS/D is primarily a function of cognitive influences, affective influences, or some combination of the two. These conceptions are examined in this subsection.

\section{Cognitive Influences on CS/D}

Cognitive influences on CS/D are multiattribute in nature and are based upon discrepancies between one's actual and ideal attribute combination for a given product or service. The actual set of attributes is based on perceived 
performance of the product or service and the ideal set of attributes is based primarily on expectations of product or servic performance. Consequently, the level of satisfaction with a product or service arises from a comparison of expectations to perceived performance.

If the relation is such that perceived performance is greater than expectations, satisfaction will occur and if perceived performance is less than expectations, dissatisfaction will result. This method, better known as the confirmation/disconfirmation of expectations approach, has been the most widely accepted determinant of CS/D for the past twenty years (Crosby, 1989; Day, 1977).

Since the aforementioned approach compares expectations to subjective evaluations of product/service performance, an understanding of these components and their composition may help to explain resulting satisfartion levels. Therefore, they are discussed below.

\section{Definition of Expectations}

The extensive use of the confirmation/disconfirmation of expectations approach has led to various interpretations by researchers of what constitutes expectations and how their formulation takes place. LaTour and Peat (1979) note that there is no precise definition of expectations, however, their review states 
that most researchers consider them to be "customers beliefs about the level of attributes possessed by a product or service". According to Steiner and Fishbein (1966), beliefs are "hypotheses regarding the existence of an object". From these two definitions, it appears that expectations are hypotheses concerning the likelihood that a product or service possesses (a) certain attribute(s).

\section{Expectation Influences}

It is not completely known how expectations are created in the confirmation/disconfirmation framework. It appears that they can be affected not only by available information on product or service attributes but by a number of other factors as well. According to Day (1977) and Sheth (1973), individual characteristics (i.e. experience, awareness of alternative brands), cost and shopping effort, and the social benefits of purchase/use are involved in the development of expectations. Other expectation influences include factors having to do with the seller's reputation such as image, trustworthiness, and credibility (Webster, 1984).

\section{Evaluation Influences}

There are issues that should be noted with respect to evaluations in the confirmation/disconfirmation of expectations apprcach. First, it is possible that a person can go through a consumption experience without consciously evaluating 
any aspect of the purchase. Second, even when conscious evaluations do take place, a situation may occur where the person is indifferent towards the purchase experience unless he/she identifies some aspect of the experience as being out of the ordinary.

It is for this reason that Day (1977) believes triggering cues or situational factors must be present in order to alert the customer to make an evaluative response and arrive at a feeling of satisfaction or dissatisfaction. Examples of triggering cues could be the discovery of a flaw in the product or service, the receipt of information in conflict with prior beliefs, or warnings by others to be careful in making the purchase. Situational factors having to do with delivery. credit, billing, and warranties can also positively or negatively affect evaluations of product or service performance.

Just as individual characteristics may affect the formulation of expectations of product or service performance, they may also affect the evaluations of product/service performance. Some of these individual differences may include the expertise as a consumer, the degree of involvement in the purchase experience, and the willingness to complain or be critical (Day, 1977).

The preceding discussion on expectation and evaluation influences shows that numerous combinations of factors can contribute to CS/D with a particular consumption situation. Behavioural and psychological theories exist which 
attempt to explain how expectations and evaluations work within the confirmation/disconfirmation framework and lead to feelings of satisfaction and dissatisfaction (Engledow, 1977; Day, 1977; LaTour and Peat, 1979; Anderson, 1973; Miller, 1977), however, a universally accepted explanation has yet to be developed.

\section{Affective Influences on CSID}

The position that CS/D results primarily from the confirmation/ disconfirmation of expectations has been questioned by researchers. Westbrook (1980) and LaTour and Peat (1979) believe CS/D is not solely a cognitive response to a purchase situation but an affective response as well.

Affective elements influencing CS/D include general states such as one's mood, feelings, disposition, motivations, sensitivity, and global attitudes. For instance, it is possible that good or bad moods, the propensity to be an optimist or pessimist, and the sensitivity to evaluate consumption situations can influence CS/D with a consumption experience. However, like expectation and evaluation influences, it has not been concluded how elements of affect influence or combine with cognitive processes in the determination of CS/D. 


\subsubsection{The Importance of CS/D to Business}

Many organizations are beginning to make an effort to determine the satisfaction levels of their clients despite the difficulties in defining and conceptualizing CS/D and in identifying the processes that customers use to evaluate products and services. Dixon (1989) believes competition is the major impetus forcing companies to adopt a customer-focus mentality and is driving the need for satisfaction data.

Companies that are not close to their customers (i.e. anticipating and fulfilling their needs) run the risk of making false assumptions regarding customer satisfaction levels and failing to take any corrective measures (Budde, 1990). The consequences of dissatisfied customers can be devastating to business. For example, Strauss (1991) reports that 27 percent of customers do not return after an unhappy experience. Furthermore, to make matters worse, Desatnick (1987) notes that many of these unhappy customers will neither complain nor buy again. but will tell their story to at least nine other people.

However, those companies that understand and react to CS/D are more likely to identify customers' changing needs and expectations (Markham, 1970), to use complaints for improving current services or indicating new service opportunities and to build lasting customer relationships (Maister, 1989; Kidd, 1989; Jackson, 1985). I ne competitive advantages resulting will come in the form 
of increased service quality, fewer dissatisfied customers, repeat purchases and higher profits. Consequently, one of the major challenges facing business is to identify, monitor, and respond to causes of CS/D on a continual basis.

\section{Causes of CS/D}

It appears from the literature that less is known about what satisfies customers than what dissatisfies them. In the past, corporate standards, such as sales, have been used as a gauge of customer satisfaction (Hunt, 1977a) instead of customer standards, such as prompt delivery. The non-use of customer standards exemplifies the lack of concern that many companies have shown towards trying to understand what factors cause their customers to be satisfied or dissatisfied. Although it is beyond the scope of this review to discuss all the causes of CS/D, this section discusses two features which influence CS/D with many consumption experiences, namely service and rising customer expectations.

\section{Cause of Satisfaction: Service}

In their book, In Search of Excellence, Peters and Waterman (1982) state that "excellent companies really are close to their customers. Other companies talk about it; the excellent companies do it." This book argues that the common element among companies with satisfied customers is an obsession with service. Little is known about service design and management because its importance to 
the economy is a relatively new phenomenon (Czepiel, 1980). According to Czepiel, Solomon, and Surprenant (1985), service is...

a task other than proactive selling, that involves
interactions with customers in person, by
telecommunications, or by mail. It is designed,
performed, and communicated with two goals in
mind: operational efficiency and customer
satisfaction.

This definition takes the viewpoint that all employees actively involved with customers are a major part of the overall service product. As a result of the transactions between the service personnel, the customer and the environment, which are often times spontaneous and simultaneous in production and consumption, service factors are difficult to specify, measure and control (Czepiel, 1980). It takes a concerted effort to understand what customers truly want before, during and after every transaction and then motivating employees to respond accordingly (Roy, 1990). Hence, good customer service is no accident nor is it easily achieved.

Regardless of the difficulties associated with service planning, companies should strive to further understand how they can improve this aspect of their business because Kennedy (1990) notes that despite companies' attempts at product differentiation, most products are close enough to commodities that service is the true factor in maintaining accounts. Therefore, quality service will increasingly represent a competitive advantage and a tremendous opportunity for 
corporate growth in the 1990s.

\title{
Cause of Dissatisfaction: Rising Expectations
}

Many reasons have been presented in the literature for customer dissatisfaction (Day, 1976; Wotruba and Duncan, 1975; Greyser and Diamond, 1974; Anderson, 1973; Anderson and Jolson, 1973). Most of these reasons focus on concerns over economic factors (i.e. rising prices), performance or quality problems and inappropriate business or marketing practices. Ways (1972) summarizes a common cause of customer dissatisfaction as follows:

\begin{abstract}
At any given moment, the public must have in mind some criteria, however imprecise, of what constitutes a satisfactory performance by business. The public keeps raising its standards-as, in an achieving society, it should. Trouble develops because the public is not aware of how rapidly it raises its standards. Because it believes its standards are unchanging, it tends to perceive business performance as moving backward.
\end{abstract}

Customers can develop overexpertations of product/service performance from misleading advertising, deceptive packaging, government enforcement of consumer protection legislation, high prices, and the increased social demand for product quality (Greyser and Diamond, 1974). Consequently, if customers' expectations of product/service performance keep rising faster than actual performance, it appears that eventual dissatisfaction is unavoidable (Day, 1976). 
Given that businesses want to remain competitive, they need to gauge the satisfaction levels of their customers. Accordingly, CS/D measurement is the focus in the next section of the review.

\subsubsection{Measurement of CS/D}

There is no universally accepted method for measuring CS/D, however, existing research in the area does specify conceptual and methodological issues that should be considered when devising a measurement program. For instance, Hunt (1977a) notes that problems can occur because of the subjectivity of satisfaction measures. As psychological constructs and/or affective states, they may be unreliable due to response bias and situational factors because there is no basis for assuming that different respondents use the same criteria in their evaluations. Moreover, subjectivity leads to aggregation problems (i.e. what one customer means by "somewhat satisfied" may not be what another customer means by the same term).

A second measurement issue has to do with CS/D's multidimensionality. It is known that many factors contribute to CS/D (both tangible and intangible) but it is difficult to account for, let alone measure them all. Hunt (1977a) argues that the number of factors to be measured must be limited because if too many are considered, the result may be that no one factor has enough weight to be nontrivial in determining the level of CS/D. 
A third measurement issue deals with scale construction. Hempel and Rosenberg (1975) note that CS/D may be part of the same continuum or may exist on different continua. They suggest this because of the possibility that a customer can be satisfied and dissatisfied with different aspects of the same purchase situation. This issue leads to another problem with scale construction, namely how these individual satisfaction and dissatisfaction scores should be weighted in determining the overall satisfaction. According to Hunt (1977a, $1977 b)$, it is not known whether overall CS/D is more dependent on the attributes customers are pleased with or on those they are displeased with.

The relative importance of the product/service attributes has been suggested as a method for weighting and comparing satisfactions when determining which attributes affect overall CS/D (Hunt, 1977a). Currently, it is not known exactly how importance relates to CS/D. Parasuraman et al. (1986) believe importance scores are a reflection of the expectations customers place on various attributes in evaluating service quality while Bultman (1989) states that by asking the importance of attributes, a better sense of the service trade-offs customers are willing to make is gained. Hunt (1977a) is skeptical of using importance measures because he believes people lack the ability to identify the attributes they consider, let alone tell how important each is to arriving at an overall CS/D rating. 
A final point to be noted with regard to scale construction is the propensity for respondents to declare that they are satisfied (use the positive part of the scale more frequently than the negative side) with the products or services in post-purchase evaluations (Hunt, 1977a). This positive bias has a tendency to skew distributions towards the satisfaction end and to complicate interpretations of the results. In order to minimize the effects of this bias, the researcher may choose to extend the scales at the satisfaction end and/or time the satisfaction measures soon after the consumption experience (i.e. to lessen the effects of dissonance).

Other measurement issucs have to do with the respondents' reliance on memory and nesting effects. Woodside et al. (1977) note that CS/D measures are reliant on respondents' memory when gauged in retrospect and could be prone to testing and reactivity effects (i.e. the testing of satisfaction may be seen as satisfying or items listed may be adopted by respondents as their own). Hunt (1977a) states that nesting is a common problem with group purchases (i.e. organizational buying) that distorts the overall satisfaction levels. It occurs when a dissatisfied participant goes along with the satisfaction of other members to keep peace among the group.

There are various methods for measuring CS/D and just as many views as to which give the most accurate readings. Researchers such as Crosby (1989) and Miller (1977) suggest measuring expectations and performance separately and 
computing the difference to measure satisfaction levels. Another method is to simply measure satisfaction itself. The rationale for using satisfaction measures in a study by Ash (1978) is that respondents can self-define what they mean by "satisfied" or "dissatisfied" and determine for themselves what the points on the scale mean. Crosby (1989) and Hunt (1977a) provide further support for using the rater's own standards. They note that respondents have little trouble when they encounter the term "satisfaction" in questionnaires and that these scores have proved useful in the past.

Hunt (1977a, 1977b) notes that there are alternative measures of overall CS/D (i.e. intention to repurchase) that can be used. Indirect or global measures are appealing because they overcome the current lack of knowledge on how to weight or add individual satisfactions/dissatisfactions, and they get all of the influences affecting the decision without having to specifically identify them.

Many of these issues cannot be adequately controlled because sound methodologies to address them have yet to be developed. The lack of standardized methodologies has led researchers to question the usefulness of CS/D as a stable measure of corporate performance. For instance, Engledow (1977) believes CS/D is a "rubber yardstick" that lacks credibility because it is judged relative to individual criterion and standards which can vary over time. According to Hunt (1977a), the way to bring order to CS/D measurement is if researchers adopt a common measurement methodology which can be built upon 
with further research.

Despite the difficulties associated with CS/D measurement, companies, researchers and public policy makers do want to use the resulting information as the basis for much of their program planning and evaluation. It is for this reason that Czepiel and Rosenberg (1977) believe that the need and the opportunities available with CS/D measurement are real, immediate and practical.

\subsection{TELEMARKETING}

Many companies are familiar with the concept of telemarketing but few have an understanding of the term or are aware of potential applications available to them (Angus Reid Associates, 1988; Alexander, 1987). Consequently, this section will briefly review telemarketing literature in four subsections. The first subsection defines telemarketing. The second subsection gives a general background on telemarketing through a discussion of its history and growth. The third subsection identifies the differences between consumer and industrial telemarketing. Finally, the last subsection comments on the use of telemarketing with computer software products. 


\subsubsection{Definition of Telcmarketing}

Telemarketing has been described as "a marketing system which combines tclecommunications technology with management information systems for planned, controlled sales and service programs" (AT\&T, 1989a), "an organized strategic approach to using the telephone" (Marshall, 1986), and a "systematic and continuous program of communicating with customers and prospects via telephone and/or other person-to-person electronic media by a sales person that does not make face-to-face contact with customers and prospects" (Moncrief et al., 1988).

For the purposes of this research, the Voorhees and Coppett (1983) definition of telemarketing as "a communication system staffed by trained personnel who use telecommunications and information technologies to conduct planned, measurable marketing activities directed at a targeted group of customers" was adopted. This definition most accurately describes the telemarketing operation that is of interest to this study. From these descriptions and numerous others in the literature, it becomes quite apparent that telemarketing is more than simply talking on the telephone. 


\subsubsection{History and Growth of Telemarketing}

Telemarketing was first practised in the United States as far back as the 1920s (Alexander, 1987). At that time, these services, known as "call collect" programs, were established by companies to take product orders from collect calls. The next fifty years saw very little progress or change in telemarketing applications or techniques.

The eventual development of the industry was caused by a number of key trends which occurred during the 1960s. According to Alexander (1987) and the New Brunswick Department of Commerce and Technology (1990), these trends included:

* technological advances in telecommunications and computers;

* widespread acceptance and use of credit cards;

* social adjustment to the women's movement as well as to smaller households;

* the need for energy conservation;

* rising costs of sales and advertising;

* competitive demands; and

* larger markets.

The growth of telemarketing in the United states in the 1970s and 1980s was tremendous as companies used this tool to adapt to the changing 
environment. Table 1 illustrates telemarketing's changing scope in recent years with respect to revenue generation and the number of individuals choosing careers as telemarketing sales representatives (TSRs).

TABLE 1

GROWTH OF TELEMARKETING IN THE U.S.

$\begin{array}{lll}\text { Year } & \text { Revenue } & \text { Number of Telemarketing } \\ \text { Billions (dollars) } & \text { Sales Representatives (000) }\end{array}$

1983

1984

1985

1986

1987

1988

1989

1990

57

70

90

120

140

171

196

225

360
175

300

950

2100

2600

3100

3500

4000

Forecast 1991

4500

This growth can be explained by telemarketing's ability to increase sales, reduce costs, boost market shares, and enhance overall competitiveness (AT\&T, 1989b; Telecom Canada, 1989). Appendix A displays a comprehensive listing of other advantages and uses of telemarketing.

Today, business-to-business telemarketing is growing at a rate of thirty to forty percent per year in the United States (Moncrief, Lamb and Dielman, 1986). The Manufacturing, Wholesale/Distribution and Publishing industries account for 
almost one-half of U.S. telemarketing operations at twenty-eight, eleven and nine percent respectively. The remaining breakdown of industries with telemarketing operations is as follow's: Finance/Banking (7\%), Insurance (6\%). Direct Marketing (5\%), Telecommunications (3\%) and all others (18\%) (Hayes, 1989).

\section{Telemarketing Developments in Canada and Abroad}

The success of telemarketing in the United States has prompted other countries to adopt this marketing technique. The first country to utilize telemarketing outside the United States was Canada (Violanti, 1988). The industry's presence in Canada is concentrated in Toronto due to telemarketing's traditional use from head office locations. In addition, the City has well established telemarketing consulting firms and large, independent telemarketing facilities which cater to this market (Kenessey, 1988; Seon, 1988). Further geographic expansion of the industry in Canada is expected as telecommunication equipment, rates and services improve (New Brunswick Department of Commerce and Technology, 1990).

The international growth of telemarketing started in the early 1980 s. Since that time, other countries such as the United Kingdom, France, Germany, Italy, Finland and the Netherlands have been establishing their own telemarketing industries. However, they are not as mature as the American or Canadian industries nor are they necessarily developing in the same manner. 
The evolutionary differences are mainly accounted for by the fact that each country's telemarketing industry is subject to unique conditions. The principal facturs influencing the varied growth and development have to do with characteristics of their individual telecommunications networks, cultures, direct marketing industries and government regulations. However, despite the different conditions affecting the industries, all of them are expected to grow significantly and flourish in the future (Violanti, 1988).

\section{Telemarketing Structure}

Regardless of the industry or country a company is part of, it has a choice with respect to the structure of its telemarketing operation. For instance, it can be set up to be centralized, decentralized or employ some combination of the two systems. In addition, these operations can be established to be reactive (i.e. receive inbound calls), proactive (i.e. make outbound calls), or both. These systems and types of telemarketing are briefly described below.

Centralized telemarketing systems generally consist of a separate telemarketing department based at a single location. They are created for the purpose of achieving senior management directed goals for designated programs and time periods. Decentralized systems are comprised of geographically scattered telemarketing divisions that are somewhat autonomous in that they have their own goals, objectives, and in some cases, measurement and control 
systems (Andersolı and Rue, 1986).

Both centralized and decentralized telemarketing systems have their own advantages ind disadvantages. For example, centralized systems are more appropriate when the management structure is strict and hierarchical in nature because it is more consistent with corporate values. Decentralized systems, on the other hand, can take advantage of regional differences in demographics and client needs. Often times, companies use combinations of the systems in order to produce the greatest gains (Anderson and Ruc, 1986).

Another important structural consideration has to do with the decision to use inbound, outbound or a combination type of telemarketing. Inbound telemarketing generally relies on customers using toll frec 1-800 numbers supplied to them through direct mail, radio, T.V., magazines, or other forms of advertising. This not oniy gives prospective rustomers an immediate way to respond to these messages but it also allows the telemarketer the opportunity to enhance customer service, take product/service orders, approve credit, take messages, provide information, and produce additional sales (McNamara, 1986).

Outbound telemarketing's primary function is to generate sales either to new or established accounts (McNamara, 1986). In sales to new accounts, it is mainly used to generate and qualify sales leads for field sales representatives through "cold calling" where prospects are contacted without warning or previous 
consent. In sales to established accounts, outbound telemarketing may be used to sell complementary products, test new products, or maintain healthy customer relations. Outbounu telemarketing is also commonly used for fundraising, market research, and the collection of accounts receivables (McNamara, 1986).

Most industrial telemarketers operate both types of telemarketing, however, a greater emphasis has been placed on outbound sales (Driscoll, 1989). This is because it offers companies a viable alternative to increasingly expensive field sales alls which have jumped from $\$ 32$ per call in 1972 (Wingis, 1981) to $\$ 200$ in 1985 (Schneider, 1985) to over $\$ 300$ today (Esterhuizen and Poirier, 1989).

Ultimately, the chosen structure (i.e. systems and types of telemarketing) should be evaluated in the context of a company's individual circumstances. This means taking into consideration issues such as the objectives of management, the available resources, operational issues, recruitment and training and the target market (Anderson and Rue, 1986).

\section{Future of Telemarketing}

The future of telemarketing is bright, however, it should be noted that telemarketing success is not automatic. Forty percent of all companies who try using it fail (Marshall and Vredenburg, 1988). This high failure rate can be attributed to a number of challenges and barriers facing the industry. Some of 
these barriers include a negative public image and attitude toward the industry. customer acceptance problems, poor telemarketing management practises and increasing government regulation. Other disadvantages, limitations/causes of failure associated with telemarketing are presented in Appendix B.

These barriers to telemarketing success and the high failure rate associated with its use supports the need for more information in the field of telemarketing. Specifically, knowledge related to CS/D and the usage of telemarketing should help companies to maximize the effectivencss of this marketing tool.

Recent developments in telecommunications technology may also help lessen the formidableness of these barriers in the future. These innovations include:

* $\quad 900$ Network Service;

* Integrated Voice Response (Audiotex);

* Videotex;

* Facsimile Machines; and

* Integrated Services Digital Network (ISDN).

Once these innovations are paired with telemarketing, the productivity of telemarketers and the number of potential applications is predicted to increase dramatically (Plakias, 1990; Tehrani, 1990b; Lloyd, 1990; Waddell, 1990; Violanti, 1988). A brief description of these innovations is provided in Appendix C. 
Given the changing social, economic and technological environments, it appears that telemarketing will be a major marketing sales tool in the future. Popular opinion supports this notion. For instance, signs that the telemarketing industry is maturing include slowly changing attitudes on the part of businesses and customers regarding its use and image, a greater understanding on the part of businesses of how it can be integrated with other marketing efforts and the growth of in-house telemarketing centres (Paganelli, 1987).

By the turn of the century in the United States, it is predicted that over a half million businesses will be using telemarketing to sell or promote fifty percent of all products and services. This will create a demand for over $8,000,000$ telemarketing positions (Alexander, 1987; Tehrani, 1990a). Likewise, by the year 2000, the Canadian telemarketing industry is expected to be a major growth industry and quadruple from its present size to employ between 800,000 to 1,000,000 people (Kenessey, 1988; New Brunswick Department of Commerce and Technology, 1990).

\subsubsection{Consumer vs. Industrial Telemarketing}

A distinction should be made between consumer and industrial telemarketing because of the focus of this thesis on the latter. This bifurcation is useful to understanding the purpose, planning, and implementation of the study as well as the interpretation of the results. 
The are many differences between consumer and industrial telemarketing. Consumer telemarketers sell goods and services to individuals or family units while industrial telemarketers sell goods and services to commercial enterprises, governments and non-profit organizations. These two customer types are not necessarily alike in their handling of purchases. For instance, the literature states industrial customers generally assess products and services with more vigour, have greater dollar and quantity purchasing power, make purchases for others, require more than one sales presentation, involve the opinions of others and negotiate longer than final or end user consumers for most purchases (Parkinson, Baker, and Moller, 1986; Howard and Sheth, 1969; Domine, 1989; Raymond, 1976).

Differences are also likely to exist with respect to the type of products consumer and industrial teiemarketers sell. Consumer products generally consist of household products, appliances and furniture purchased for personal use while industrial products often include heavy equipment, components, raw materials and supplies purchased for resale or for use in goods and services to be produced. It should be noted, however, that not all goods can be classified as consumer or industrial and that many products fall into both categories (Raymond, 1976).

Consumer and industrial telemarketing operations require characteristic structures and marketing approaches to the extent that these differences in customers and products exist. Pope (1981) summarizes concisely the structural and marketing differences between these two fields. For instance, industrial 
telemarketers often have the advantages of being supported by a field sales force, having greater script flexibility, handling both inbound and outbound calls, and having targeted customer/prospect lists unlike consumer telemarketers.

However, there are certain structural and marketing difficulties to industrial telemarketing. For instance, Pope (1981) states that industrial telemarketing demands better control procedures and enhanced telemarketer training with respect to product knowledge and selling skills. Overall, though, even with these additional costs, Pope concludes that industrial telemarketing companies still have an advantage over their consumer telemarketing counterparts when it comes to using the telephone as a marketing tool. A summary of these dissimilarities between consumer and industrial telemarketing is presented in Appendix D.

\subsubsection{Telemarketing of Computer Software Products}

There is a telemarketing application in every industry regardless of whether the product is simple or complex, inexpensive or expensive or purchased by general consumers or business customers (McKean, 1987). The sales of computer software products and services is no exception. In fact, since eighty percent of the Fortune 500 companies use some form of telemarketing (Alexander, 1987), it is highly likely that many software developers utilize this tool is some manner. 
One successful software developer that uses telemarketing as an integral part of its sales process is Lotus Development Corporation (Rudolf, 1986). The company's primary goal with this function is to develop a top-rate, proactive inside sales force of account managers responsible for selling the company, its people and its products. In meeting this objective, Lotus has implemented a number of programs to increase telemarketer effectiveness, morale and productivity These programs focus on customized training, customer service, recruitment/career planning, management and supervisory skills development.

Although the methods used to develop these capabilitics are not publicly available, it is believed that some type of internal service performance measures were taken in order to assess telemarketer skills, to devclop training programs and to determine the extent (i.e. appropriatc types of products/services, lunctions) to which a proactive sales stance could be taken.

\subsubsection{Literature Review Summary}

Businesses today are striving to satisfy customers through quality service and can use telemarketing in meeting this challenge in both the consumer and industrial markets. Related literature supports telemarketing's influence on customer satisfaction (Domine, 1989; AT\&T, 1989a; Telecom Canada, 1989; Esterhuizen and Poirier, 1989; Curran, 1987), and how it is particularly useful for companies selling technical capital goods or computer products (Alexander, 1987; 
Wingis, 1981; Noble, 1986; Bailey, 1988).

However, these same sources fail to specify if and why customers are satisfied and dissatisfied using telemarketing for purchasing technology-based goods or computer products nor do they identify the situations, service conditions and applications CS/D is most likely achieved. In addition, it is not known if other factors, such as customer characteristics, have any influence on these feelings. Without this information, business telemarketers have very little guidance regarding how they did, or why they did not achieve satisfied customers.

The advantages/uses and disadvantages/limitations associated with telemarketing are the result of how well companies plan, implement, and control the operations. Consequently, organizations implementing telemarketing require performance and usage information in order to evaluate how well these procedures aid in the achievement of their service objectives.

As noted earlier, it is commonly viewed that a logical service performance measure is CS/D (Engledow, 1977; Markham, 1970; Maister, 1989; Kidd, 1989; Jackson, 1985). The literature documents that these feelings are difficult to define, conceptualize and measure but extremely important to business success. Therefore, CS/D with industrial telemarketing deserves further investigation. The factors influencing this relationship are the focus of the study and are the basis for the research questions. 


\section{CHAPTER 3 RESEARCH QUESTIONS AND HYPOTHESES}

This chapter addresses the research problem by focusing on the synthesis of CS/D and industrial telemarketing and their relationship to one another. This is accomplished by presenting non-empirically supported viewpoints from the general satisfaction, telemarketing and organizational buying behaviour literature. This literature was the basis for identifying measures which can be used to determine the level of CS/D as well as factors which may be related to CS/D and the usage of industrial telemarketing. These following three sections develop and identify the study's research questions and corresponding hypotheses through a discussion of these subject areas.

\subsection{LEVEL OF CS/D}

Research Question 1: Are business-to-business customers satisfied with the telemarketing of computer software products and services?

As mentioned earlier, the identification and use of global measures is appealing (Hunt, 1977a, 1977b) in determining the level of CS/D. Four measures were selected from the CS/D and telemarketing literature to serve as composite measures of CS/D with industrial telemarketing. The rationale behind the use of multiple measures as opposed to one measure is that the determination of CS/D is critical to this study and that the use of multiple measures should scrve to support or validate that satisfaction is being measured. 
These measures include (1) an overall satisfaction measure with the telemarketing department for purchases of products and (2) services; (3) a measure of the confirmation/disconfirmation of customer expectations with the telemarketing service; and (4) a measure of customer willingness to recommend the telemarketing service to business associates. Each of these measures is discussed briefly below.

\section{Overall Satisfaction Measure}

An overall measure of satisfaction with the telemarketing of computer software products and services is essential because it is unknown how the individual satisfactions/dissatisfactions with the various service and nonservice factors contribute to overall CS/D. Such a measure is common in CS/D research (Crosby, 1989; Angus Reid Associates, 1988; Hunt, 1977a, 1977b; Newman, 1989) when an objective is to determine the general level of satisfaction/dissatisfaction among a group of customers.

This study uses two overall CS/D measures. One pertains to overall CS/D using telemarketing to purchase software products and the other relates to overall CS/D using telemarketing to purchase software support services. They were selected because the primary function of the sponsoring company's telemarketing department is to sell the company's products and services and because it is unknown if customers' satisfaction levels are different for products and services 
when purchasing by telephone.

\section{Confirmation / Disconfirmation of Expectations}

The confirmation/disconfirmation of expectations measure of CS/D has been widely acknowledged in the literature as a means to gauge the level of CS/D with a variety of products and services (Anderson, 1973; Anderson and Jolson, 1973; Bultman, 1989; Crosby, 1989; Day, 1977; Engledow, 1977; Hempel and Rosenberg, 1975; Hunt, 1977a, 1977b; LaTour and Peat, 1979; Miller, 1977; Westbrook, 1980; Wotruba and Duncan, 1975). In addition, since service is widely regarded in the literature as influencing customer satisfaction (Peters and Waterman, 1982; Czepiel, 1980; Roy, 1990; Kennedy, 1990), its measurement is justified. Therefore, for the third measure, customers were asked to rate their satisfaction with the service of the sponsoring company's telemarketing department compared to their expectations

\section{Willingness to Recommend Service}

It has been recognized in the literature that satisfied and dissatisfied customers tell others about their purchase experiences (Desatnick, 1987; Czepiel, Solomon and Surprenant, 1985; Kidd, 1989; Marra, 1986; Ford executive, 1985) In fact, Angus Reid Associates (1988) found that word-of-mouth communication is the most popular method of promoting telemarketing services. Therefore, the 
final general measure seeked to determine the willingness of customers to recommend the sponsoring company's telemarketing service to business associates.

Given the numerous advantages telemarketing offers business-to-business customers, the following hypothesis has been formulated:

H1: A majority of business-to-business customers are satisfied with the telemarketing of computer software products and services.

\subsection{FACTORS RELATED TO CS/D WITH TELEMARKETING}

This section addresses the study's first objective which is to document CS/D with industrial telemarketing and determine what factors are related to this satisfaction/dissatisfaction. There is little empirical research in the literature regarding factors which specifically are related to CS/D with telemarketing, however, it was possible to identify service factors and customer characteristics which may have an influence on CS/D with industrial telemarketing. These factors and characteristics are discussed in the next two subsections.

\subsubsection{Service Factors}

Besearch Ouestion 2: Which telemarketing service factors are most highly associated with CS/D? Which telemarketing service factors are most important to customers when they purchase computer software products and services over the telephone? How similar are these two groups of factors? 
The literature prescribes numerous service factors which industrial telemarketers and telemarketing operations should perform in order to keep customers satisfied (AT\&T, 1989b; Bencin, 1984; Bencin, 1986; Bultman, 1989; Curren, 1987; Domine, 1989, Greenhalgh, 1986; Maister, 1989; Markham, 1970; Maynard, 1986; McNamara, 1986; Moncrief, Lamb, and Dielman, 1986; Moncrief et al., 1988; Noble, 1986; Perruzza, 1988; Sanchez, 1986; Schneider, 1985; Smyth, 1986; Telecom Canada, 1989; Voorhees and Coppett, 1983; Webster, 1980; Wingis, 1981). This literature was the basis for the seventeen service related factors selected for the study and the second hypothesis. The derived list of service factors and the hypothesis are as follows:

1) Convenience

2) Speed filling customer requests

3) Ability to speak clearly

4) Listening to customer concerns

5) Understanding customer needs

6) Knowledge of company products

7) Knowledge of competitive products

8) Ability to answer customer questions

9) Quality of advice given

10) Courtesy extended to customers
11) Accuracy of shipment order

12) Shipment timeliness

13) Updates of order status

14) Regularity of Contact

15) Keeping customers informed of new products and promotions

16) Ability to handle complaints

17) Communication link to other company departments or personnel

H2: Each of the seventeen telemarketing service factors is associated highly with CS/D with industrial telemarketing, however, some of these factors are more important to customers when purchasing computer software products and services over the telephone. 


\subsubsection{Customer Characteristics}

Rescarch Question 3: What effect do customer characteristics have on overall CS/D with the telemarketing of computer software products and services?

This study examined the relationships between three customer characteristics and CS/D with industrial telemarketing. These characteristics include the experience a customer has using business-to-business telemarketing, the age of the customer and the size of the customer organization.

H3: Each of the three customer characteristics has a significantly large effect size on all measures of CS/D with the telemarketing of computer software products and services. Specifically, experience has a significant positive relationship with customer satisfaction; customer age has a significant negative relationship with customer satisfaction; and company size has a significant positive relationship with customer satisfaction.

These relationships are hypothesized despite conflicting findings from previous CS/D and organizational buying behaviour research regarding the relationships that demographic and experience characteristics have on CS/D (Ash, 1978; Hunt, 1977a; Westbrook and Newman, 1978; Woodside et al., 1977; Wotruba and Duncan, 1975). The reasoning underlying this hypothesis is discussed below. 


\section{Experience}

The experience a customer has purchasing products/services over the telephone may affect CS/D with industrial telemarketing. Hunt (1977a), Sheth (1973), and Day (1977) believe that experienced users rather than inexperienced users are more likely to make appropriate choices and have satisfactory purchase experiences because of their familiarity with the product or service (i.e. their expectations are complete). Therefore, it is believed that the experienced telemarketing users are more satisfied with the telemarketing of computer software products and services than inexperienced telemarketing users. The number of times the customer has purchased industrial products and services via telemarketing in the last year was the measure used to gauge this experience.

\section{Age of the Customer}

Age has been found to have a weak or insignificant Iclationship with CS/D in studies dealing with consumer and organizational buyer behaviour (Westbrook and Newman, 1978; Woodside et al., 1977) and a strong association with innovation resistance in a study done by Ram (1987) and numerous other research papers found in Rogers (1971). Consequently, because telemarketing can be considered an innovation (Marshall, 1986) and is used in both the consumer and industrial markets, there appears to be a contradiction on $h w$ age of the customer is related to CS/D with industrial telemarketing. 
A study by Hamilton (1989) has made an attempt to solicit the attitudes and opinions of telemarketing of general consumers by age group. He found that the older the person, the greater likelihood that he/she found the telemarketing sales of products annoying. Therefore, based on these consumer findings, it is believed that older industrial customers are less satisfied with the telemarketing of computer software products and services than younger customers. Due to the sensitivity of age questions and upon the recommendation of the sponsoring company, the study utilizes the number of years the customer has been in the workforce fulltime as an alternate measure.

\section{Company Size}

Company size (i.e. number of employees) may be a factor related to CSID with industrial telemarketing. It is assumed that managers in larger companies make 9 greater number of purchases thus are faced with a greater amount of bureaucratic paperwork than their counterparts at smaller companies. Under these circumstances, busy managers can realize time savings from telemarketing's ability to eliminate the need to fill out and mail in orders (AT\&T, 1989a) and/or meet face-to-face with a sales representative for each purchase. Consequently, managers at larger companies are expected to be more satisfied with the telemarketing of computer software products and services than their counterparts at smaller organizations. 


\subsection{FACTORS RELATED TO TELEMARKETING USAGE}

Little has been concluded witi: respect to telemarketing's appropriate sales and service role. This is ironic given the image problems telemarketing has suffered in the pist (Schneider, 1985; Angus Reid Associates, 1988), and the profound effect the manner in which it is used can ?ave on CS/D. Gilpen (1989) states telemarketing is most effective when used in a situation where a prior relationship exists between the company and the customer. Unfortunately, he fails to specify what these situations are or to elaborate on the nature of these relationships.

Alexander (1987) explains this lack of information on the situations telemarketing's use is most appropriate by noting that general rules do not exist regarding which sales and service situations require personal calls and which warrant telephone calls. She believes management discretion is necessary because there always will be accounts which will require a personal sales call.

Therefore, in order to help distinguish accounts requiring personal sales calls from those where telemarketing's use is appropriate, this section addresses the study's second objective which is to collect customer perceptions regarding the appropriate usage of industrial telemarketing. Like the previous section, there is little empirical research in the telemarketing litcrature regarding factors which specifically affect customer usage. However, unlike the previous section, 
this lack of information has made even the identification of influential telemarketing usage factors difficult.

Research Question 4: What are the most important factors which determine whether customers would purchase and would not purchase computer software products and services over the telephone?

Specifically, an effort to gain some insight into why customers use or do not use telemarketing for product purchases is made through an analysis of their requirement for product demonstrations as well as their price sensitivity to telephone purchases. These factors were chosen because they are contentious issues that have been eluded to in the literature (Alexander, 1987; Morcrief, Lamb, and Dieiman, 1986; Moncri et al, 1988; Bailey, 1988; Marshall and Vredenburg, 1988; Wingis, 1981) but not directly addressed by research in the past. In addition, they are of particular interest because of the influence they are believed to have on telemarketing acceptance and usage.

H4: The two most important reasons stated by customers for and for not purchasing computer software products and services over the telephone pertain to the requirement for product demonstrations and product/service price.

Each of these factors as well as their corresponding research questions and hypotheses are discussed in the following subsections. 


\subsubsection{Requirement for Product Demonstrations}

Kennedy (1990) believes inside sales representatives (i.e. telemarketers) can handle all aspects of account management that does not require face-to-face contact. Since product demonstrations generally require this physical presence at the customer's location, it is possible that customer perceptions of telemarketing appropriateness may be related to their assessment of the requirement for product demonstrations. Moncrief et al. (1988) note that the requirement for face-to-face contact is dependent upon the circumstances surrounding each consumption situation. The product and purchase types involved are two such circumstances.

\section{Product Types}

Hunt (1977a) categorizes products into different types based on their characteristics. His classifications formed the basis for the product breakdown in this study. It was determined that the software products under investigation could be categorized into three groups, these being mainline products, complementary products and service products. Mainline products are the premier or "flagship" products which generally are characterized as being more technical or complex in nature and more expensive than other company offerings (e.g. fourthgeneration language). Complementary products are generally less expensive and purchased in separate transactions to enhance the performance of the mainline 
products (e.g. application development, data management and reporting tools). Service products are generally the least expensive of the product offerings, acquired simultaneously with purchases of mainline and complementary products and intangible in nature (e.g. education courses, training, consulting and service contracts).

The products were categorized into these groups for measurement purposes and completed with the aid of the sponsoring company. It is realized that these classifications may not always be clear to customers, especially those of the mainline and complementary products. However, because the sponsoring company categorizes its products in a similar manner in company brochures, customers will not likely be confused by this categorization method.

The differences betwcen these product types may have an influence on customer telemarketing usage. However, it is unknown if such tendencies exist among the customers of the sponsoring company. Therefore, an initial investigation of this issue is warranted.

Research Question 5: Are certain software product types more apt to be purchased over the telephone?

It is not known if software customers distinguish between the different product types when purchasing by telephone. However, it is believed that some discretion does take place. 
H5: Complementary and service products are more likely to be purchased through telemarketing than mainline products.

\section{Purchase Types}

The type of purchase refers to the "uniqueness" of a particular product or service purchase situation. Two purchase types will be examined, these being first-time anu subsequent purchases. With first-time purchases, it is assumed that customers have no experience purchasing or using the product or service. A subsequent purchase represents an upgrade or additional purchase of a previously purchased product or service. Therefore, with these purchases, it is assumed that the customer has experience purchasing and using the product or service.

No previous telemarketing research has addressed customer perceptions of the requirement for product demonstrations by product and purchase type. However, conflicting arguments by various telemarketing experts with respect to these issues have been documented. For instance, Moncrief et al. (1988) note that telemarketing should be used in a primary role when routinized selling processes and non-technical products are involved (i.e. complementary or service products) and a supporting role to field sales when the selling process is unique and the products are technica! in nature (i.e. mainline products). These views may be due to the fact that in organizational buying, new purchase experiences are perceived by the customer to have a gruater perceived risk than repetitive or routine purchases (Sheth, 1973). 
However, in contrast to these beliefs, Rudolf (1986), Alexander (1987) and Bailey (1988) assert that telemarketing can and is being used by many companies to introduce and sell their principal or mainline products, some of which are expensive and technical in nature.

In order to examine these issues, the study addressed the following research questions:

Besearch Question 6: For first-time purchases, how is the requirement for product demonstrations by product type related to the appropriateness of telemarketing by product type?

Research Question 7: For subsequent purchases, how is the requirement for product demonstrations by product type related to the appropriateness of telemarketing by product type.

These relationships were examined by asking customers to rate the importance of demonstrations and appropriateness of telesales as low, medium or high for the following purchase circumstances (i.e. based on the three product and two purchase types):

1) First-time purchases, Mainline products (FTM);

2) Subsequent purchases, Mainline products (S/M);

3) First-time purchases, Complementary products (FT/C);

4) Subsequent purchases, Complementary products (S/C);

5) First-time purchases, Service products (FT/S); and

6) Subsequent purchases, Service products (S/S). 
The importance and appropriateness measures were used for weighting and comparison purposes. Like satisfaction, these measures are subjective in nature and are believed to have similar difficulties associated with their measurement. Therefore, no definition of importance and appropriateness was given to customers and they applied their own standards to these ratings.

From the previous discussion, two hypotheses regarding the nature of the relationship between customer perceptions of the importance of demonstrations and the appropriateness of telemarketing for purchases of computer software products and services have been surmised. They have been based on the belief that industrial customers remain committed, at least partially, to face-to-face contact when purchasing these types of products and services.

H6: For first-time purchases, there is a negative relationship between the importance of demonstrations by prodilct type and the appropriateness of telemarketing by product type i.e. first-time customers discriminate by product type and place more importance on demonstrations for mainline products than for complementary or service products, therefore, perceive telemarketing as being less appropriate for mainline products than for complementary or service products.

H7: For subsequent purchases, there is a negative relationship between the importance of demo.strations by product type and the appropriateness of telemarketing by product type i.e. repeat customers discriminate less by product type than first-time purchasers by reporting lower importance on demonstrations and higher telemarketing appropriateness for all product types. 
Figure 1 illustrates these hypotheses through a graph of the expected median values of the demonstration importance and the telemarketing appropriateness ratings by purchase circumstance. These median values were calculated by assigning value weightings of one, two and three to the low, medium and high ratings respectively. 
FIGURE 1

\section{ESTIMATED MEDIAN VALUES OF THE DEMONSTRATION IMPORTANCE AND THE TELEMARKETING APPROPRIATENESS RATINGS BY PURCHASE CIRCUMSTANCE}

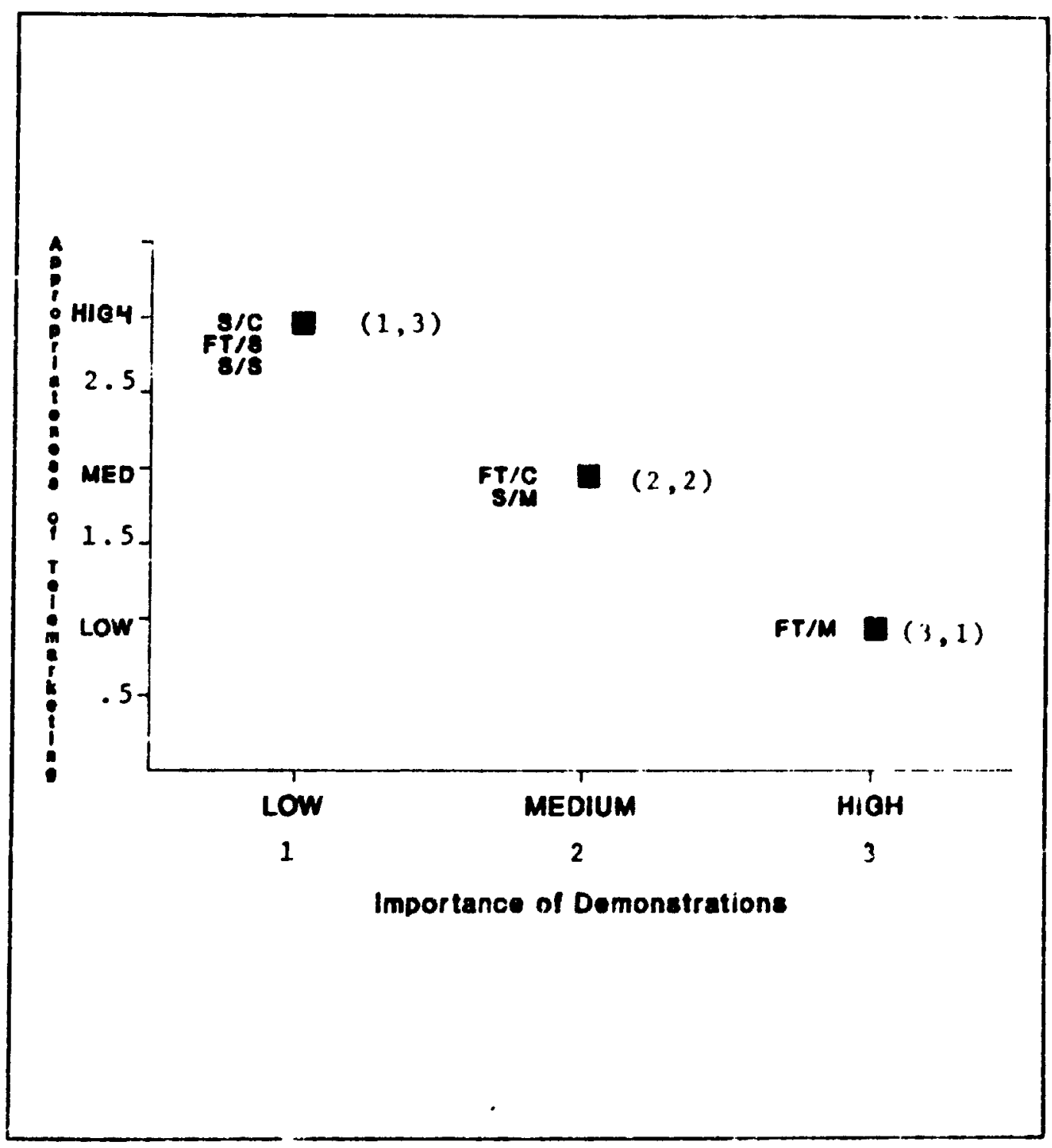


Figure 1 represents the distinctions expected to exist between how custcmers see the importance of demonstrations and appropriateness of tclemarketing by product type and purchase type. For firsi-time purchases, mainline products are predicted to rate low in telemarketing appropriateness and high in demonstration importance, complementary products are anticipated to rank medium on both measures and service products are expected to rank low in demonstration importance and high in telemarketing appropriateness. Thus, first-time telemarketing purchases of mainline products are perceived to be high in risk while service purchases are low in risk and purchases of complementary products lie in between the two.

For subsequent purchases, it is believed that there will be less discrimination by product type than for first-time purchases. Mainline product purchases are forecasted to rate medium on both measures and the complementary product purchases are presumed to become low in demonstration importance and high in telemarketing appropriateness. Service product purchases are expected to receive the same ratings as they did for first-time purchases.

Consequently, with experience purchasing the various product types, the differences between them regarding demonstration importance and telemarketing appropriateness are predicted to become smaller as is the perceived risk of telephone purchases. 


\subsubsection{Product / Service Price}

Another factor which may influcnec customer usage of telemarketing for purchases is product or service price. There is little known about the amount of money people are willing to spend over the telephone and if it varics depending on the product and purchase types.

Research Question 8: What is the highest price customers would pay on a telephone purchase of a computer software product or service? Do these limits encompass all product types? Are the limits conditional? If yes, what factors do the limits depend upon? Do these limits and conditions vary between firsttime and subsequent purchases?

Moncrief et al. (1988) believe that industrial telemarketing adds no value to a selling strategy when the types of products being sold are expensive. Bailey (1988) counters this belief that big-ticket items cannot be sold over the telephone by noting that General Electric's telemarketing operation routinely sells products in the $\$ 20,000$ price range and has led to $\$ 400,000$ and $\$ 100$ million dollar sales in the past. Wingis (1981) also asserts telcmarketing's ability to sell expensive capital goods through a reference to AT\&T's success at selling fifteen of its Horizon systems with an average valuc of $\$ 50,000$ each, five of which were sold with no field sales call at all.

A recent Telemarketing magazine survey of telcmarketing operations tends to support both arguments. For instance, it found that 47 percent of the 
respondents reported the value of the products they sold over the telephone was under $\$ 100$. Table 2 displays the value breakdowns from the study.

\section{TABLE 2}

\section{DOLLAR VALUE OF PRODUCTS SOLD THROUGH TELEMARKETING}

Less than $\$ 100$

$\$ 100-\$ 499$

$\$ 500-\$ 999$

$\$ 1,000-\$ 4,999$

$\$ 5,000-\$ 24,999$

Over $\$ 25,000$
$47 \%$
$22 \%$
$8 \%$
$10 \%$
$8 \%$
$6 \%$

Source: Hayes, 1989

However, the same study revealed that six percent of the operations sell products worth over $\$ 25,000$ and that the average telemarketing sale to be $\$ 18,284$ from a range of products costing from 35 cents to two million dollars (Hayes, 1989).

It is unknown if business customers' spending limits vary based on the purchase type; that is if customers are willing to spend larger sums of money on subsequent rather than first-time purchases. Moreover, if this is the case, the reasons for the differences are not fully understood. Based on his work in the field of telemarketing, Shipp (1989) believes that the frequency a customer has spoken with a telemarketer and the relationship building that has taken place is the main impetus behind more expensive purchases instead of the amouln of experience with the product or service. 
Given telemarketing's recent expansion into the industrial market (Bailey, 1988; Wingis, 1981) and the limited number of strong customer-telemarketer relationships believed to currently exist in Canada, it is believed that the purchase type (i.e. experience using the product or service) is likely to hiive an impact on spending limits.

H8: Telemarketing customers place lower dollar limits on first-time product purchases than on subsequent product purchases i.e. price is more of a barrier to telemarketing usage for first-time purchascs or until some experience with the supplier's technology has been acquired. 


\section{CHAPTER 4 RESEAPCH METHODOLOGY}

This research seeks to generate information regarding CS/D with the industrial telemarketing of computer software prodicts and support services. In order to accomplish this, the sponsorship of a software developer which actively markets its products and services via industrial telemarketing was secured. Since it is necessary that the firm's customers be contacted in order to collect the required information, the research methodoingy was planned so that the study's objectives could be achieved without affecting the integrity of this company's te!emarketing operation.

This chapter gives a detailed outline of the research methodology used for this study in five sections. The first section describes the research design. Section two discusses the developrient of the data collection instrument used for the study. Thre sampling methodology and operatior al procedures followed are covered in sections three and four respectively. Finally, section five specifies the data analysis techniques thai were applied to the research questions.

\subsection{RESEARCH DESIGN}

The research design used was ex-post facto and descriptive in nature. This framework was chosen because of the scarcity of present knowledge on CS/D as It relates to industrial telemarketing and also because this design is considered 
one of the best methods to study and describe large populations (Davis and Cosenza, 1988).

There are two types of descriptive studies avalahle to the researcher, longitudinal and cross-sectional designs. A cross-sectional design uas used since the sample of elements from the population of interest uas measured at a single point in time. A longitudinal design uas not feasible for this study mainly because of time constraints on the research and the improbabilly that the respondents would be accessible over an extended period of time (1.e. Jue to) positions changes $u$ ithin their respective organizations).

A major computer softuare developer participated in this study. The company is particularly ueli suited for the study for the follouing reasons:

* it is a large softuare firm with convenient locatuons:

* it operates a telemarkeung department typical of most in the industry (Hayes, 1989). For instance, it represents a manufacturing company, has a head office location, an in-house, centralized structure, is partially automated, employs hetueen 1 and 5 full time representatives responsible for customers in specific geographical regions, performs inbound and outbound functions and has been in business for less than 5 yeurs;

* it produces a uide range of mannline, complementary and service products which are marketed over the celephone;

* all of the products and services have been upgraded since being first introduced. This point is important because if only some of the products have been upgraded, responses could be biased to such products or services; 
* the telemarketing department's customer base is substantial in size and has a national scope; and

* it has a genuine interest in the study's results and is willing to cooperate with the researcher and commit the necessary resources to the project.

The researcher, managers from the sponsoring company and Carleton University professors worked together throughout the planning and implementation phases of the research. The meetings and open communication that took place ensured that the concerns of all parties were considered throughout the development of the study.

\subsection{DATA COLLECTION / SURVEY DEVELOPMENT}

The data collection instruments originally proposed for the research were self-completed mail questionnaires. However, based upon the results of two pretests, it was concluded that a telephone survey would better serve the purposes of the research. This change in data collection method did not affect the general content of the study, its research questions or corresponding hypotheses.

However, because methodological changes took place from that whicl: was set forth in the study's proposal, an explanation of the pretest results and survey evolution is warranted. As a result, the following three subsections briefly describe the proposed mail questionnaire, the pretest results and the improved telephone survey. 


\subsubsection{Mail Questionnaire}

The mail questionnaire originally proposed for the research was comprehensive in scope. Its content was based upon the literature review and comments from telemarketers, field sales representatives and managers from the sponsoring crganization, as well as Carleton University professors. Thus, the questions were designed to address all issues relevant to this study and (o also gather specific information on other topics of particular interest to representatives of the sponsoring company (i.e. company mailings, 1-800 number).

The resulting questionnaire was comprised of nominal product. demographic and sample characteristic questions, numerous five point itemized rating scales, open-ended responses, an 11-point service importance/satisfaction rating scale, five global satisfaction measures and a section for comments. The 11-point scale was utilized at the urging of the sponsoring organization hecause it is a scale the sponsoring organization's Data Analysis Manager was comfortable with and had success with in the past. A sample copy of this mail questionnaire is presented in Appendix $\mathrm{E}$.

\subsubsection{Pretest Results}

Two separate pretests of the mail questionnaires were conducted in order to eliminate any possible problems in its design. The first pretest of the mail 
questionnaire was conducted through facsimile machines to three telesales customers representing Newfoundland, Ontario and Alberta in March, 1990. Each customer completed the questionnaire promplly and faxed it back to the sponsoring organization's office for analysis. It was generally revealed in this initial screening that the questionnaire was too long, the scales were inappropriate, the presentation was "too busy" and that some questions were ambiguous, awkwardly worded or unclear. This design resulted in questions being left blank, partially answered or answered inappropriately.

These problems were addressed in a variety of ways which included rewording, adding and deleting questions, collapsing answer categories into fewer groups, creating more multiple choice responses, spacing questions further apart on the page and adding columns to scales where necessary. Carleton University professors and the sponsoring company's Telemarketing Manager provided useful feedback throughout the revision process.

The second pretest took place in May, 1990. It was originally intended to be the general survey which would collect the required data for the study. However, due to a combination of logistical problems, key management changes at the sponsoring organization as well as poor timing (i.e. summer vacation months), twenty nine questionnaires were returned representing a response rate of approximately 6 percent. Since sufficient information could not be generated by the number of completed questionnaires and problems still existed with the 
questionnaire, this mailing was treated as a second, more comprehensive pretest.

It became apparent from the second pretest that the mail data collection method was not appropriate for gathering information for the study and that a new method which afforded greater interviewer-interviewee interaction was required. It was also evident that any new method chosen would have to have a greater possibility of generating a high response rate in a relatively short period of time and at a low cost.

\subsubsection{Telephone Survey}

Given these circumstances, the most feasible data collection medium was the telephone. As a result, the mail questionnaire was converted to a telephone format. Again, this involved rewording questions, deleting and combining questions, shortening scales, eliminating open-ended responses and expanding answer categories where appropriate. Dillman (1977) proved to be a useful resource throughout this process. All changes were approved by the graduate supervisors at Carleton University and the sponsoring organization's new Telemarketing Manager.

The resulting telephone survey was built for fast and accurate data collection. It addressed issues pertinent only to the research at hand and comprised mainly of nominal product, telemarketing usage and sample 
characteristic questions, three and five-point itemized rating scales and four global satisfaction measures. Furthermore, compared to the original mail questionnaire, it was a more concise, less confusing data collection instrument which had a greater potential to encourage participation and generate useful surveys by respondents. A sample copy of the telephone survey is displayed in Appendix F.

\subsection{SAMPLING METHODOLOGY}

The sampling methodology used in the research was based upon tradeoffs. Time and cost considerations were balanced against the expected value of the data (Tull and Hawkins, 1980). In doing so, the goal to ensure representativeness from certain population subgroups and to keep selection errors to a minimum had to be given special attention. All facets of the sampling process applied in this study are explained below.

Population: Customer companies and government departments/agencies across Canada that have either had contact with the sponsoring company's telemarketing department since its introduction in 1987 or that have purchased products and services from the sponsoring company. It is believed that as long as customers had experience in at least one of these areas, they could provide well-informed viewpoints to the research. 
Sampling Frame: Since the sponsoring company divides its corporate customer data base into five distinct regions (i.e. Toronto, Queher. Ottawa, West and Maritimes), the most current regional computer printouts of the names of these organizations was used (February, 1991). Based on the forementioned requirements, there was a population total of exactly 706 eligible companies listed on the five printouts.

Sampling Unit: One business customer from each company or government department/agency.

Sampling Method: Quota sample controlled for by the sponsoring company's five Canadian sales regions. Persons were selected to fill the quota for each region using systematic sampling.

Sample Size: A sample size of 100 or 14.2 percent of the population was selected based on the trade-offs mentioned earlier and the belief that a larger sample would not provide additional information to the study's results. In addition, due to the large number of customers who received a mail questionnaire during the pretest phase of the research, a much larger sample could not be afforded without repetition. Table 3 displays the regional breakdowns.

TABIR 3

REGIONAL BREAKDOWNS OF CUSTOMER ORGANIYATIONS

\begin{tabular}{|c|c|c|c|}
\hline$\frac{\text { REGION OF }}{\text { COUNTRY }}$ & $\frac{\text { NUMBER OF CUSTOMIEB }}{\text { ORGIANIZATIONS }}$ & $\begin{array}{l}\text { POPULAIION } \\
\text { BKLAKDOWNS }\end{array}$ & $\begin{array}{l}\text { UUULA } \\
\text { SAMPLI }\end{array}$ \\
\hline Toronto & 200 & $28 \%$ & 28 \\
\hline Quebec & 182 & $26 \%$ & 26 \\
\hline Ottawa & 98 & $14 \%$ & 14 \\
\hline West & 162 & $23 \%$ & 23 \\
\hline Maritimes & 64 & $9 \%$ & 9 \\
\hline Total: & 706 & $10(0 \%$ & $1(x)$ \\
\hline
\end{tabular}


Sampling Plan: Prior to making any telephone calls, the specified number of companies to be called from each region were selected. Specifically, this was done by taking a computer printout, picking a company at random and systematically choosing every seventh (i.e. $K=N / n$ or $706 / 100$ ) organization on the list thereafter until the desired number was reached. For those instances when the end of the list was reached (i.e. due to non-response), the counting would started the beginning of the list again and the organizations already selected were skipped.

\subsection{OPERATIONAL PROCEDURES}

Once the organizations to be called were identified, the interviews were conducted. These were completed from the sponsoring company's telemarketing department between the dates of February 4 and February 22,1991. A private work area, a telephone with a WATS line and password access to the department's specialized customer database was provided. Telemarketers employed by the company provided training regarding how to obtain the required information from the system (i.e. company and contact names, telephone numbers, if the organization is a customer or a prospect, length of time has been a customer, last date contacted, previously purchased products or services and related comments).

There were a number of operational procedures that were followed during the interview process. It is believed that their implementation increased the probability of response, decreased response times and allowed for maximum consistency and control. These procedures are described below. 
1) The researcher conducted all of the telephone interviews.

2) All interviews were conducted daily during business hours only (i.c. 9:(X) A.M. to 5:00 P.M.).

3) The researcher maintained an affiliation with the sponsoring organization instead of with Carleton Uriversity's Master of Management Studies program when administering the survey.

4) Anonymity and confidential treatment of customers was guaranteed. Customers were informed of this at the beginning of the interview.

5) Before each interview, the selected contacts were identified. In each case. the primary contact was called first, as in most cases there was more than one contact at each organization. To ensure that the appropriate persons were interviewed, each contact was screened for the following:

i) to crosscheck with the names of persons that had participated in the pretests. Only persons who did not receive the pretests were considered for interviews;

ii) to see if the customer had previous experience with the telemarketing service and/or the sponsoring company's products. If the person had experience with at least one of these areas, their cooperation for the interview was sought. If the contact had no experience in either area, he/she was asked to refer the intervicwer to a person with such experience. For most of the interviews, this screening step was automatic as customers immediately informed the researcher of any inexperience with the service or products and referred someone else as a contact if this was the case; and 
iii) to be sure that any experience with the company's telephone service is indeed with telemarketing and not telesupport. These are two separate functions at the sponsoring company. The telemarketing department specializes in the sales and service of company products and services while telesupport concentrates on investigating and answering specialized technical inquiries by customers. It is important to the validity of the study's results that customers understand that the two departments are separate when answering the survey. Therefore, whenever it was felt to be required, customers were made aware of this distinction.

6) The interviewer was polite, courteous and used non-pressure tactics when questioning respondents. Customers appeared to be very receptive to this.

7) Messages were left with selected contacts if they were not available when called. Callbacks were made to individuals not returning the messages a total of three times on three separate days. If they still could not be reached or were not answering their phones, further efforts were not made in order to avoid upsetting the customers.

8) A detailed call guide documenting pertinent information for every call made was maintained throughout the interview process. It contained information of the company and contact names, telephone numbers, start and finish times of calls, survey status and comments.

9) The call guides were reviewed daily to ensure that interviews previously scheduled were kept (i.e. some were planned up to two weeks in advance), that more than one was not scheduled for the same date and time and that interviews were organized appropriately around the different regional time zones.

10) All interviewee comments and non-response bias were documented during the interview process. A brief report of the customer comments was provided to the sponsoring company by the researcher. 
These procedures were followed and interviews were conducted until the quota sample of 100 surveys was collected. Throughout and following this process, all answers were checked for consistency and completeness. Once these editing and quality control procedures were complete, the responses were coded, keyed and analyzed.

\subsection{DATA ANALYSIS}

The data was analyzed using Carleton University's CP-6 mainframe computer and the Statistical Package for the Social Sciences (SPSS). Norusis (1990) was the reference used with this program. The analysis was concerned primarily with determining how selec ed service factors and customer characteristics are associated with CS/D and identifying factors and relationships related to industrial telemarketing usage. The specific techniques used to analyze the data corresponding to each of the study's research questions are stated below.

Research question one examined the four measures of CS/D with industrial telemarketing using frequencies, measures of central tendency and Pearson correlations. These techniques were used so that the consistency of the measures and the level of satisfied, indifferent and dissatisfied customers existing among the respondents could be determined. 
Research question two utilized Pearson correlations in order to identify the telemarketing service factors that are associated highly with customer satisfaction. In addition, through frequencies and weighted comparisons, the researcher identified the telemarketing service factors which are most important to customers when they use telemarketing and then contrasted them with the mean satisfaction scores of the service factors.

Research question three employed the Coleman analysis (Coleman, 1964) to determine the effects (i.e. sizes of the relationships) that experience purchasing products and services via telemarketing, customer age and size of the customer company have on CS/D with the industrial telemarketing of computer software products and services. This multivariate technique utilizes crosstabulations and the method of least squares in order to express the effects of these sample characteristics on satisfaction in terms of a single parameter. This technique also accounts for the effect sizes of any unexplained variation due to other variables not included in the model.

Research questions four through eight examined customer perceptions regarding telemarketing usage with computer software products and support services. Frequencies and qualitative analysis were used for each of these questions. The questions examining specific relationships (research questions 6 and 7) included crosstabulations, median values and Spearman's rank order correlations in their analyses. Research question eight required a comparison of 
spending limits to the prices of the sponsoring company's products. Price ranges for the product types were formulated with the aid of the sponsoring company in order to effectively contrast these figures. Other demographic and telemarketing usage questions in the questionnaire were measured using frequencies. Appendix $\mathrm{G}$ further explains where these methods are used through a linkage of the research questions, telephone survey and data analysis. 


\section{CHAPTER 5 RESEARCH FINDINGS AND INTERPRETATION}

The research findings and their interpretation are presented in six sections. The first section examines the study's response rate and comments on the likelihood of bias in the data. Section two describes the sample of organizations and business customers in order to determine if it is representative of the population and has the potential to provide reliable information with respect to the issues of interest. The third section presents the data which pertains to the overall level of CS/D with industrial telemarketing. Sections four and five detail the results regarding factors which are related to CS/D with telemarketing and factors which are related to telemarketing usage respectively. Finally, the last section discusses other pertinent findings that are based on observations made be the researcher and the comments of customers during the interviews.

\subsection{RESPONSE RATE}

The quota sample of 100 telephone interviews was achieved during the three week period they were conducted from the sponsoring organization. In order to reach this sample size, a total of 250 calls (i.e. initial calls and callbacks) were made to 135 of the company's business customers. Therefore, the response rate was 74.1 percent. Considering the busy daily routines and the difficulty that can be expected in contacting these individuals, this participation level is believed to be very good. Table 4 displays the response rate data by region. 
TABLE 4

\section{RESPONSE RATE DATA BY REGION}

\section{Region Total Number of Contacts Maue to Reach Quota}

\section{Toronto Quebec Ottawa \\ West \\ Maritimes}

Total
35

41

24

24

11
135

\begin{tabular}{cc}
\multicolumn{2}{c}{ Non-response } \\
Number & Peicent \\
7 & $20 \%$ \\
1.5 & $37 \%$ \\
10 & $42 \%$ \\
1 & $4 \%$ \\
2 & $18 \%$
\end{tabular}

35

The distribution of the non-response did vary across the five regions of the country. The Quebec and Ottawa regions, in particular, had substantially higher levels than the othe: regions. It appears that they have a higher proportion of customers that refused interviews because of no experience with the company's telemarketing department. This and other reasons for non-response hy customers are presented in Tahle 5 . 
TABLE 5

\section{REASONS FOR CUSTOMER NON-RESPONSE}

Reason

1) Did not return calls.

2) Contact no longer with the company.

3) Contact away on vacation/conferences

4) Contact could not be reached due to late shiftwork hours.

5) No experience with the sponsoring company's telemarketing department.

6) No experience with the company's software 3* products.

7) R.efusal because already answered recent 2

8) Language problems

Frequency

9) No reason / just does not want to answer.

Total
3

5

2

1

$13^{*}$

3

3

(* These persons refused to answer questions even though their shortcoming in experience in one of the required areas did not affect their eligibility to participate.)

Upon examination of the reasons for non-response, it is believed that its cffect or bias on the data is negligible. This belief is due to the fact that most persons contacted that had experience with either the telemarketing service, the software products or with both did agree to participate in the study. In other words, there were peo-'e that agreed to be interviewed that had similar characteristics to the non-respondents. 


\subsection{DESCRIPTION OF SAMPLE}

A description of the sample is necessary in order to determine if it is representative of the population and if any errors exist which may affect the results. Information was collected from each respondent regarding the nature of his/her company, its size in gross dollar revenue and number of employees. his/her position in the company, the number of years he/she has been in the workforce fullime, the last time contact was made with the sponsoring company's telemarketing department and the number of times he/she has used telemarketing in the last year to purchase products and services. These sample statistics are detailed in Tables 6 through 12.

The sample statistics show that small, medium and large companies, based on 1990 gross dollar revenue figures and the number of employees, from all major industry sectors are represented. Furthcrmore, the data indicates that a balance of younger and older respondents wich fairly technical backgrounds and different levels of experience using telemarketing comprise the sample. The most common contacts at the companies included MIS Directors/Managers, Datat Processing Directors/Managers, Technical Support Specialists and Technical Analysts. Although similar population statistics are not available, some representativeness is evident as the proportion of the top two industry sectors in the sample (i.e. Manufacturing and Transportation and Distribution) directly correspond to those found in the Hayes (1989) study. 
TABLE 6

NATURE OF BUSINESS BY REGION

Region

Toronte Quebec Ottawa West Maritimes Total

Industry

Resour:--based

Health Services

Manufacturing

Communications

Government

Finance/Banking

Information Services

Utilities

Insurance

Wholesale, Retail \&

Value Added Reseller

Cultural and

Entertainment

Real Estate and

Construction

Transportation and

Distribution

Educational

Tourism

Non-profit

Total

$\begin{array}{cccccc}1 & 4 & 0 & 4 & 1 & 10 \\ 3 & 0 & 1 & 0 & 0 & 4 \\ 15 & 6 & 3 & 1 & 2 & 27 \\ 2 & 1 & 1 & 3 & 0 & 7 \\ 1 & 0 & 1 & 1 & 1 & 4 \\ 0 & 2 & 0 & 1 & 0 & 3 \\ 2 & 3 & 2 & 1 & 1 & 9 \\ 1 & 0 & 1 & 1 & 0 & 3 \\ 0 & 1 & 0 & 1 & 0 & 2 \\ 1 & 5 & 0 & 1 & 2 & 9 \\ 0 & 0 & 2 & 0 & 0 & 2 \\ 0 & 0 & 0 & 2 & 0 & 2 \\ 1 & 4 & 2 & 4 & 0 & 11 \\ 0 & 0 & 0 & 2 & 2 & 4 \\ 0 & 0 & 0 & 1 & 0 & 1 \\ 1 & 0 & 1 & 0 & 0 & 2 \\ -- & - & - & - & - & - \\ 28 & 26 & 14 & 23 & 9 & 100\end{array}$

TABLE 7

RANGE OF CUSTOMISR COMPANIES' 1990 GROSS DOLLAR REVENUE

Low

$\$ 1,200,000$
Median

$\$ 67,500,000$
High

$\$ 90,000,000,000$ 
TABLE 8

\section{NUMBER OF EMPLOYEES AT THE CUSTOMER COMPANIES}

\section{Range}

Under 25

25 to 50

51 to 100

101 to 250

251 to 500

501 to 1000

1001 to 5000

Over 5000
Nunlor of Compunic:

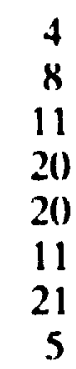

4

8

20)

20)

11

21

5

$\begin{array}{ll}\text { Total } & 100\end{array}$

'TABLE 9

FUNCTIONAL POSITIONS OF THE RESPONDENTS

Position

MIS Director/Manager

Data Processing Director/Manager

President/Chief Executive Officer

Computer-Technical Instructor

Computer-Technical Designer/Development

Computer-Technical Support Specialists

Computer-Technical Analyst

Programmer

Controller

Consultant

Investment Analyst

Accountant

Corporate Management*
Number of Persons

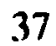

11

1

2

6

10

10

8

2

1

1

2

9

100

Total

(* includes a V.P., Finance; a V.P., Management Information Systems; a Gencral Manager; an Operations Manager; a Branch Manager; a Project Leader; a Payroll Manager; a Computer Centre Manager; and a Production Services Manager.) 
TABLE 10

NUMBER OP YEARS IN THE WORKFORCE FULLTIME

Bange

Under 5

5 to 10

11 to 15

16 to 20

21 to 25

Over 25

Total
Number of Persons

6

17

22

28

11

16

100

TABLE 11

TIME OF LAST CONTACT WITH THE SPONSORING COMPANY'S TELEMARKETTNG DEPARTMENT

Time

Under two weeks ago

One month ago

Six weeks ago

Two months ago

Three months ago

Four months ago

Six months ago

One year ago

Over one year ago

Never

Don't know
Number of People

21

17

1

12

5

4

10

8

5

14

3

100

Total 
TABLE 12

NUMBER OF TELEPHONE PURCHASES MADE IN THE I.AST YEAR

\section{Number of Times}

None

Once

Twice

Three

Four

Five

Six

Eight

Nine

Ten

Twelve

Fifteen

Twenty

Twenty-five

Thirty

Fifty

Sixty

Seventy

Eighty

One Hundred

Two Hundred

Don't Know
Number of Peoples

11

4

11

11

3

5

4

2

1

8

3

3

5

1

4

2

2

\section{1}

1

5

4

9

100

Population representativeness is important because one of the potential disadvantages with a quota sample is that it may increase the likelihood of selection errors. This error is believed to be small because the researcher was working from aceurate information with respect to the number of customers hy region and because the sampling plan allowed for persons within these groups to be selected on a random basis. In addition, it was noted that there was no 
propensity shown by respondents from any of the regions to answer the questions in a similar fashion.

Table 11 shows that a majority of the business customers (i.e. 70 percent) have had contact with the company's telemarketing department within the last six months. This is particularly important to note because it means that customers should have been able to recall from memory the experience with the sponsoring company's telemarketing department with some reliability, thus keeping the effects of history and timing errors to a minimum.

\subsection{LEVEL OP CSID}

Four measures of CS/D with industrial telemarketing described in the literature review were used in the study. These were (1) the satisfaction customers have using telemarketing to purchase software products; (2) the satisfaction customers have using telemarketing to purchase software services; (3) the satisfaction customers have with the telemarketing service compared to their expectations; and (4) customer willingness to recommend the sponsoring company's telemarketing service to business associates. Each was measured using a five-point itemized rating scale.

Table 13 display's the resulting frequencies associated with the customer ratin.s of their satisfaction using telemarketing to purchase software products 
(Prodsat) as well as the measures of central tendency

\section{TABLE 13}

\section{SATISPACTION USING TELEMARKETING TO PURCHASE COMPIJTER SOFTWARE PRODUCTS (PRODSAT)}

\begin{tabular}{|c|c|c|c|}
\hline Rating & Value & Erequency & $\frac{\text { Valid }}{\text { Percent }}$ \\
\hline Very Dissatisfied & 1 & 1 & 4.2 \\
\hline Dissatisfied & 2 & 1 & 4.2 \\
\hline Indifferent & 3 & 4 & 16.7 \\
\hline Satisfied & 4 & 12 & 50.0 \\
\hline Very Satisfied & 5 & 6 & 25.0 \\
\hline Subtotal: Persons & ve ratings & 24 & 100.0 \\
\hline \multirow{4}{*}{\multicolumn{2}{|c|}{$\begin{array}{l}\text { Have not purchased software products } \\
\text { or services over the telephone } \\
\text { Purchased services only } \\
\text { Unknown } \\
\text { Have not and will not purchase software } \\
\text { products or services over the telephone }\end{array}$}} & 30 & \\
\hline & & 30 & \\
\hline & & 0 & \\
\hline & & 16 & \\
\hline \multicolumn{2}{|c|}{ Subtotal: Persons who did not give ratings } & 76 & \\
\hline \multicolumn{2}{|l|}{ Total } & 100 & \\
\hline
\end{tabular}

Mean: 3.9

Median: 4.0

Mode: 4.0

This table shows that of the 24 persons with experience purchasing software products over the telephone, 75 percent were satisficd with the experience. However, of the remaining 76 customers who did not give ratings, 30 had no experience purchasing software products or services over the telephonc 
but would consider doing so in the future, 30 had only purchased software services over the telephone and 16 stated that under no circumstances would they purchase any software products or services via telemarketing. Consequently, it appears that there is a large proportion of customers that have still not accepted or have seen the need to use telemarketing to purchase computer software products.

Table 14 shows similar information for customer satisfaction using telemarketing to purchase software support services (Servsat). Customer usage and satisfaction purchasing support services over the telephone is higher than that of software products. The number of persons with experience purchasing support services via telemarketing was more than double that of software products at 49 (i.e. 48 ratings and one unknown) and approximately 90 percent of these customers reported that they were satisfied doing so. The remaining breakdown includes 30 customers with no experience purchasing products or services over the telephone that would consider doing so in the future, 16 people that stated under no circumstances would they purchase any software products or services via telemarketing and 5 customers with experience using telemarketing to purchase computer software products only.

It is interesting to note from the preceding two tables that while $\mathbf{3 0}$ customers have experience using telemarketing to purchase services only, only five customers have similar experience exclusively with products. Although not 
shown, 19 people had experience purchasing both products and services via telemarketing. This suggests that for many people experience purchasing support services over the telephone comes prior to experience purchasing software products over the telephone.

TABLE 14

SATISFACTION USING TELEMARKETING TO PURCHASE SUPPORT SERVICES (SERVSAT)

\begin{tabular}{|c|c|c|c|}
\hline Bating & Value & Frequency & $\underset{\text { Percent }}{\text { Valid }}$ \\
\hline Very Dissatisfied & 1 & 1 & 2.1 \\
\hline Dissatisfied & 2 & 0 & 0.0 \\
\hline Indifferent & 3 & 4 & 8.3 \\
\hline Satisfied & 4 & 27 & 56.3 \\
\hline Very Satisfied & 5 & 16 & 33.3 \\
\hline Subtotal: Person & ve ratings & 48 & 100.0 \\
\hline
\end{tabular}

Have not purchased software products $\quad 30$

or services over the telephone

Purchased products only 5

Unknown 1

Have not and will not purchase software $\quad 16$

products or services over the telephone

jubtotal: Persons who did not give ratings 52

$\begin{array}{ll}\text { Total } & 100\end{array}$

Mean: 4.2

Median: 4.0

Mode: 4.0 
Table 15 provides the frequency breakdowns of the third CS/D measure, that being satisfaction with the service provided by the telemarketing department compared to customer expectations (Expect).

TABLE 15

SATISFACTION WITH THE TELEMARKETING SERVICE COMPARED TO EXPECTATIONS (EXPECT)

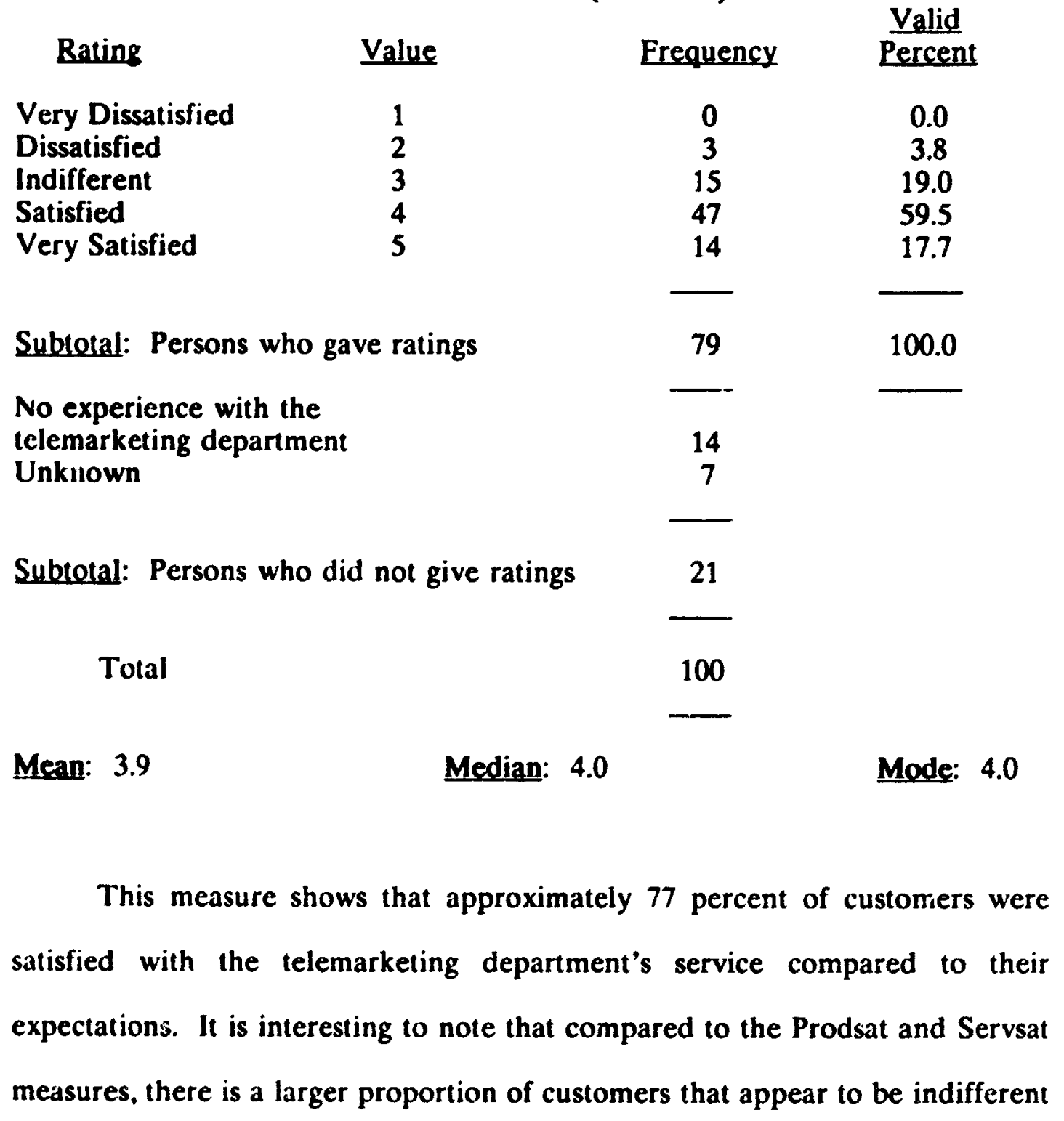


(i.e. 19 percent). This higher proportion of indifference suggests that the Expect measure may be a more stringent gauge of CS/D or that some customers do not have expectations regarding telemarketing service performance. The results also show that 86 customers have had experience with the sponsoring companys telemarketing service (i.e. 79 customers who gave ratings and seven customers whose ratings were unknown). Only 14 customers surveyed had no experience speaking with a telemarketing representative of the sponsoring company.

The final gauge of CS/D is customer willingness to recommend the telemarketing service to business associates (Willing). Table 16 displays the customer responses and related frequencies associated with this measure. The results show that approximately 68 percent of customers were willing to recommend the telemarketing service to business associates. Compared to the other CS/D measures, this measure has the lowest satisfaction rating and mean score as well as the largest proportion of indifference ratings (i.e. 27 percent). Possible reasons for this may be due to service problems, a lack of interest or experience with telemarketing among customers and/or other personal factors (i.e. one's propensity to recommend services to others). However, considering this rating from another point of view, it may be very good if a high scorc on customer willingness to recommend the service is more difficult to achicve than high scores with the other measures. 


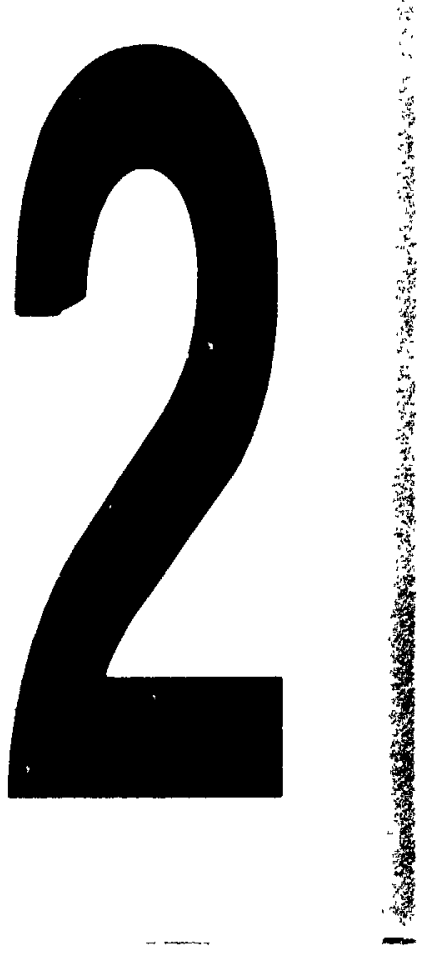

PM-1 31/2" $\times 4^{\prime \prime}$ PHOTOGRAPHIC MICAOCOPY TARGET NBS $1010 a$ ANSI/ISO \#2 COUIVALENT

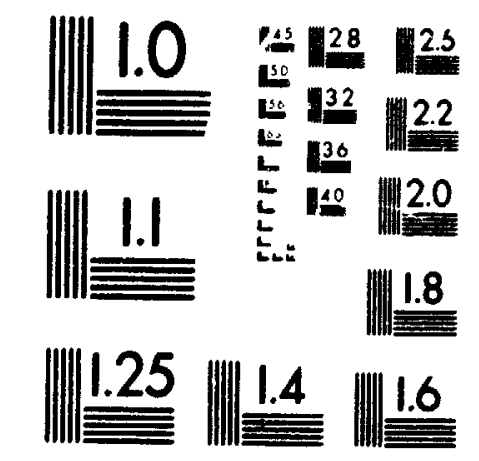

PRECISIONSW RESOLUTION TARGETS

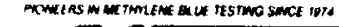


TABLE 16

\section{WILLINGNESS TO RECOMMEND THE TELEMARKETING SERVICE TO BUSINESS ASSOCIATES (WILLING)}

\begin{tabular}{|c|c|c|c|}
\hline Rating & Value & Frequency & $\begin{array}{l}\text { Vialid } \\
\text { Percent }\end{array}$ \\
\hline Very Unwilling & 1 & $\mathbf{0}$ & 0.0 \\
\hline Unwilling & 2 & 4 & 4.9 \\
\hline Indifferent & 3 & 22 & 27.2 \\
\hline Willing & 4 & 37 & 45.7 \\
\hline Very Willing & 5 & 18 & 22.2 \\
\hline \multicolumn{2}{|c|}{ Subtotal: Persons who gave ratings } & 81 & $1(0) .0$ \\
\hline \multicolumn{2}{|c|}{$\begin{array}{l}\text { No experience with the } \\
\text { telemarketing department } \\
\text { Unknown }\end{array}$} & $\begin{array}{c}14 \\
5\end{array}$ & \\
\hline \multicolumn{2}{|c|}{ Subtotal: Persons who did not give ratings } & 19 & \\
\hline Total & & 100 & \\
\hline
\end{tabular}

Mean: 3.8

Median: 4.0

Mode: 4.1)

Based on these four CS/D measures, it is evident that customers are generally satisfied with the industrial telemarketing of computer soft ware products and support services. This position is supported by the fact that no more than four customers expressed dissatisfaction (i.e. rated one or two) on any of the measures. In order to better understand how the four CS/D measures are associated and to rive an idea as to the consistency with which CS/D is being measured, Pearson correlations between them were conducted. The results arc listed in Table 17. 
TABLE 17

PEARSON CORRELATIONS BETWEEN THE CS/D MEASURES

$\begin{array}{llll} & \text { Servsat } & \text { Expect } & \text { Willing } \\ \text { Prodsat } & * .7643 & .7403 & .6817 \\ & \left(\begin{array}{c}(19) \\ \mathrm{P}=.000\end{array}\right. & \begin{array}{l}(23) \\ \mathrm{P}=.000\end{array} & \begin{array}{l}24) \\ \mathrm{P}=.000\end{array} \\ \text { Servsat } & & .4361 & .4873 \\ & & (46) & (47) \\ & \mathrm{P}=.001 & \mathrm{P}=.000 \\ \text { Expect } & & .5659 \\ & & (79) \\ & & & \mathrm{P}=.000\end{array}$

(* The first number is the Pearson coefficient. The number in brackets below is the number of cases. $P$ gives the probability level of error of the one tailed test of significance)

The correlations reveal that the degree of association between the satisfaction using telemarketing for product purchases (Prodsat) and the other measures is particularly high (i.e. .68 to .76). This may signify that if customers are satisfied purchasing software products over the telephone, they are likely to be satisfied on the other measures as well. In addition, it indicates that the importance of the Prodsat measure may be greater than the importance of the other measures in terms of overall CS/D with industrial telemarketing.

In summary, the strong and significant positive relationships between the CS/D measures tend to support that the CS/D results are valid and that the consistency with which CS/D is being measured is high. 


\subsection{FACTORS RELATED TO CS/D WITH TELEMARKETING}

The findings pertaining to factors related to CS/D with telemarketing are presented in two subsections. The first subsection identifies the telemarketing service factors which are associated highly with CS/D and are important (o) customers. The second subsection presents the effect sizes and specifies the nature of the relationships between selected customer characteristics and CS/D.

\subsubsection{Service Factors}

This research identified seventeen service factors from the literature which are specifically performed by telemarketing representatives. Customers were asked to rate each of these factors on a five-point itemized satisfaction scale. Pearson correlations were pes.ormed in order to determine which of these service factors are associated highly with the four CS/D measures. The significance of these relationships was also examined with the CS/D measures. A significance: level of a $\leq .01$ was chosen because of the large number of lests that were conducted and in order to keep the probability of errors to a minimum. The resulis are displayed in Table 18. 
TABLE 18

PEARSON CORRELATIONS BETWEEN THE TELEMARKETING SERVICE FACTORS AND THE CS/D MEASURES

\begin{tabular}{|c|c|c|c|c|c|c|}
\hline \multirow{2}{*}{\multicolumn{2}{|c|}{ Service F?utors }} & \multicolumn{4}{|c|}{ CS/D Measures } & \multirow[b]{2}{*}{$\begin{array}{c}\text { Number of Measures } \\
\text { significant at } \\
\alpha \leq .01\end{array}$} \\
\hline & & Prodsat & Servsat & Expect & Willing & \\
\hline 1. & Convenience & $\begin{array}{l}.0917 \\
(21) \\
P=.346\end{array}$ & $\begin{array}{c}.1375 \\
(44) \\
\mathrm{P}=.187\end{array}$ & $\begin{array}{l}.3913 \\
(74) \\
P=.000\end{array}$ & $\begin{array}{l}.1580 \\
(76) \\
P=.086\end{array}$ & 1 \\
\hline 2. & $\begin{array}{l}\text { Speed Filling } \\
\text { Requests }\end{array}$ & $\begin{array}{l}.2293 \\
(21) \\
P=.159\end{array}$ & $\begin{array}{c}.5785 \\
(44) \\
P=.000\end{array}$ & $\begin{array}{l}.4661 \\
(73) \\
P=.000\end{array}$ & $\begin{array}{l}.2639 \\
(75) \\
P=.011\end{array}$ & 3 \\
\hline 3. & $\begin{array}{l}\text { Ability to } \\
\text { Speak Clearly }\end{array}$ & $\begin{array}{l}.6571 \\
(22) \\
P=.000\end{array}$ & $\begin{array}{c}.3728 \\
(45) \\
P=.006\end{array}$ & $\begin{array}{l}.4227 \\
(75) \\
P=.000\end{array}$ & $\begin{array}{l}.2769 \\
(77) \\
P=.007\end{array}$ & 4 \\
\hline 4. & $\begin{array}{l}\text { Listening to } \\
\text { Customer Concerns }\end{array}$ & $\begin{array}{l}.2911 \\
(17) \\
P=.128\end{array}$ & $\begin{array}{c}.3997 \\
(38) \\
P=.006\end{array}$ & $\begin{array}{l}.4663 \\
(67) \\
P=.000\end{array}$ & $\begin{array}{l}.3221 \\
(68) \\
P=.004\end{array}$ & 3 \\
\hline 5. & $\begin{array}{l}\text { Understanding } \\
\text { Needs }\end{array}$ & $\begin{array}{l}.3582 \\
(20) \\
\mathrm{P}=.060\end{array}$ & $\begin{array}{c}.3112 \\
(43) \\
P=.021\end{array}$ & $\begin{array}{l}.4291 \\
(72) \\
P=.000\end{array}$ & $\begin{array}{l}.3449 \\
(73) \\
P=.001\end{array}$ & 2 \\
\hline 6. & $\begin{array}{l}\text { Knowledge of } \\
\text { Company Products }\end{array}$ & $\begin{array}{l}.6116 \\
(20) \\
P=.002\end{array}$ & $\begin{array}{l}.2893 \\
(37) \\
P=.041\end{array}$ & $\begin{array}{l}.4413 \\
(66) \\
P=.000\end{array}$ & $\begin{array}{l}.3085 \\
(67) \\
P=.006\end{array}$ & 3 \\
\hline 7. & $\begin{array}{l}\text { Knowledge of } \\
\text { Competitive } \\
\text { Products }\end{array}$ & $\begin{array}{l}.7071 \\
(6) \\
P=.058\end{array}$ & $\begin{array}{c}.6794 \\
(7) \\
P=.047\end{array}$ & $\begin{array}{l}.6069 \\
(19) \\
P=.003\end{array}$ & $\begin{array}{l}.5354 \\
(20) \\
P=.007\end{array}$ & 2 \\
\hline 8. & $\begin{array}{l}\text { Ability to } \\
\text { Answer } \\
\text { Questions }\end{array}$ & $\begin{array}{l}.6676 \\
(20) \\
P=.001\end{array}$ & $\begin{array}{c}.4965 \\
(43) \\
P=.000\end{array}$ & $\begin{array}{l}.6002 \\
(73) \\
P=.000\end{array}$ & $\begin{array}{l}.4320 \\
(74) \\
P=.000\end{array}$ & 4 \\
\hline 9. & $\begin{array}{l}\text { Quality of } \\
\text { Advice Given }\end{array}$ & $\begin{array}{l}.7143 \\
(16) \\
P=.001\end{array}$ & $\begin{array}{c}.4566 \\
(36) \\
P=.003\end{array}$ & $\begin{array}{l}.5743 \\
(61) \\
P=.000\end{array}$ & $\begin{array}{l}.4311 \\
(62) \\
P=.000\end{array}$ & 4 \\
\hline 10. & Courtesy & $\begin{array}{l}.4387 \\
(22) \\
P=.021\end{array}$ & $\begin{array}{l}.2863 \\
(45) \\
P=.028\end{array}$ & $\begin{array}{l}.4305 \\
(76) \\
P=.000\end{array}$ & $\begin{array}{l}.2657 \\
(78) \\
P=.009\end{array}$ & 2 \\
\hline
\end{tabular}

(* The first number is the Pearson coefficient. The number in brackets below is the number of cases. P gives the probability level of error of the one tailed test of significance.) 
TABLE 18 (cont.)

PEARSON CORRELATIONS BETWEEN THE TELEMARKETING SERVICE FACTCRS AND THE CS/D MEASURFS

\begin{tabular}{|c|c|c|c|c|c|c|}
\hline & \multicolumn{6}{|c|}{ CS/D Measures } \\
\hline & Service Factors & Prodsat & Servsat & Expect & Willing & $\begin{array}{c}\text { Number of Measures } \\
\text { significant at } \\
\alpha \leq .01\end{array}$ \\
\hline 11 & $\begin{array}{l}\text { Accuracy of } \\
\text { Shipment Order }\end{array}$ & $\begin{array}{l}* .2013 \\
(20) \\
P=.197\end{array}$ & $\begin{array}{l}.1641 \\
(42) \\
P=.150\end{array}$ & $\begin{array}{l}.1947 \\
(49) \\
P=.090\end{array}$ & $\begin{array}{l}.1573 \\
(49) \\
P=.140\end{array}$ & 0 \\
\hline 12. & $\begin{array}{l}\text { Shipment } \\
\text { Timeliness }\end{array}$ & $\begin{array}{l}.0602 \\
(20) \\
P=.400\end{array}$ & $\begin{array}{l}.3194 \\
(41) \\
P=.021\end{array}$ & $\begin{array}{l}.2937 \\
(48) \\
P=.021\end{array}$ & $\begin{array}{l}.2545 \\
(48) \\
P=.040\end{array}$ & 1 \\
\hline 13. & $\begin{array}{l}\text { Updates of } \\
\text { Order Status }\end{array}$ & $\begin{array}{l}.1299 \\
(12) \\
F=.344\end{array}$ & $\begin{array}{l}.3599 \\
(26) \\
P=.035\end{array}$ & $\begin{array}{l}.4196 \\
(30) \\
P=.010\end{array}$ & $\begin{array}{l}.3923 \\
(30) \\
P=.016\end{array}$ & 1 \\
\hline 14. & $\begin{array}{l}\text { Regularity of } \\
\text { Contact }\end{array}$ & $\begin{array}{l}.1255 \\
(19) \\
P=.304\end{array}$ & $\begin{array}{l}.4964 \\
(42) \\
P=.000\end{array}$ & $\begin{array}{l}.4221 \\
(73) \\
P=.000\end{array}$ & $\begin{array}{l}.3883 \\
(75) \\
P=.000\end{array}$ & 3 \\
\hline 15. & $\begin{array}{l}\text { Keeping Informed } \\
\text { of New Products } \\
\text { and Promotions }\end{array}$ & $\begin{array}{l}.3402 \\
(20) \\
P=.071\end{array}$ & $\begin{array}{l}.3405 \\
(42) \\
P=.014\end{array}$ & $\begin{array}{l}.0645 \\
(73) \\
P=.294\end{array}$ & $\begin{array}{l}.0777 \\
(75) \\
P=.254\end{array}$ & 1 \\
\hline 16. & $\begin{array}{l}\text { Ability to } \\
\text { Handle } \\
\text { Complaints }\end{array}$ & $\begin{array}{l}.7603 \\
(14) \\
P=.001\end{array}$ & $\begin{array}{l}.2728 \\
(29) \\
P=.076\end{array}$ & $\begin{array}{l}.4770 \\
(48) \\
P=.000\end{array}$ & $\begin{array}{l}.3040 \\
(49) \\
P=.017\end{array}$ & 2 \\
\hline 17. & $\begin{array}{l}\text { Communication } \\
\text { Link with other } \\
\text { Company Personnel }\end{array}$ & $\begin{array}{l}.7099 \\
(14) \\
P=.002\end{array}$ & $\begin{array}{l}.3918 \\
(26) \\
\mathrm{P}=.024\end{array}$ & $\begin{array}{l}.3859 \\
(49) \\
P=.003\end{array}$ & $\begin{array}{l}.2900 \\
(50) \\
P=.021\end{array}$ & 2 \\
\hline & $\begin{array}{c}\text { Number of Factors } \\
\text { significant at } \\
a \leq .01\end{array}$ & 6 & 7 & 15 & 10 & \\
\hline
\end{tabular}

(* The first number is the Pearson coefficient. The number in brackets below is the number of cases. P gives the probability level of error of the one tailed test of significance)

The data shows that all seventeen telemarketing service factors are positively correlated with each of the CS/D measures. However, the number of 
significant factors does vary depending on the measure. For instance, customer satisfaction using telemarketing for purchasing sof:ware products (Prodsat), customer satisfaction using telemarketing for purchasing services (Servsat), customer satisfaction with the telemarketing department's service compared to expectations (Expect) and customer willingness to recommend the telemarketing department to business associates (Willing) have significant associations with six, seven, fifteen and ten service factors respectively. This result indicates that the Expect measure may be the most accurate measure of CS/D

The number of service factors having significantly strong relationships (i.e. coefficients of .5 or greater) with $\mathrm{CS} / \mathrm{D}$ also vary depending on the measure. The Prodsat measure is strongly correlated with six factors (i.e. ability to speak clearly, knowledge of company products, ability to answer questions, quality of advice given, ability to handle complaints and communication link with other company personnel); the Servsat measure is strongly associated with one factor (i.e. speed filling requests); the Expect measure is strongly associated with three factors (i.e. knowledge of competitive products, ability to answer questions and quality of advice given); and the Willing measure is strongly associated with one measure (i.e. knowledge of competitive products).

Therefore, when these findings are considered with the results of the previous section, the Expect and Prodsat measures appear to stand out as more rigorous measures of CS/D. However, because none of the measures consistently 
emerged as a more reliable gauge of CS/D, all four measures were used to identify the service factors highly associated with CS/D. Seven of the telemarketing service factors turned out to be highly associated with CS/D (i.e. significant with at least three of the four measures). These factors include:

* $\quad$ Speed Filling Requests;

* Ability to Speak Clearly;

* Lisiening to Customer Concerns;

* Knowledge of Company Products;

* Ability to Answer Questions;

* Quality of Advice Given; and

* Regularity of Contact.

In addition to this knowledge of telemarketing service factors strongly associated with CS/D, information regarding which of the seventeen service factors are most important to customers was collected. Specifically, this data was gathered by asking customers to state, based on the list of seventecn tclemarketing service factors, the three factors most important to them; by ranking thesc important factors by the frequency and percent of customers stating them; and by calculating weighted summations of the three importance levels. These results are displayed in Table 19. 
TABLE 19

TELEMARKETING SERVICE FACTORS MOST IMPORTANT TO CUSTOMERS

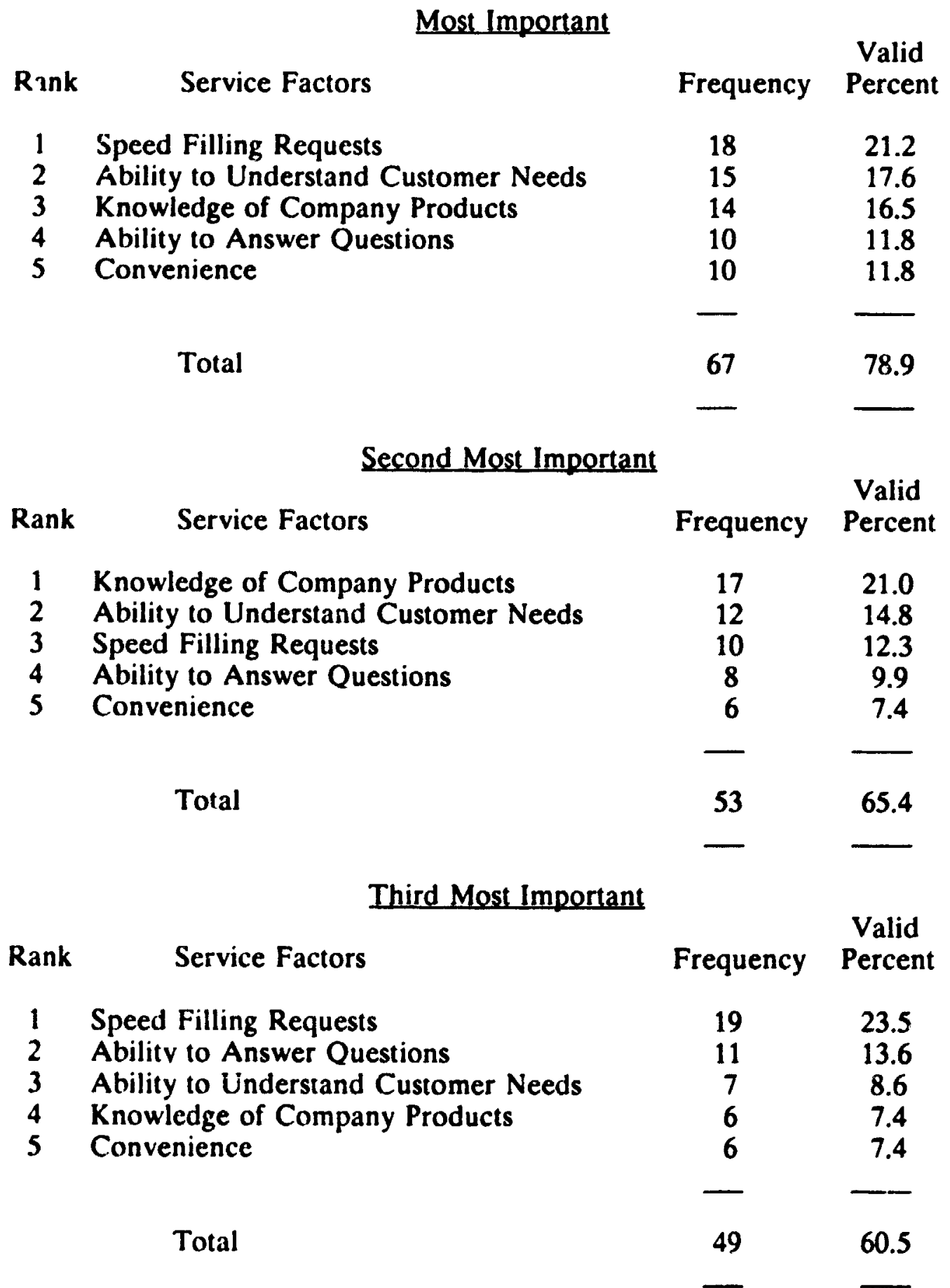


TABLE 19 (cont.)

TELEMARKETING SERVICE FACTORS MOST IMPORT.ANT TO CUSTOMERS

\author{
Weighted Summation Calculations \\ Most Important $=3$ points \\ Second Most Important $=2$ points \\ Third Most Important $=1$ point
}

\begin{tabular}{|c|c|c|c|}
\hline Service Factors & Calculations & & $\begin{array}{l}\text { Qverall } \\
\text { Rink }\end{array}$ \\
\hline Speed Filling Requests & $18(3)+10(2)+19(1)$ & $=93$ points & 1 \\
\hline $\begin{array}{l}\text { Knowledge of Company } \\
\text { Products }\end{array}$ & $14(3 ;+17(2)+6(1)$ & $=82$ points & 2 \\
\hline $\begin{array}{l}\text { Ability to Understand } \\
\text { Customer Needs }\end{array}$ & $15(3)+12(2)+7(1)$ & $=76$ points & 3 \\
\hline $\begin{array}{l}\text { Ability to Answer } \\
\text { Questions }\end{array}$ & $10(3)+8(2)+11(1)$ & $=57$ points & 4 \\
\hline Convenience & $10(3)+6(2)+6(1)$ & $=48$ points & 5 \\
\hline
\end{tabular}

The results show that five telemarketing service factors were consistently stated by customers as being the most important to them. In order of the weighted summation of their importance, these service factors include the specel filling requests, knowledge of company products, the ability to understand customer needs, the ability to answer questions and convenience.

Three service factors are both highly associated with CS/D and among the most important to customers. These factors include the speed filling requests, 
knowledge of company products and the ability to answer questions. Consequently, it would appear to be in the best interests of the sponsoring company's telemarketing department to be especially cognizant regarding satisfying customers on these service factors. The mean ratings of the sponsoring company's pe:formance on the service factors is displayed in Table 20.

TABLE 20

CS/D WITH THE SPONSORING COMPANY'S PERFORMANCE ON THE TELEMARKETING SERVICE FACTORS

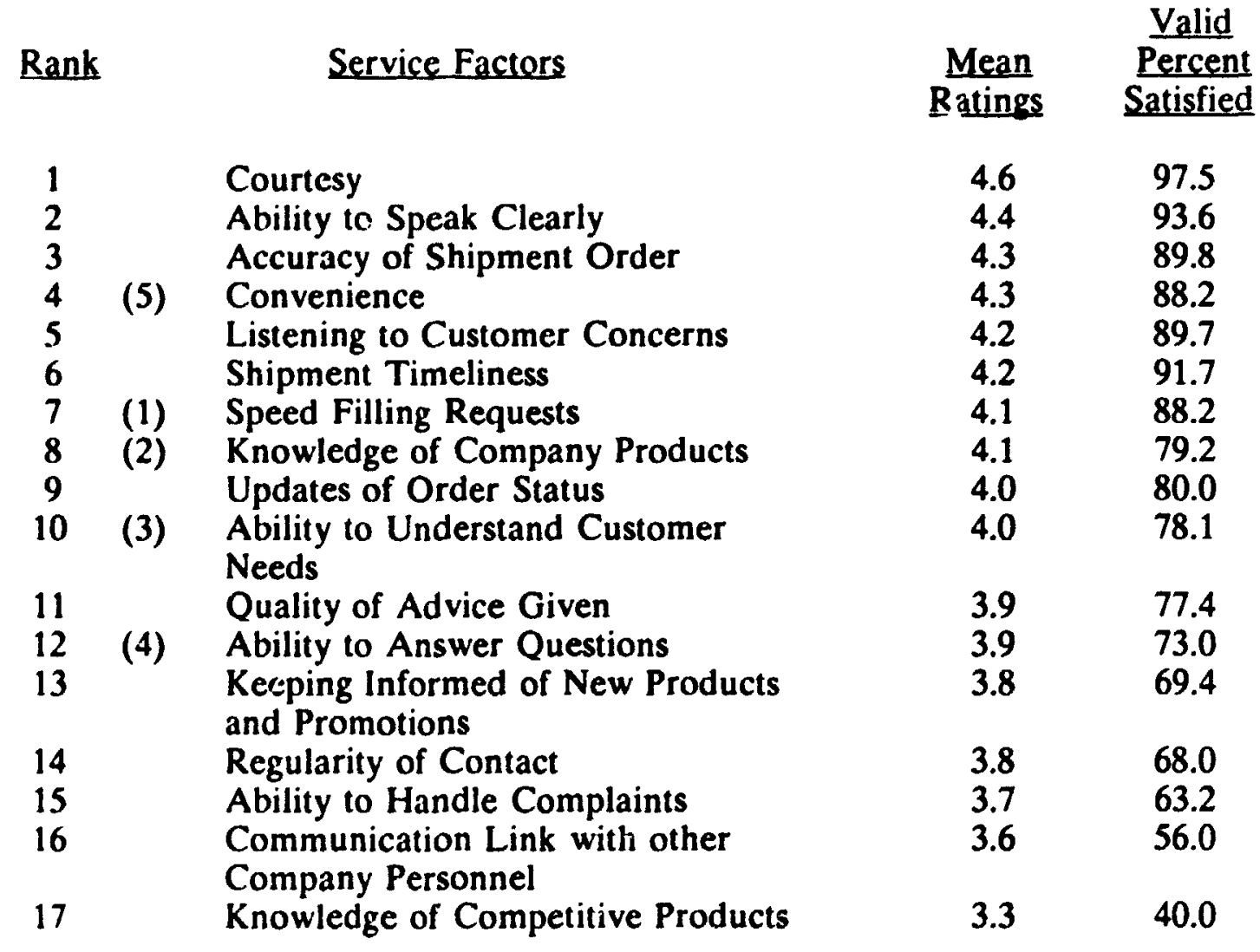

The sponsoring company's customers are generally satisfied with the performance of the department on the service factors examined. With respect to 
the five factors considered most important by their customers (i.e. the rilnkings: in brackets), the department is performing well. For instance, on four of the five factors, the mean rating is 4.0 or above (i.e. representing satisfied or very satisfied) and the percentage of satisfied customers is approximallely 80 percent and up. The only service factor that was stated to be important by customers that could be improved is the ability to answer questions as it ranked twelfth among the seventeen attributes and had a customer satisfaction level of 7.3 percent.

The telemarketing service factors with the lowest mean satisfaction ratings have to do with the department's ability io keep customers informed of new products and promotions, the regularity of contact, the ability of the telemarketcrs to handle complaints, the department's capacity as a communication link with other company personnel and the level of telemarketer knowledge of competitive products.

The lower mean ratings on three of these attributes (i.e. ability to handle complaints, communication link with other company personnel and knowledge of competitive products) should not cause undue concern. It was noted that customers generally did not request the sponsoring company's telemarketing department to perform these services. This inexperience is evidenced by the high proportion of customers that responded not applicable, unknown or indifferent when asked their satisfaction with the department's performance on these factors 
(i.e. 66 to 87 percent of customers responded in one of these ways when asked to rate these factors). The absence of responses regarding CS/D with the department's ability to handle complaints may be a positive sign in that it may he reflective of few complaints and indicative of the general satisfaction with the sponsoring company's telemarketing service.

The two service factors which may require some attention by the sponsoring company's telemarketing department are keeping customers informed of new products and promotions and regularity of contact. Both of these service functions are performed by the department and received lower mean satisfaction ratings.

The importance of keeping informed of new products and promotions ranked tenth among the seventeen factors. However, in contrast, it rated thirteenth in customer satisfaction. This difference does not necessarily signify a large problem but it does suggest that customer needs may not be completely fulfilled in this area. Comments from interviewees have confirmed this assertion.

The difference between the importance of regular contact by telemarketing representatives and customer satisfaction is opposite to the previous case in that satisfaction ranked higher at fourteenth and in importance, it ranked last. As with the previous case, this is not a serious inconsistency, however, it does indicate that the telemarketing department may be more than fulfilling the need 
for direct contact. In order to check this inequality. Table 21 displays the distributions of customers ${ }^{`}$ preferred frequency of contact versus the frequencies of their last contact.

TABLE 21

\section{PREFERRED FREQUENCY OF TELEMARKETING CONTACT VS. FREQUENCY OF LAST TELEMARKETING CONTACT}

\author{
Frequency of \\ Preferred Contact
}

Frequency of Last Contact
Once every two weeks

Once every month

Once every six weeks

Once every two months

Once every three months

Once every four months

Once every six months

Once every year

Over one year

Whenever new information

arises

I will initiate the call

Never

Unknown

Total
0

3

1

9

9

5

12

4

0

21

18

16

2
Under two weeks ago

One month ago

Six weeks ago

Two months ago

Three months ago

Four months ago

Six months ago

One year ago

Over one year ago

Never

Unknown
21

17

1

12

5

4

10

8

5

14

3

100

The frequencies show that the preferred frequency with which customers would like to speak with sponsoring company's telemarketing department generally lies between once every two to six months (i.e. 35 percent). This proportion is similar to the frequency of last contact for the same time period (i.e. 31 percent). Consequently, there is no support that the regularity of contact is is too extensive or not adequately meeting customers needs within the two to six 
month range.

Howeve: upon examination of the time period from two to six weeks. there does appear to be a substantial difference in the call frequencies (i.e. 39 customers were contacted with'n that time period but only four customers stated it as a preferred time period of contact). This discrepancy does lend support to the suggestion that the telemarketing department may be more than fulfilling the need for direct contact within the two to six week range.

It is important to note that many customers (i.e. 18 percent) prefer to initiate the call instead of being called by a telemarketing representative. This implies that industrial telemarketıng operations should have a capability to accept inbound calls and that care should be taken not to aggravate certain customers by contacting them too often. This data also shows that 21 percent of customers prefer to be contacted only whenever new information arises. This preference indicates that when telemarketers cail customers, they better have something pertinent to say (i.e. particularly suited to that customer's computing needs) or else the call may he seen as intrusive and dissatisfying to customers.

Another interesting finding is that 16 percent of customers stated that they would prefer to never be contacted by a telemarketing representative from the sponsoring company. L'pon examination of the specific cases, it was revealed that half of these individuals were the same persons who have never been contacted 
by the department in the past. This statistic suggests that even when exposed to telemarketing, CS/D still remains mixed.

\subsubsection{Customer Characteristics}

Three customer characteristics were analyzed using the Coleman (1964) multivariate analysis technique. These factors included the experience customers have using telemarketing to purchase products and services (1.e. number of telephone purchases made in the last year), the number of years they have been in the workforce fulltime (i.e. representative of age) and the size of their respective companies (i.e. number of employees). As with the previous section. these factors have been examined for their associations (i.e. effect sizes) with the four CS/D measures.

The Coleman technique required that each of the characteristics of interest be divided into two groups. This division was made by splitung the frequency distributions of each characteristic into two groups of approximately equal size. As a result of the divisions, the customer characteristucs were defined as follous:

\section{Experience}

- Less Experienced (Less): Customer made betueen 0 to 5 purchases over the telephone in the last year $(45 \%)$.

- More Experienced (More): Customer made greater than 5 purchases over the telephone in the last year $(55 \%)$. 
Age of the Customer

Younger: 15 years and under in the workforce fulltime (45\%).

Older: 16 years and up in the workforce fulltime (55\%).

\section{Company Size}

- $\quad$ Small Company: 250 employees and under (43\%).

- $\quad$ Large Company: 251 employees and up (57\%).

The results of this analysis are presented in the following Tables and in Appendix H. Tables 22 through 25 show the results of the crosstabulations between the customer characteristic groups and the CS/D measures and Table 26 presents a summary of the effect sizes each characteristic has on the four CS/D measures. A less stringent significance level was selected (i.e. $\alpha \leq .10)$ because of the manipulation made to the data and because of the low number of cases in the characteristic groups. Appendix $\mathrm{H}$ gives a detailed example of the procedures and calculations which led to the resulting effect size values.

\section{TABLE 22}

RELATION OF COMPANY SIZE, AGE AND AMOUNT OF EXPERIENCE USING TELEMARKETING TO SATISFACTION USING TELEMARKETING FOR PURCHASING COMPUTER SOFTWARE PRODUCTS (PRODSAT)

\begin{tabular}{|c|c|c|c|c|c|c|c|c|}
\hline & \multicolumn{4}{|c|}{ Small Company } & \multicolumn{4}{|c|}{ Large Company } \\
\hline & & unger & & & & unger & & \\
\hline & Less & More & Less & More & Less & More & Less & $\mathbf{M}$ \\
\hline $\begin{array}{l}\text { \% satisfied } \\
\text { groun* }\end{array}$ & 22 & 10 & 30 & 7 & 13 & 17 & 22 & \\
\hline \# group* & 9 & 10 & 10 & 14 & 8 & 18 & 18 & \\
\hline
\end{tabular}

( ${ }^{*}$ the number of sample customers who possess the characteristics of that group.) 
TABLE 23

RELATION OF COMPANY SIZE, AGE AND AMOUNT OF EXPERIENCE USING TELEMARKETING TO SATISFACTION USING TELEMARKETING FOR PURCHASING COMPUTER SOFTWARE SERVICES (SERVSAT)

\begin{tabular}{lcccccccc} 
& \multicolumn{3}{c}{$\begin{array}{c}\text { Small Company } \\
\text { Younger }\end{array}$} & \multicolumn{4}{c}{ Older } & \multicolumn{3}{c}{$\begin{array}{c}\text { Large Company } \\
\text { Younger }\end{array}$} & \multicolumn{2}{c}{ Older } \\
& Less & More & Less & More & Less & More & Less & More \\
\% satisfied & 56 & 40 & 70 & 29 & 13 & 33 & 67 & 31 \\
\# group* & 9 & 10 & 10 & 14 & 8 & 18 & 18 & 13
\end{tabular}

TABLE 24

RELATION OF COMPANY SIZE, AGE AND A.MOUNT OF EXPERIENCE USING TELEMARKETING TO SATISFACTION WITH THE TELEMARKETING SERVICE COMPARED TO EXPECTATIONS (EXPECT)

\begin{tabular}{ccc} 
Small Company & \multicolumn{2}{c}{ Large Company } \\
Younger Older & \multicolumn{2}{c}{ Younger Older } \\
Less More Less More & Less More Less More
\end{tabular}

$\begin{array}{lcccccccc}\text { \% satisfied } & 67 & 70 & 60 & 79 & 13 & 67 & 72 & 38 \\ \text { \# group* } & 9 & 10 & 10 & 14 & 8 & 18 & 18 & 13\end{array}$

TABLE 25

RELATION OF COMPANY SIZE, AGE AND AMOUNT OF EXPERIENCE: USING TELEMARKETING TO WILLINGNESS TO RECOMMEND THE SERVICE TO BUSINESS ASSOCIATES (WILLING)
Small Company
Younger Older
Less More Less More
Large Company
Younger Older
Less More Less More

$\begin{array}{lcccc}\% \text { satisfied } & 33 & 70 & 50 & 71 \\ \text { \# group* } & 9 & 10 & 10 & 14\end{array}$

$\begin{array}{llll}13 & 61 & 67 & 46\end{array}$

$\begin{array}{llll}8 & 18 & 18 & 13\end{array}$

(* the number of sample customers who possess the characteristics of that group.) 


\title{
TABLE 26
}

\section{SUMMARY OF THE CUSTOMER CHARACTERISTIC EFFECT SIZES ON THE CSID MEASURES}

\author{
CS/D Measures
}

Effects of

Sample Characteristics

Experience

Significance

Age

Significance

Company Size

Significance

Effects of

Unexplained Variation

Random Shock in

the direction of

Satisfaction

Random Shock in

the direction of

Dissatisfaction

Total
Servsat Prodsat Expect Willing

$\begin{array}{lll}-.183 & -.075 & .105\end{array}$

$\begin{array}{llll}.0256^{*} & .1736 & .130 & .0125^{*}\end{array}$

.213

$\begin{array}{llll}.138 & .048 & .08 & .143\end{array}$

$\begin{array}{llll}.0707 * & .2743 & .1949 & .0655^{*}\end{array}$

$\begin{array}{llll}-.128 & .015 & -.215 & -.093\end{array}$

$\begin{array}{llll}.0885 * & .4246 & .0102 * & .1635\end{array}$

.510

.185

.598

.383

.663

.827

.432

.354

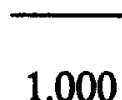

1.000

1.000

(* Significant at $\alpha \leq .10)$

The crosstabulations show a fairly equal distribution of the customers among the various characteristic groups. This distribution gives some confidence that the variability of the effect sizes are not adversely affected by the number of cases in each cell. 
It can be seen in Table 26 that all three customer characteristics have a significant associations with two of the four CS/D measures and that the number of significant characteristic effects sizes varies across these measures. For instance, the Servsat measure is significant for all characteristics, the Willing measure is significant for the experience and age characteristics, the Expect measure is significant only for the company size characteristic and the Prodsat measure is significant for none of the characteristics.

These results generally show relatively small effect sizes and a large amount of unexplained variation due to other variables in the direction of both satisfaction and dissatisfaction. In order to help explain the findings, a discussion of the significant relationships between each customer characteristic and the CS/D measures is given below.

\section{Experience}

It was found that telemarketing experience does have a significant cffect on satisfaction using telemarketing for purchasing services (Servsat) and on customer willingness to recommend the service to business associates (Willing). The relative size of the partial relationship between telemarketing experience and Servsat was -.183 . This negative value implies that the more expcrience customers have using telemarketing, the more dissatisfied they are purchasing the sponsoring company's services by telephone. Possible explanations for this arc: 
* it may reflect poor performance by the department or other companies in the past regarding the sales of services over the telcphone (i.e. poor performance that only customers with more experience would know of); and

* it may be indicative of difficulties in meeting rising service expectations of customers (brought about by the greater experience) regarding the purchase of services over the telephone.

It is interesting to note that despite the negative relationship with Servsat, the effect size of telemarketing experience on customer willingness to recommend the service (Willing) is significantly positive at .213 . This inconsistent result suggests that the magnitude of any dissatisfaction purchasing services over the telephone is not great enough to prevent customers from recommending the service.

It is difficult to explain the specific association between telemarketing experience and customer willingness to recommend the telemarketing department given the existence of many personal and situational factors which can influence the relationship as well (i.e. availability of alternative choices, previous satisfaction with telephone purchases, company image). However, it may be that customers with greater telemarketing experience are more willing to recommend the telemarketing department to business associates because of the greater likelihood this general experience has given realistic expectations regarding telemarketing usage. It is believed that customers with these realistic expectations are morc likely to be satisfied, hence more likely to be willing to recommend the telemarketing department. 


\section{Age of the Customer}

Customer age was shown to have significant relationships with satisfaction using telemarketing to purchase services (Servsat) and the willingness (1) recommend the service to business associates (Willing). The effect sizes were .138 and .143 respectively. It seems that older customers are more satisfied using telemarketing for service purchases and are more willing to recommend the service to business associates than younger customers. This result is consistent with the experience findings because, as the crosstabulations in Tables 23 an.1 25 show, large proportions of the satisfied individuals not only had less experience using telemarketing but were older as well.

This age/experience linkage raises the question of whether these factors interact with one another in influencing customer satisfaction. Interaction effects are often signified by zero effect values. Since none of the experience and age effect sizes close to zero are significant, this interaction is unlikely.

\section{Company Size}

Company size has significant negative relationships with satisfaction using telemarketing for service purchases (Servsat) at -.128 and with satisfaction with the service compared to expectations (Expect) at -.215 . In other words, larger companies are less satisfied using telemarketing to purchase services over the 
telephone and seem to be less satisfied with the service compared to their expectations. It is possible that these effects are the result of the following:

* larger customers feeling they deserve a field sales call for all purchases because of their size;

* bureaucratic internal purchasing policies at large firms are inflexible and require purchases to be made from field sales representatives;

* purchases at smaller companies are generally smaller in quantity and dollar size, therefore, their managers see the use of the telephone as more appropriate; and

* the telemarketing service expectations of customers at smaller companies may not be as high as customers at larger companies, therefore, they are more tolerant of potential service inefficiencies.

In summary, the results of this subsection on customer characteristics are not consistent with the results of the previous subsection on service factors in so far as specifying the factors which are related the CS/D with telemarketing. The previous subsection was able to identify seven telemarketing service factors which are highly associated with telemarketing on at least three of the CS/D measures whereas this subsection could not show that customer characteristics were highly associated with any more than two of the CS/D measures. When considered logether, these results show that service factors likely have a greater influence than customer characteristics on CS/D with the industrial telemarketing of computer software products and services. 


\subsection{FACTORS RELATED TO TELEMARKETING USAGE}

This section provides the findings concerning research questions four through eight pertain to factors related to telemarketing usage. The factors of particular interest are the requirement for product demonstrations and product/ service price because they are believed to be the main influences affecting telemarketing acceptance and usage by industrial customers. In order to assess the validity of the above claim, interviewees were asked if they would consider purchasing software products through telemarketing only and what the most important reason is for and for not doing so. The results are presented in Tables 27 through 29.

The data in Table 27 shows that 84 percent of customers accept the use of telemarketing for purchases of software products and services (i.e. $38 \%$ of customers stated that they have purchased software products and services in this manner and $46 \%$ stated that they would corsider doing so in the future). (Of those persons who had not used telemarketing but would consider doing so in the future, 22 percent proclaimed that they would not place any conditions on the purchases while 78 percent stipulated conditions under which they would make telephone purchases. The two conditions most commonly stated by these individuals have to do with prior existence of information about or experience using the product. The remaining sixteen percent of customers declared that they never would purchase software products or services solely via telemarketing. 
TABLE 27

\section{CUSTOMER ACCEPTANCE OF TELEMARKETING}

\section{Extent of Acceptance}

Frequency

Have purchased software products and

services through telemarketing.

Have not purchased software products and services through telemarketing but would consider it in the future...

a) without conditions. 10

b) depending on if the product is a service. 4

c) depending on if the purchase is an 2 upgrade.

d) depending on the product complexity. 4

e) depending on the product price. 1

f) depending on if the customer has 8 prior experience using the product.

g) depending on if the customer receives 3 a trial period with the product.

h) depending on if the customer receives 2 a prior demonstration of the product.

i) depending on if the product is available 4 through the local sales representative.

j) depending on the amount of prior 7 information received.

k) depending on the type of machine the 1 product will be used with.

Have nct purchased software products and services 16 through teiemarketing and will not in the future. 


\section{TABLE 28}

\section{MOST IMPORTANT REASONS FOR USING TELEMARKETING FOR PURCHASING COMPUTER SOFTWARE PRODUCTS AND SERVICES}

\section{$\underline{\text { Reason }}$}

Frequency

1. The product is not too complex.

2. Have previous knowledge or experience with the product

2

3. Fast Service.

4. Product not available through local sales representative.

5. Cost-effective.

6. Remote geographic location of customer company.

7. Reputation of seller.

8. Ability to control the contact time.

9. Customer purchase records are readily available.

10. Convenience.

11. No demonstration is required.

12. Have not and will not purchase over the telephone.

Total
7

40

1

6

1

1

1

1

20

4

16

TABLE 29

MOST IMPORTANT REASONS FOR NOT USING TELEMARKETING FOR PURCHASING COMPUTER SOFTWARE PRODUCTS AND SERVICES

\section{$\underline{\text { Reason }}$}

1. The product is too complex.

2. High product price warrants a sales call.

3. No previous knowledge or experience with the product.

4. A demonstration is required.

5. Product is available through the local sales representative.

6. Lower credibility of the telemarketing representatives.

7. If it is a first-time purchase of the product.

8. If no prior information was received.

9. Do not need the product.

10. If other personnel are involved in the purchase.

11. Purchasing is not my department's responsibility.

12. Impersonal way to conduct business.

13. Need more detailed information.
Frequency 
It is evident from Table 28 that customers use telemarketing to purchase software products and services mainly because of the speed and convenience it offers. This finding is consistent with earlier findings which show these factors to be among the top five most important service factors. Customers also stated thcy would use telemarketing because they have previous product knowledge or experience, it is cost-effective and they do not require product demonstrations.

Customers do not to use telemarketing for purchasing software products and services primarily because of demonstration requirements brought about by a lack of previous knowledge or experience with the product. Price considerations, a fceling that these products are too complex, the need for more detailed information, the availability of the products through local field representatives and its impersonal nature are other common reasons for not using telemarketing.

The results indicate that the requirement for product demonstrations and price factors that are of interest to this thesis are not among the main considerations for using telemarketing but are the first and third most stated reasons for not using telemarketing. The research findings associated with these factors are presented in the following two subsections. 


\subsubsection{Requirement for Product Demonstrations}

Customer demonstration requirements were examined in order to determine the degree to which they are a hindrance to telemarketing acceptance and usage. This was accomplished by collecting purchase history data from customers and asking them their perceptions regarding the importance of demonstrations and the appropriateness of using telemarketing by product type (i.e. mainline, complementary and service) and purchase type (i.e. first-time and subsequent).

The purchase history information that was gathered pertains to four areas: (1) the number of companies that have purchased the various software products and services; (2) the interviewee involvement in these purchases; (3) the corresponding purchase type(s) (i.e. first-time or subsequent); and (4) the purchase methods used (i.e. :elemarketing, field sales, combination telemarketing, and field sales or third-party distributor). Tables 30 and 31 display the frequencies for the first two areas and Table 32 presents crosstabulations of the data between areas three and four. The product numbers in the tables refor 10 different products which are offered by the sponsoring company over the telephone. 
TABLE 30

\section{PURCHASE FREQUENCY BY PRODUCT TYPE}

Purchased by the Company

Product Type

$\underline{\text { Yes }}$

No

Mainline

Product M1

97

3

Product M2

\section{Complementiary}

Product C1

Product C2

Product C3

40

60

Product C4

0

100

0

100

Product C5

Product C6

Product C7

7

93

18

82

Product C8

24

76

2

10

98

90

\section{Service}

Product S1

54

46

Product S2

76

24

Product S3

33

67

Product S4 
TABLE 31

PURCHASE INVOLVEMENT BY PRODUCT TYPE

Involved

Product Type

Yes

No

Nox Applicalbe

Mainline

Product M1

Product M2

77

5

20

3
94

\section{Complementary}

Product $\mathrm{C} 1$

Product C2

Product C3

Product C4

Product C5

Product C6

Product C7

Product C8
32

0

0

6

16

20

2

8

Service

Product $\mathrm{S} 1$

Product S2

Product S3

Product S4
47

65

27

21

$\begin{array}{rr}8 & 60 \\ 0 & 100 \\ 0 & 100 \\ 1 & 93 \\ 2 & 82 \\ 4 & 76 \\ 0 & 98 \\ 2 & 90\end{array}$

60

100

93

82

76

90 
TABLE 32

CROSSTABULATIONS OF PURCHASE TYPE BY PURCHASE METHOD BY PRODUCT TYPE

Purchase Method

Purchase Typed

$\frac{\text { Telephone }}{\text { Sales }} \quad \frac{\text { Field }}{\text { Sales }}$

Combination Third

Unknown Total

Product Type

Mainline

Product M1

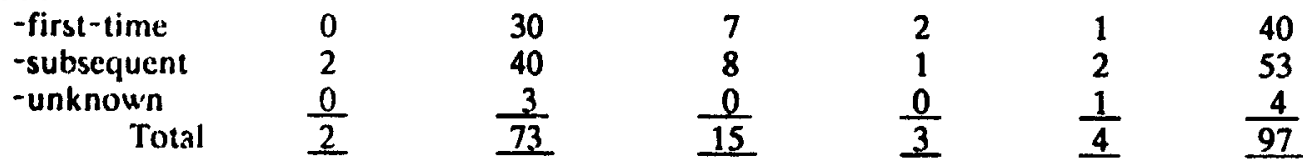

Product M2

-first-time

-subsequent

\begin{tabular}{l}
0 \\
0 \\
\hline
\end{tabular}

\begin{tabular}{l}
3 \\
0 \\
\hline 3 \\
\hline
\end{tabular}

\begin{tabular}{l}
3 \\
$\frac{1}{3}$ \\
\hline
\end{tabular}

\begin{tabular}{l}
0 \\
0 \\
\hline
\end{tabular}

\begin{tabular}{l}
0 \\
0 \\
\hline
\end{tabular}

6

$\frac{0}{6}$

Complementary

Product C1

-first-time

-subsequent

- unknown

Total

\begin{tabular}{l}
4 \\
0 \\
0 \\
\hline
\end{tabular}

15

12

$\frac{2}{29}$

4
3
$\frac{1}{7}$

\begin{tabular}{l}
0 \\
0 \\
0 \\
\hline 0
\end{tabular}

23

15

$\frac{0}{0} \quad \frac{2}{40}$

Product C2

-first-time 0

-subsequent

\begin{tabular}{ll}
0 & 0 \\
$\frac{0}{0}$ & $\frac{0}{0}$ \\
\hline
\end{tabular}

\begin{tabular}{l}
0 \\
$\frac{0}{0}$ \\
\hline
\end{tabular}

0

$\underline{0} \quad \underline{0}$

0

$\frac{0}{0}$

$\frac{0}{0}$

Product C3

-first-time

-subsequent

0

0

0

0
0
0

0
$\frac{0}{0}$

0

$\frac{0}{0}$

$\frac{0}{0}$

$\underline{0}$

Product C4

-first-time

-subsequent Total $\frac{1}{5}$

\begin{tabular}{l}
1 \\
$\frac{1}{2}$ \\
\hline
\end{tabular}

\begin{tabular}{l}
0 \\
0 \\
\hline
\end{tabular}

0
0
0

5

$\frac{2}{7}$

Product C5

$\begin{array}{ccccccc}\text {-first-time } & 0 & 7 & 3 & 0 & 0 & 10 \\ \begin{array}{c}\text {-subsequent } \\ \text { Total }\end{array} & \frac{1}{1} & \frac{6}{13} & \frac{1}{4} & \frac{0}{0} & \frac{0}{0} & \frac{8}{18}\end{array}$


TABLE 32 (cont.)

\section{CROSSTABULATIONS OF PURCHASE TYPE BY PURCHASE METHOD} BY PRODUCT TYPE

\begin{tabular}{|c|c|c|c|c|c|c|}
\hline \multirow[b]{2}{*}{$\begin{array}{l}\text { Purchase Type/ } \\
\text { Product Type }\end{array}$} & \multicolumn{5}{|c|}{ Purchase Method } & \multirow[b]{2}{*}{ Total } \\
\hline & $\frac{\text { Tclephone }}{\underline{\text { Silles }}}$ & $\frac{\text { Field }}{\text { Sales }}$ & Combination & $\begin{array}{l}\text { Third } \\
\text { Party }\end{array}$ & Unknown & \\
\hline $\begin{array}{l}\text { Product C6 } \\
\text {-first-time } \\
\text {-subsequent } \\
\text { Total }\end{array}$ & $\begin{array}{l}0 \\
0 \\
\underline{0}\end{array}$ & $\begin{array}{r}12 \\
\frac{8}{20} \\
\end{array}$ & $\begin{array}{l}3 \\
1 \\
4 \\
\end{array}$ & $\begin{array}{l}0 \\
0 \\
\end{array}$ & $\begin{array}{l}0 \\
0 \\
0 \\
\end{array}$ & $\begin{array}{r}15 \\
9 \\
24 \\
\end{array}$ \\
\hline $\begin{array}{l}\text { Product C7 } \\
\text {-first-time } \\
\text {-subsequent } \\
\text { Total }\end{array}$ & $\begin{array}{l}0 \\
0 \\
0 \\
\end{array}$ & $\begin{array}{l}2 \\
\frac{0}{2} \\
\end{array}$ & $\begin{array}{l}0 \\
0 \\
Q \\
\end{array}$ & $\begin{array}{l}0 \\
0 \\
\end{array}$ & $\begin{array}{l}0 \\
0 \\
0 \\
\end{array}$ & $\begin{array}{l}2 \\
0 \\
2 \\
\end{array}$ \\
\hline $\begin{array}{l}\text { Product C8 } \\
\text {-first-time } \\
\text {-subsequent } \\
\text { Total }\end{array}$ & $\begin{array}{l}0 \\
0 \\
0 \\
\end{array}$ & $\begin{array}{r}6 \\
3 \\
9 \\
\end{array}$ & $\begin{array}{l}1 \\
0 \\
1\end{array}$ & $\begin{array}{l}0 \\
0 \\
\text { l }\end{array}$ & $\begin{array}{l}0 \\
0 \\
\end{array}$ & $\begin{array}{r}7 \\
3 \\
10 \\
\end{array}$ \\
\hline
\end{tabular}

Service

Product S1

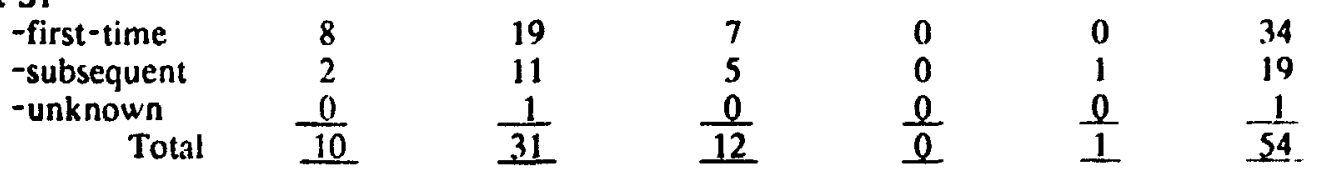

Product S2

$\begin{array}{crrrrrr}\text {-first-time } & 22 & 24 & 12 & 0 & 2 & 60 \\ \text {-subsequent } & 5 & 7 & 2 & 0 & 0 & 14 \\ \text {-unknown } & \frac{1}{28} & \underline{0} & \underline{0} & \underline{0} & \frac{1}{3} & \frac{2}{76} \\ \text { Total } & \underline{31} & \underline{14} & \underline{0} & \underline{3} & \underline{\underline{3}}\end{array}$

Product S3

$\begin{array}{ccccccc}\text {-first-time } & 12 & 13 & 6 & 0 & 0 & 31 \\ \text {-subsequent } & \frac{1}{13} & \frac{0}{13} & \frac{1}{7} & \frac{0}{0} & \frac{0}{2} & \frac{2}{33} \\ \text { Total } & \underline{13} & \underline{13} & \underline{1} & \end{array}$

Product S4

-first-time

-subsequent

-unknown

Total $\frac{1}{10}$ $\begin{array}{r}9 \\ 0 \\ 1 \\ 10 \\ \hline\end{array}$

\begin{tabular}{l}
4 \\
1 \\
$\frac{0}{5}$ \\
\hline
\end{tabular}

\begin{tabular}{l}
0 \\
0 \\
0 \\
\hline 0
\end{tabular}

1
0
1
1 
The historical data shows that a majority of the customers interviewed have made first-time and/or subsequent field sales purchases of the sponsoring company's primary mainline product (M1). This makes sense intuitively because this particular product is well established in the marketplace and generally precedes the purchase and use of other complementary and :,ervice products offered by the company.

The service products are the next most widely purchased group of products followed by the complementary products. This indicates that mainline and complementary product purchases are often accompanied by related purchases of services. This is consistent with the definition of services provided in the literature review. Table 31 shows that for most product purchases, the interviewce was directly involved in the purchases. Therefore, this historical purchase data is assumed to be fairly reliable.

Table 32 shows that the purchase type frequencies do vary by product type. For instance, the mainline product, M1, has a rreater number of subsequent purchases than first-time purchases while the opposite is true for services. In addition, the split between first-time and subsequent purchases for the complementary products is fairly even.

It also appears from the crosstabulations that the purchase methods vary by product type. Customers primarily employ field sales representatives either 
alone or in some combination with telemarketing to purchase the mainline and the complementary products and rarely use telephone sales alone. In contrast 10 this, customers seem to purchase services using each of these purchase methods. In fact, with the exception of product $\mathrm{S} 1$, there is no clear indication that field sales or telemarketing is used more than the other for services purchases.

It is difficult to accurately determine from Table 32 whether the requirement for product demonstrations by product and purchase type influences the types of purchase methods used. This uncertainty is due to the existence of other factors which likely affected these frequencies. For instance, the number of first-time versus subsequent purchases could depend on the product type (i.c. some companies may never require a second purchase), the length of time the product has been in existence (i.e. product $\mathrm{M} 2$ has only first-time purchases because it is a new product), the number of upgrades since inception, product quality, satisfaction with previous purchases, competition and the economy.

Since the sponsoring company actively markets all of its computer softwarc products and services through field sales and telemarketing, the historical information does not adequately explain why services are purchased over the telephone more than the mainline and complementary products. Therefore, in order to better understand customer purchase behaviour with respect to these types of products and services, they were asked for their opinions regarding the the requirement for product demonstrations and the appropriateness of 
purchasing through telcmarketing for each product and purchase type.

Six diffcrent purchase circumstances made up of different combinations of product and purchase types were rated by customers as either low, medium or high for their telcmarketing appropriateness and demonstration importance. These circumstances included the following:

1) First-time purchases, Mainline products (FTM);

2) Subscquent purchases, Mainline products (S/M);

3) First-time purchases, Complementary products (FT/C);

4) Subsequent purchases, Complementary products (S/C);

5) First-time purchases, Service products (FT/S); and

6) Subsequent purchases, Service products (S/S).

It was noted that customcrs had no problems distinguishing between mainline, complementary and service products nor did they have difficulty with the meaning of "importance" and "appropriateness" when rating these circumstances on the factors of interest. Given that the low, medium and high ratings used have value weightings of one, two and three respectively, Figure 2 presents the findings regarding the central tendency of customer responses through a graph of the actual median values of the demonstration importance and the telemarketing appropriateness ratings by purchase circumstance. 
FIGURE 2

ACTUAL MEDIAN VALUES OF THE DEMONSTRATION IMPORIANCE AND THE TELEMARKETING APPROPRIATENFSS RATINGS BY PURCHASE CIRCUMSTANCE

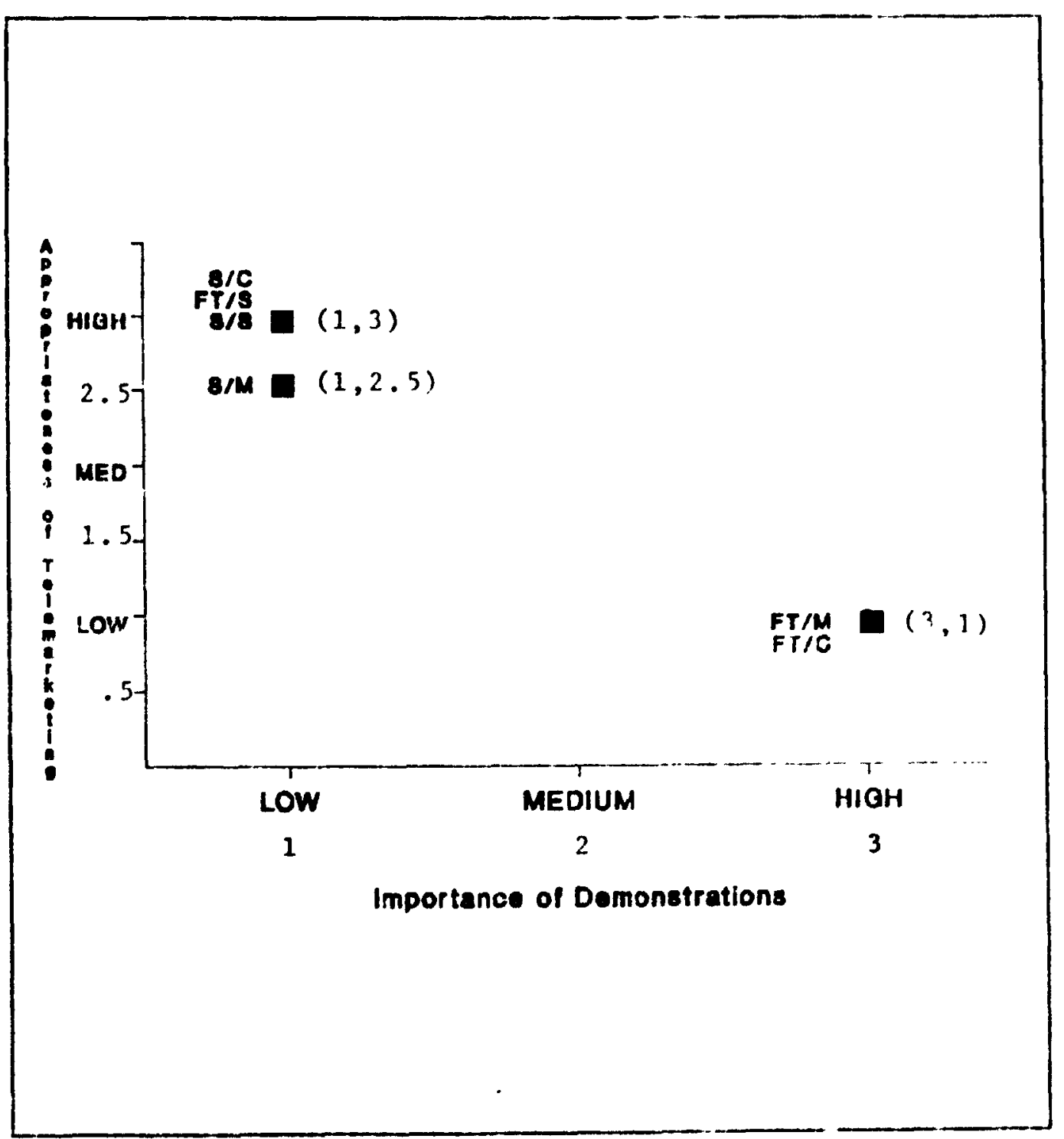


Figure 2 illustrates that for first-time purchases, a distinction between how customers sec the importance of demonstrations and appropriateness of telemarketing is cvident for only service products. Mainline and complementary products rated low in tclemarketing appropriateness and high in demonstration importance and services rated high in telemarketing appropriateness and low in demonstration importance. The mainline and service product ratings were expected, however, complementary products were not anticipated to rate the same as mainline products.

Therefore, it appears that first-time telemarketing purchases of mainline and complementary products are viewed similarly by customers in that they are considered to have a higher risk associated with them. The results also suggest that customers have very definite bipolar opinions regarding their willingness to purchase certain products over the telephone (i.e. they either will or will not purchase over the telephone).

For subsequent purchases, customers discriminated less by product type than for first-time purchases. In fact, the differences between the ratings were less than what was predicted. The complementary and service products rated high in telemarketing appropriateness and low in demonstration importance as expected, however, the mainline products were viewed similarly with ratings of medium to high in telemarketing appropriateness and low in demonstration importance. 
Consequently, with experience purchasing the various product types, the differences between them regarding demonstration importance and telemarketing appropriateness do become smaller as does the perceived risk of telephone purchases. Unlike the analysis of the purchase frequencies, these findings show clearly that the product and purchase types do have an influence on the chosen purchase methods.

Once it was established that relationships existed between the measures of telemarketing appropriateness and demonstration importance for the different product and purchase types, Spearman rank order correlations were used to substantiate this and to determine the nature and strength of the associations. The findings are presented in Table 33.

TABLE 33

\section{SPEARMAN RANK ORDER CORRELATIONS OF TELEMARKETING APPROPRIATENESS AND DEMONSTRATION IMPORTANCE BY PRODUCT AND PURCHASE TYPE}

\begin{tabular}{|c|c|c|c|c|c|}
\hline$\frac{\text { First-time }}{\text { Mainline }}$ & $\frac{\text { Subsequent }}{\text { Mainline }}$ & $\begin{array}{c}\text { First-time } \\
\text { Complementary }\end{array}$ & $\begin{array}{l}\text { Subsegiculi } \\
\text { Complenientary }\end{array}$ & $\frac{\text { First-time }}{\text { Service }}$ & $\frac{\text { Subsequent }}{\text { Service }}$ \\
\hline (FT/M) & (S/M) & $(\mathrm{FT} / \mathrm{C})$ & $(\mathrm{S} / \mathrm{C})$ & (FT/S) & $(\mathrm{S} / \mathrm{S})$ \\
\hline $\begin{array}{l}*-.3907 \\
(84) \\
P=.000\end{array}$ & $\begin{array}{l}-.8136 \\
(84) \\
P=.000\end{array}$ & $\begin{array}{l}-.8079 \\
(84) \\
P=.000\end{array}$ & $\begin{array}{l}-.8125 \\
(84) \\
P=.000\end{array}$ & $\begin{array}{l}-.8 \vdots 18 \\
(84) \\
P=.000\end{array}$ & $\begin{array}{l}-.6588 \\
(84) \\
P=.(0) 0\end{array}$ \\
\hline
\end{tabular}

(* The first number is the Pearson coefficient. The number in brackets below is the number of cases. $P$ gives the probability level of error of the one tailed test of significance) 
The correlations between the importance of product demonstrations and the appropriateness of telemarketing show very strong significant negative relationships for the product and purchase types. This strong association supports the belief that customer perceptions of the requirement for product demonstrations is a strong indicator of telemarketing's appropriateness for given purchase circumstances.

It is intcresting to note that for first-time purchases, the relationship is much weaker for mainline products $(-.3907)$ and gets much stronger for complementary products $(-.8079)$ and even stronger for service products $(-.8519)$. In contrast, for subsequent purchases, mainline products show the strongest association $(-.8136)$ and are followed closely by complementary products $(-.8125)$ while service products have a slightly weaker association (-.6588).

The low coefficient values for first-time purchases of mainline products and subsequent purchases of service products were lower than expected and were the result of a strong consensus in the data. Crosstabulations of the first-time purchase ratings in Tables 34 through 36 and of the subsequent purchase ratings in Tables 37 through 39 further explain this point. The figures in bold signify the ratings where the strength of the consensus is greatest. 
TABLE 34

CROSSTABULATIONS OF TELEMARKETING APPROPRIATENESS AND DEMONSTRATION IMPORTANCE FOR FIRST-TIME PURCHASES OF MAINLINE PRODUCTS (FTM)

Demonstration Importance

Telemarketing

Appropriateness

Low Medium High Total

Low

Medium

High

0

0

0

1

0

80

2

0

)

Total

-

2

82

84

TABLE 35

CROSSTABULATIONS OF TELEMARKETING APPROPRIATENESS AND DEMONSTRATION IMPORTANCE FOR FIRST-TIME PURCHASES OF COMPLEMENTARY PRODUCTS (FT/C)

Demonstration Importance

Telemarketing

Appropriateness

Low

Medium

High

Total

Low
Medium
High

0

0

59

59

0

3

14

6

20)

1

1

5

Total

15

66

84 
TABLE 36

CROSSTABULATIONS OF TELEMARKETING APPROPRIATENESS AND DEMONSTRATION IMPORTANCE FOR FIRST-TIME PURCHASES OF SERVICE PRODUCTS (FT/S)

Demonstration Importance

Telemarkcting Appropriatencss Low Medium High Total

\section{Low \\ Medium \\ High}

\begin{tabular}{l}
2 \\
2 \\
45 \\
\hline
\end{tabular}

49

$\begin{array}{r}2 \\ 18 \\ 2 \\ \hline\end{array}$

22

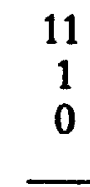

12
15

21

47

84

TABLE 37

CROSSTABULATIONS OF TELEMARKETING APPROPRIATENESS AND DEMONSTRATION IMPORTANCE FOR SUBSEOUENT PURCHASES OF MAINLINE PRODUCTS (SM)

Demonstration Importance

Telemarketing

Appropriateness

$$
\text { Low }
$$

Medium

High

Total

Low

Medium

High

1
4
38

2

20

4

11
4
0

14

28

42

Total

43

26

15

84 
TABLE 38

CROSSTABULATIONS OF TELEMARKETING APPROPRIATENESS AND DEMONSTRATION IMPORTANCE FOR SUBSEOUENT PURCHASES OF COMPLEMENTARY PRODUCTS (S/C)

Demonstration Importance

Telemarketing

Appropriateness

Low

Medium

High

Total

Low

Medium

High

2

0

10

12

15

3

47

0

50

Total

52

18

14

84

TABLE 39

CROSSTABULATIONS OF TELEMARKETING APPROPRIATENESS AND DEMONSTRATION IMPORTANCE FOR SUBSEQUENT PURCHASES OP SERVICE PRODUCTS (S/S)

Demonstration Importance

Telemarketing Appropriateness

Low

Medium

High

Total

Low
Medium
High

3
2

2
64

0
5
4

5

$1 \quad 8$

0

68

Total

69

9

6

84 
The crosstabulations show that the purchase circumstances receiving the weakest correlations arc, in actuality, the circumstances where customers responded most similarly. Therefore, looking at the results differently, it can be surmised that for first-time purchases of mainline products and subsequent purchases of service products, most customers have similar opinions regarding the requirement for product demonstrations and appropriateness of telemarketing; that for first-time and subscquent purchases of com ${ }^{-1} \cdot$ mentary products there is a larger range of opinions and less consensus regarding these factors; and for firsttime purchases of service products and subsequent purchases of mainline products there is the least amount of agreement.

The findings show that customer requirements for product demonstrations do vary among the product and purchase types and that customer viewpoints are rather definitive. Regarding this factor, service products appear to be the most appropriate for telephone sales followed by complementary products and mainline products for both first-time and subsequent purchases. However, it is important to note that for suhsequent purchases, the discrimination between the product types has decreased to the point where ?ustomers consider all product types to be equally appropriatc for telemarketing. 


\subsubsection{Product / Scrvice Price}

It was lound that product or service price is a factor which influences customer acceptance and usage of industrial telemarketing. In order to find out the extent of this influence and to increase our understanding of why it exists, customers were asked to state the dollar limits that they are willing to spend on first-time and subsequent telcphone purchases and any conditions which apply to these limits. The results are presented in Tables 40 through 42

The dollar limits or prices customers are willing to pay for telephonc purchases of computer software products are clearly delineated. Table $\mathbf{4 0}$ shows that for both purchase types, most customers fall into one of four groups. These groups consist of persons who either (1) place dollar limits which are $\$ 2,000$ and under on telephone purchases; (2) place dollar limits greater than $\$ 2,000$ on telephone purchases; (3) place no dollar limits on telephone purchases; or (4) do not know how much they would spend on telephone purchases.

There are differences between the dollar limits by purchase type despite their similar groupings. For instance, the number of persons placing dollar limits which are $\$ 2,000$ and under is greater for first-time purchases than for subsequent purchases (i.e. 35 customers vs. 17 customers) while the opposite is true for those customers placing no limits on telephone purchases (i.e. 12 customers vs. 17 customers). In addition, 19 customers that were able to specify a dollar limit for 
TABLE 40

FREQUENCIES OF DOLLAR LIMITS ON TELEMARKETING PURCHASES BY PURCHASE TYPE

Dollar Limit

Under $\$ 100$

$\$ 101-\$ 300$

$\$ 301-\$ 500$

$\$ 501-\$ 1,000$

$\$ 1,001-\$ 2,000$

$\$ 2,001-\$ 3,000$

$\$ 3,001-\$ 5,000$

$\$ 5,001-\$ 10,000$

$\$ 10,001-\$ 20,000$

$\$ 20,001-\$ 30,000$

$\$ 30,001-\$ 50,000$

$\$ 50,001-\$ 100,000$

Over $\$ 100,000$

No limit

Not Applicable (i.c. not my decision)

Unknown

Unknown but would increase from the first-time dollar limit Have not and will not purchase over the phone

Total
First-time Subsequent

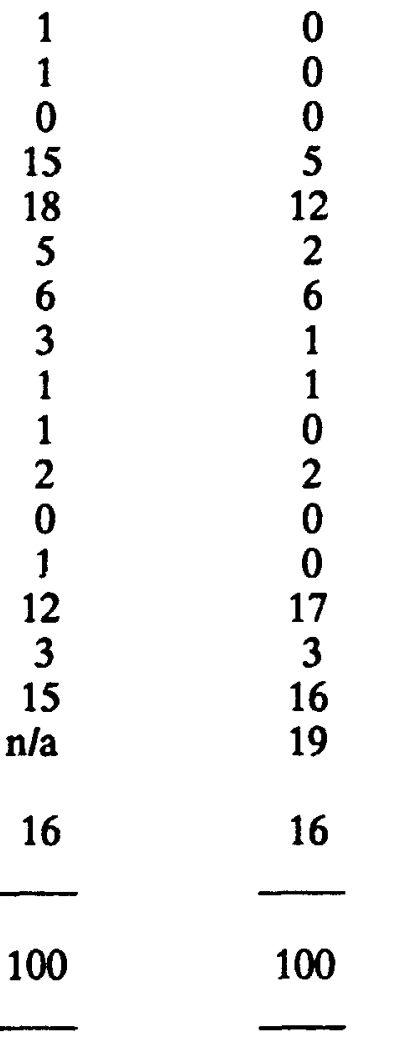

TABLE 41

NUMBER OF CUSTOMERS PLACING CONDITIONS ON THE DOLLAR LIMITS BY PURCHASE TYPE

Responsc

No

Yes

Not Applicable (i.e. not my decision)

Unknown

Have not and will not

purchase over the phone

Total
First-time Subsequent

\begin{tabular}{cc}
23 & 10 \\
54 & 67 \\
3 & 3 \\
4 & 4 \\
16 & 16 \\
\hline 100 & \\
\hline
\end{tabular}


TABLE 42

\section{CONDITIONS WHICH INFLUENCE THE DOLLAR LIMITS} BY PURCHASE TYPE

\section{Factor}

1) Budget / funds available.

2) Product complexity.

3) Must be an upgrade purchase.

4) Must be a purchase of a service.

5) The product is available only over the telephonc.

6) Need for the product.

7) Recommendation by a software specialist.

8) The availability of support.

9) The number of copies purchased.

10) Must be a PC product

11) Prior information received (i.e. mailings, brochures).

12) Previous knowledge or experience with the product (i.e. trials).

13) No demonstration is required

14) Agreement of other users.

15) Upper management approval.

16) Comfort level with the product.

17) Previous demonstration must be given.

18) Commitment to the scller's products.

19) Credibility of the seller.

20) Multiple reasons.

Did not place conditions on the dollar limits.

Not Applicable (i.e. not my decision) Unknown

Have not and will not

purchase over the phone

Total
First-time Subsequent

$\begin{array}{rr}2 & 2 \\ 3 & 3 \\ 2 & 2 \\ 11 & 8 \\ 1 & 1 \\ & \\ 3 & 3 \\ 1 & 1 \\ & \\ 1 & 2 \\ 1 & 0 \\ 2 & 2 \\ 5 & 6\end{array}$

$10 \quad 10$

$\begin{array}{ll}1 & 1 \\ 1 & 1 \\ 0 & 3 \\ 1 & 1 \\ 6 & 6 \\ 0 & 4 \\ 0 & 1 \\ 3 & 3\end{array}$

27

14

\begin{tabular}{cc}
3 & 3 \\
0 & 1 \\
16 & 16 \\
\hline
\end{tabular}

100 
first-time purchases but could not for subsequent purchases were still able to speculate that the dollar amount would increase from the first-time limit. These frequency differences show that high dollar limits are not exclusive to subsequent purchases only, however, they do reveal that customers are more cautious when it comes to spending money on first-time telephone purchases than subsequent telephone purchases.

This caution on the part of customers may have a direct bearing on the types of products that can be sold through telemarketing. In order to determine if these limis encompass all product types, pricing information on the product types was gathered. The sponsoring company's product prices tend to vary and overlap in many instances because they depend on many factors (i.e. the customers' machine type, the number of copies/licenses purchased, if it is an upgrade purchase, etc.). However, service products generally range in price from under $\$ 100$ to $\$ 2,000$, complementary products from $\$ 2,001$ to $\$ 20,000$ and mainline products from $\$ 20,001$ to $\$ 200,000$.

When these price ranges are compared with the dollar limits stated by the customers, it seems thit all product types can be purchased via telemarketing regardless of the purchase type. However, some differences do exist between the purchase types when the frequency of customers stating dollar limits in these price ranges are compared. For first-time purchases, service products are more likely to sell over the telephone than the mainline and complementary products 
(i.e. 35 customers stated limits in the service price range; 15 customers stated limits in the complementary product price range; and 16 customers stated limits in the mainline product range). For subsequent purchases, it appears that price is less of a discriminating factor and that all product types have fairly equal chances of being purchased over the telephone (i.e. 17 customers stated limits in the service price range; 10 customers stated limits in the complementary product price range; and 19 customers stated limits in the mainline product price range)

Table 41 indicates that almost everyone that gave dollar limits was able to specify whether they would or would not place conditions on the amounts. It was revealed that 67 customers put conditions on subsequent telephone purchases in comparison to 54 customers who put conditions on first-time telephone purchases. A possible explanation for this difference may be that customers need an increase in reassurance to correspond with the increase in doilar limits which were shown to be generally associated with subsequent purchases.

Customers stated twenty conditions which influence the dollar limits by purchase type. These conditions and the frequency with which they were cited are displayed in Table 42 . It can be seen that for many people the same conditions influenced the dollar limits regardless of the purchase type. More commonly stated conditions stipulated that the purchase must be of a service product, that a previous demonstration must be given and that the limit depends on the amount of previous knowledge or experience with the product. Thus, it 
is evident that some of the conditions not only influence the dollar limits but the use of the telephone altogether.

Three observations have been made based on this dollar limit information. First, it seems that the dollar limits do not vary by product type because it was not stated by many customers as a condition of the limit. Therefore, because most of the stated dollar limits apply to all product types, any products priced lower than the staled dollar limits would be appropriate for telemarketing. Those products priced above the stated dollar limits would be best marketed through field sales representatives. Second, there is a shift in emphasis to a greater need for support, prior information, previous knowledge or experience (i.e. trials) and upper management approval with greater dollar outlays over the telephone. Third, it is interesting to note the emergence of customer commitment to the seller's products and company credibility as conditions which influence subsequent dollar limits. These new conditions suggest that elements of relationship building and trust must be evident before customers will be willing to spend more over the telcphone.

In summary, the results of this subsection on product/service price are only somewhat consistent with those results of the previous subsection on the requirement for product demonstrations in so far as specifying the purchase circumstances where the use of lelemarketing is most appropriate. The previous subsection was able to conclusively specify (i.e. due to a large consensus in the 
data) the purchase circumstinces where the use of telemarketing is appropriate based on the requirement for product demonstrations. However, this subsection was not able to completcly support the conclusive findings of the previous subsection because of the cqual and large variance in the dollar limits for each purchase type. When considered together, these results generally show that product/service price is not likely a primary consideration nor is the use of the telephone for making purchises of computer software products and services as long as customers have experience with the products (i.e. through previous purchases) or have been given product demonstrations.

\subsection{OTHER FINDINGS}

A number of other lactors and observations not statistically tested or measured surfaced during the customer interviews. They are based upon the comments of customers and deserve mention because they may also have impacted the study's results. In addition, a discussion of these factors and observations is relevant as they may have strategic implications on the way companies organize and integrate their telemarketing departments into their overall marketing operations.

These factors appear to be potential barriers to customer satisfaction, acceptance and usuge of industrial telemarketing. They appear to fall into two main groups; those which are under the control of the seller and those which are 
not under the control of the seller. Each of these barriers are identified and discussed below along with possible solutions of how to overcome them where applicable.

\subsubsection{Barricrs to Telemarketing Controlled by the Seller}

Potential barricrs to industrial telemarketing which fall under the control of the seller pertain to structure, management, training, support, marketing and customer perceptions of the seller's motives for using telemarketing. The first barrier pertains to the preference that was exhibited, particularly by the Quebec customers, to make telephone purchases througn their field sales representatives instead of the telcmarketing representatives in Ottawa. This greater inclination to call local representatives may be due to any number of reasons (i.e. culture, geographic proximity, loyalty to the ficld sales representative, knowledge of the telemarketing department's existence, etc.). However, it does raise the possibility that a decentralized telemarketing structure may be more appropriate for Quebec (i.e. foster greater satisfaction and usage) while a centralized structure could remain to handle the other regions.

The second areal under the control of the seller is management. It can be a barrier to customer satisfaction with telemarketing when performance measures are not consistent with scrvice priorities. For instance, some customers expressed that they felt the telemarketers did not make an effort or take enough time to 
answer their questions or solve their problems. This may be due, in part, (o) telemarketers not having the appropriate knowledge but may also be due to the fact that management mcasures telemarketer effectiveness by the amount of sales and not by the number of problems solved, questions answered or satisfied customers. It could be that because performance is measured based on sales, telemarketers are reluctant to spend extra time on problems if it cuts into their sales time.

A third barrier could be telemarketer training. Although most customers seemed generally satislied with the knowledge of the telemarketers, others stated that, unlike lield sales representatives, telemarketers have not kept abreast with changes in their respective industries and did not have an adequate level of technical knowledge. Thus, it appears there are two types of telephone customers, those who like to speak with technical persons and those who are not as concerned with the technical aspects of the products.

This observation regarding two types of customers raises the issues of how much technical product knowledge telemarketers should have when selling software products and services and how technical inquiries should be handled. The sponsoring company currently has a telemarketing department staffed with individuals with Jittle or no technical expertise that refer technical questions to another telephone service called telesupport. However, telesupport has also come under criticism by customers for not having technical personnel immediately 
available who can answer tcchnical inquiries. The delays that occur as a result of not having technical personncl readily available has caused dissatisfaction to some customers.

A possible solution to this problem is to ensure that technical personnel are available to answer the telephones. If this is not feasible, then some telemarketers or telesupport personnel should be given more technical product or computer training. The result will be a group of telemarketers comprised of a mix of individuals with general and technical knowledge able to handle requests from all customers regardless of their nature quickly and effectively. This would also lessen the confusion some customers have regarding who they are to call when they require product information.

Another barrier which may hinder the satisfaction, acceptance and usage of industrial telemarketing is the availability of support. By support, customers are referring to receiving adequate prior written information on the products and their release times, heing provided demonstration disks or videocassettes, getting the opportunity to reccive trial periods with the product and having personnel or an on-line datahase readily available to answer their questions through 1-800 numbers. With such support and increased product knowledge, customers stated that they would fecl more secure and comfortable with the idea of purchasing products and services over the telephone. 
The fifth barrier to industrial telemarketing which is under the control of the seller is the marketing of the products and of telemarketing service. For instance, it is possible that certain products are not purchased over the telephone as frequently as others beciause they are not as actively promoted or made available to the same degree through this medium. For nstance, it was observed that in some instance, services and less complex products were purchased over the telephone because of reforrals by the field sales representatives and because they were more aggressivcly marketed by telemarketers.

Poor marketing of the service itself may be a cause of industrial telemarketing satisfaction, acceptance and usage problems. Some of the customers were unaware that they could purchase products other than services through the sponsoring company's telemarketing departmeri and that telemarketing representatives are competent, trained individuals able to fulfill their purchase needs. In addition, some customers have the viewpoint that the sales process involves too much interaction and time and cannot be accomplished over the telephone under any circumstances.

Customers can he celucatcd about the merits and uses of the telemarketing department through the usc of other media (i.c. mailouts, documentation and annual reports) through referrals by ficld siles representatives (i.e. perhaps they could distribute the business cards of the telemarketers with their own) and by the telemarketers themsclves in thcir own conversations with prospects and 
customers.

The final controllable barrier which may positively or negatively influence industrial tclemarketing sittisfaction, acceptance and usage is customer perceptions of the seller's motives for using telemarketing. It was noted that the customers who are proponents of tclcmarkcting view the use of telemarketing as efficient, an increase in service (1) them (i.c. convenience), cost effective and good management. However, other customers acknowledged the use of telemarketing as a cut in personal scrvice to them and an effort by the company to centralize its sales function. It may be possible to change these perceptions by marketing the advantages of the service to customers and putting aside fears of decreases in service.

\subsubsection{Barricrs to Telemarketing Not Controlled by the Seller}

The second group of barriers to industrial telemarketing satisfaction, acceptance, and usage are those which are not under the control of the seller. These include the buyer corporate purchasing policies, customer loyalty to field sales representatives and telemarketing's poor reputation and image.

Buyer corporate policies can be a barrier because of their influence on the decision to purchase through telemarketing. Some respondents mentioned that they would consider purchasing software products over the telephone but could 
not due to company regulations which insist upon product demonstrations, limit manager's budgets, stipulate upper management approval, maintain that all purchase orders must be in writing, require that more than one person be involved in the process, give the authority to make purchases only to purchasing departments/personncl, or demand the recommendation of a consultant/specialist beforehand. The requirement that all purchase orders be in writing is no longer a major barrier to tclemarkeling with the emergence of facsimile machines.

Customer loyalty to field sales representatives is another obstacle to telemarketing acceptance and usatge. Customers scem to have a greater trust in field sales representatives possibly because of the personal ii.e. face-to-face) service they provide. In addition, they seem to have a preference for dealing with the same person for all their necds uhen a long time relationship has developed and the service has been good in the past.

In order to overcome this visual disadvantage teicinarketing suffers from and to build customer loyally to telemarketing representatives, the issue has been raised that perhaps telemarketers should be given the opportunity to visit customers. There are opposing vicw's regarding this role change. One opinion is that it would be advantageous for telemarketers to visit customers because a face could be associated with the voice and the relationship could be made more personal. Another viewpoint is that it would not be a good idea for telemarketers to see customers bccause this would eliminate the cost advantages telemarketing 
enjoys as a result of not misking such calls. Visits by telemarketers may also confuse customers as to whom they should deal with and likely cause disputes and an adversarial relationship to devclop with field representatives. Therefore, in order to keep customers satisfied and ensure their continued patronage, it does not seem appropriate to allow telemarketers to form close personal relationships with clients as long as thcir turnover rate remains higher than field sales representatives. A more realistic means to introduce telemarketers to customers may be through providing them opportunities to participate at conferences and trade shows.

The last uncontrollable barrier to industial telemarketing satisfaction, acceptance and usage has to do with telemarketing's poor reputation and image. This factor is uncontrollible because despite the generally favourable perceptions of the sponsoring company's telemarketing department, there are still customers who do not regard the telephone as an effective sales tool. These negative perceptions of the sponsoring company's telemarketing department and tclemarketing, in general, app ar to be influenced by previous poor service from the company's tclesupport department and other companies' telemarketing departments as well as the carcless use of the telephone by many consumer telemarketers.

It appears that customer res!:-ect and trust will only be gained if the industry collectively conducts husiness in a responsible manner. Examples of how 
telemarketer practices can change to possibly improve the general image of telemarketing include paying close attention to the regularity with which customers are contacted in order to avoid becoming intrusive and using direct mailings instead of a telephone call in those instances when both mediums are equally effective (i.e. information on special promotions). 


\section{CHAPTER 6 CONCLUSIONS AND RECOMMENDATIONS}

The conclusions and recommendations of the research are given in four sections. The first section provides a summary of the study's research questions, hypotheses and findings. The limitations of the research and comments with respect to their impact on the research findings are discussed in section two. Section three details the benefits and strategic implications of the research for the sponsoring company and other business telemarketers, researchers and customers. Finally, section four suggests other areas in the field of CS/D with industrial telemarketing that deserve research attention and consideration in the future.

\subsection{SUMMARY}

Research Question 1: Are business-to-business customers satisfied with the telemarketing of computer software products and services?

H1: A majority of business-to-business customers are satisfied with the telemarketing of computer software products and services.

Findings: Supported. Most customers reported being satisfied or very satisfied with the service based on the four CS/D measures that were used. None of the measures consistently emerged as a more reliable gauge of CS/D with industrial telemarketing.

Research Question 2: Which telemarketing service facto:s are most highly associated with CS/D? Which telemarketing service factors are most important to customers when they purchase computer software products and services over the telephone? How similar are these two groups of factors? 
H2: Each of the seventeen telemarketing service factors is associated highly with CS/D with industrial telemarketing, however, some of these factors are more important to customers when purchasing computer software products and services over the telephone.

Findings: Supported. All seventeen service factors exariined were positively associated with customer satisfaction. Seven of these factors had particularly strong associations (i.e. significant with at least three of the four CS/D measures) ter). These factors included speed filling requests, ability to speak clearly. listening to customer concerns, knowledge of company products, ability to answer questions, quality of advice given and regularity of contact.

Five of the seventeen factors were consistently stated as being most important to customers when they purchase software products and services over the telephone. These factors in order of importance were speed filling requests, knowledge of company products, ability to understand customer needs, ability to answer questions and convenience. Thus, three of the top five most important attributes were also ones with strong associations with satisfaction (i.e. speed filling requests, knowledge of company products and ability to answer questions).

Research Question 3: What effect do customer characteristics have on overall CS/D with the telemarketing of computer software products and scrvices?

H3: Each of the three customer characteristics has a significantly large effect size on all measures of CS/D with the telemarketing of computer software products and services. Specifically, experience has a significant positive relationship with customer satisfaction; customer age has a significant negative relationship with customer satisfaction; and company size has a significant positive relationship with customer satisfaction.

Findings: Not supported. Each of the customer characteristics had significant associations with only two of the four CS/D measures. Generally, the effect sizes were small and a large amount of unexplained variation was evident in the direction of both satisfaction and dissatisfaction for each of the (:S/I) measures.

Experience had a significant negative relationship with satisfaction using telemarketing to purchase services (Servsat) and a significant positive relationship with customer willingness to recommend the service (Willing). Agc had a significant positive relationship with these same two measures. Company size had a significant negative relationship with satisfaction using telemarketing to purchase services (Servsat) and satisfaction with the service compared to expectations (Expect). 
Rescarch Oucstion 4: What are the most important factors which determine whether customers would purchase and would not purchase computer software products arid services over the telephone?

H4: The two most important factors stated by customers for and for not purchasing computer software products and services over the telephone pertain to the requirement for product demonstrations and product/service price.

Findings: Partially supported. The factors for purchasing and for not purchasing software products over the telephone are different. The top factors for purchasing over the telephone are fast service and convenience. The most important factors for not purchasing over the telephone are similar to what was hypothesized. These factors include the requirement for product demonstrations and lack of previous knowledge or experience with the products. High product price and product complexity were tied as the number three factors for not purchasing over the telephone.

Rescarch Question 5: Are certain software product types more apt to be purchased over the telephone?

H5: Complementary and service products are more likely to be purchased through telemarketing than mainline products.

Findings: Partially supported. Service products were found to be the product type that was purchased in substantial quantities over the telephone. However, complementary products were closer to mainline products in being much less likely or rarely purchased in this manner.

Rescarch Question 6: For first-time purchases, how is the requirement for product demonstrations by product tvpe related to the appropriateness of telemarketing by product type?

H6: For first-time purchases, there is a negative relationship between the importance of demonstrations by product type and the appropriateness of telemarketing by product type.

Findings: Supported. Strong negative relationships between the importance and the appropriateness ratings were found for all product types. Both mainline and complementary products rated high in demonstration importance and low in telemarketing appropriateness while service products rated low in demonstration importance and high in telemarketing appropriateness. Consequently a large discrimination between the product types was evident for these purchases. 
Research Question 7: For subsequent purchases, how is the requirement for product demonstrations by product type related to the appropriateness of telemarketing by product type.

H7: For subsequent purchases, there is a negative relationship between the importance of demonstrations by product type and the appropriateness of telemarketing by product type.

Findings: Supported. Strong negative relationships between the importance and the appropriateness ratings were found for all product types. Both, complementary and service products rated low in demonstration importance and high in telemarketing appropriateness while mainline products rated low in demonstration importance and medium-high in telemarketing appropriateness. Consequently, very little discrimination between the product types was evident for these purchases.

Research Question 8: What is the highest price customers would pay on a telephone purchase of a computer software product or service? Do these limits encompass all product types? Are the limits conditional? If yes, what factors do the limits depend upon? Do these limits and conditions vary between first-time and subsequent purchases?

H8: Telemarketing customers place lower dollar limits on first-time product purchases than on subsequent product purchases.

Findings: Partially Supported. The number of persons placing lower dollar limits was greater for first-time purchases than for subsequent purchases, however, some very high first-time limits were stated by customers. Specifically, it was found that, regardless of purchase type, customers could be placed into four groups based on the dollar limits they stated. These groups consisted of persons who either (1) placed small dollar limits which are $\$ 2,000$ and under; (2) placed dollar limits greater than $\$ 2,000$; (3) placed no limit on the purchase; and (4) do not know how much they would spend on telephone purchases. Thus, the stated dollar limit ranges did encompass all product types.

Twenty conditions were identified which influence the amount customers spend over the telephone. These conditions were more likely to be placed on subsequent purchases than on first-time purchases. The most commonly stated conditions had to do with the requirement that the purchase must be of a service product, the requirement for previous knowledge or experience with the product and the requirement that a previous demonstration be given. These conditions were found to influence the dollar limits regardless of the purchase type. 


\subsection{LIMITATIONS OF THE RESEARCH}

There are a number of limitations to the research that should be noted. Many of these are beyond the control of the researcher. First, there are limitations to the survey instrument that was used. The telephone survey used was susceptible to problems due to interviewer effects and its complexity (Tull and Hawkins, 1980). For instance, the language of the interviewer (i.e. English) may have influenced responses of individuals from the Quebec region. The inability of some respondents to fully express themselves in English may have been responsible for the greater proportion of negative responses in the $r$ gion. In addition, the potential exists that translation problems may have caused the responses to questions to be biased towards answers which are convenient or more easily understood.

Another drawback to the survey is the complexity of some questions. Even though steps were taken as a result of pretests to decrease this problem, some questions remained lengthy and dependent on the memory of the respondents (i.e. questions $3,4,5,6,16$ and 17 of the telephone survey). It was assumed that the survey instructions were understood, however, without the aid of visual cues, this is not easily confirmed.

A second limitation which is difficult to completely account for is nonresponse. Although steps were taken to decrease non-response (i.e. scheduling 
of convenient interview times and callbacks), it is possible that persons refusing for reasons other than those mentioned may have different viewpoints than those individuals that responded to the survey (i.e. they may be dissitisfied but not complaining). However, since only six persons refused to participate in the survey without specifying a reason, any non-response error is believed to have been kept to a minimum.

A third limitation is related to the study's dependency upon the accuracy of the sponsoring organization's customer database for the contact names and to verify much of the purchase history information. In some instances, replacement personnel were interviewed when contact names were outdated either because the individual left the company or was no longer in the position on record. It was assumed that the information given by these replacements was accurate even though it could not be verified.

The fourth limitation deals with the nature of the research and the inability to generalize from the results. This study is a cross-sectional, one company case analysis that is applicable only to the industrial telemarketing of computer software and products and support services. In addition, if the respondent is a member of what was a group decision to buy, which is common in industrial purchases, his/her views may not be represe.tative of the other members that were involved in the purchase. Other empirical research must be completed before conclusions can be made about the population representativeness of the 
sample, the stability of the results over time, if they are similar to views held by other telemarketing customers and if they apply to the telemarketing of other types of technical and non-technical industrial products or services.

The final limitation involves three issues which may confound the interpretation of the study's results. The first issue deals with the difficulty that some respondents had separating their satisfaction ratings of the telemarketing department with ratings of their satisfaction (1) with the sponsoring company's other telephone service (i.e. telesupport); (2) with purchasing over the telephone from their field sales representatives; or (3) with the company in general. Efforts were made to lessen any confusion but there is a possibility that the CS/D ratings may be somewhat reflective of customer feelings towards these other areas as well.

The second issue is concerned with the data transformation that had to take place in order to use the Coleman multivariate analysis. This technique requires that dichotomous attributes be used. Since the raw data was not in this form, it had to be split into these dichotomous groups. According to Coleman (1964), some information is lost when the data is reduced in this manner. Therefore, the likelihood exists that the resulting effect sizes may be somewhat obscured. It was determined based on an analysis of the residuals from the model (see Appendix $\mathrm{H}$ for an example) that any such tendencies in the data ocurred in both the direction of satisfaction and dissatisfaction and showed no consistent 
pattern.

The last issue pertains to the multidimensional nature of the research in which it was virtually impossible to identify and measure all of the variables which influenced the CS/D, demonstration importance and telemarketing appropriateness ratings. The identification of other potential barricrs to customer satisfaction, acceptance and usage of industrial telemarketing surfaced during the interviews supports this point.

This multidimensional nature of the research is the reason why the results were based on the measurenent of specific service and usage factors and customer characteristics. It is believed that the direct inquiry that took place minimized the influence of other variables and enabled fairly accurate measurements of the relationships pertaining to the factors of interest. In addition, because multiple measures of CS/D were used and because customers were allowed to base their ratings on their own subjective criteria, it is believed that most of the influences affecting these feelings were implicitely accounted for in the ratings and that the validity of the CS/D measures was high. 


\subsection{BENEFITS AND STRATEGIC IMPLICATIONS OF THE RESEARCH}

The research provides valuable CS/D and usage information regarding the industrial telemarketing of computer software products and support services. Business telemarketers, the sponsoring organization, researchers and customers can particularly benefit from this knowledge. These specific benefits are described below.

\section{Benefits to Business Telemarketers}

Benefits to business telemarketers and the sponsoring organization can realize benefits in the areas of service planning, market analysis, telemarketing field sales role definition and revenue forecasting. For instance, the results can be instrumental in the alteration or formulation of service objectives, strategies and standard operating procedures for organizations currently selling or planning to sell software products and services via industrial telemarketing.

Specifically, the direct customer feedback regarding the relative importance of the service factors and the degree of the telemarketing department's success or shortcomings satisfying customers with respect to these factors can help the sponsoring company and other organizations to identify and correct service deficiencies or gaps in their operations. This service information can also be useful in the development of telemarketing training programs which concentrate 
on providing knowledge and skills to telemarketers which are satisfying and important to customers. In addition, a knowledge of service factors which atre appealing to customers may prove helpful when devising scripts or making presentations to prospective customers.

The historical purchase information collected (i.e. product and purchase types, customer involvement in purchase and purchase methods used) helps to specify current customer consumption habits and to determine if certain products are more likely to be purchased over the telephone than others. In addition, customer opinions of the most important reasons for using and for not using telemarketing provide explanations for the existence of these practises and serves to explain different levels of CS/D among the customers.

The sample statistic data gave an indication as to the type of customers (i.e. nature of business, functional position, company size, age) who use and do not use the sponsoring company's telemarketing service. This type of information is useful in identifying target markets with high telemarketing potential, as well as those segments not currently being serviced through this medium.

Other usage information provided insight into the circumstances or extent to which telemarketing can be used as a marketing tool presently and in the future. For instance, knowledge regarding customer flexibility with respect (o) foregoing product demonstrations and with respect to maintaining dollar limits 
on telephone purchases helped to specify the purchase circumstances most appropriate for telemarketing and the roles/relationships the telemarketers and field representatives should play with respect to these purchases. This information can be particularly useful when allocating finite resources (i.e. number of telemarketers, time) to various tasks.

Furthermore, this dollar limit information allows a forecast to be made of telemarketing's future service and revenue potential for computer software products and services. This information will be of particular interest to potential business telemarketers that are evaluating whether or not to implement an industrial telemarketing operation on the basis of cost to benefit and that are making decisions regarding the types of products that should be marketed in this manner.

The ability to conduct a comparative analysis between customer perceptions of telemarketing usage and the sponsoring company's own viewpoints or practices regarding telemarketing usage is another benefit of the research. If the perceptions are the same, it is likely that the current or planned usage is appropriate. However, if the perceptions are different, new opportunities for use may be identified. It appears that the current use is generally consistent with customer perceptions and consumption patterns (i.e. service products are most appropriate to purchase through telemarketing). However, the finding that customers are generally indifferent towards making many service and upgrade 
purchases over the telephone or through field sales indicates that the telemarketing department may be able to take an even larger role in selling these products.

Finally, because this is the first customer satisfaction survey of the sponsoring company's telemarketing department, the results may be useful in providing feedback regarding service improvrments. The findings may also serve as benchmarks or provide a guide for future work in the area of CS/D with industrial telemarketing.

\section{Benefits to Researchers}

The benefits to researchers relate to the building of current theory in the area of CS/D with industrial telemarketing. Specifically, current theory has been augmented in areas pertaining (1) to prescribed industrial telemarketing scrvice factors; (2) to the relationship that customer characteristics have with $C S / D$ with industrial telemarketing; and (3) to the appropriate sales and scrvice role of telemarketing in industrial markets. In addition, the literature is supported in the area of CS/D measurement.

For instance, the literature prescribes numerous telemarketing scrvices which telemarketers should perform to keep customers satisfied. Of the seventeen telemarketing service factors studied, three factors were both associated 
highly with CS/D and important to customers. Therefore, this finding narrowed the list of telemarketing service factors by differentiating between those factors which are prescribed versus those factors which ar ? essential to good service.

Another area where present theory has been augmented pertains to the relationship between customer characteristics and CS/D with isfustrial telemarketing. The literature states that experienced users rather than inexperienced users are more likely to make appropriate choices and have satisfactory experiences due to their expectations being complete (Hunt, 1977a; Sheth, 1973; Day, 1977). Hence, it was hypothesized that a siguificant positive relationship exists between telemarketing experience and customer satisfaction.

The findings showed inconsistent results with this hypothesis (i.e. one significant positive relationship and one significant regative relationship with two of the CS/D measures). The fact that this finding is contradictory to that of the literature suggests that other measures of experience may be related to CS/D with industrial telemarketing (i.e. experience with the product) or that telem.sketing experience has a weak association with CS/D.

Age of the custorner was hypothesized to have a significant negative relationship with CS/D based on the Hamilton (1989) consumer study. As was the case with the experience characteristic, the findings pertaining to the age characteristic were inconsistent with the hypothesis (i.e. two positive relationships 
with two of the CS/D measures). The findings of the experience and age characteristics, the small coefficient values of the significant measures and the large amount of unexplained variation on all CS/D measures for each characteristic suggest that customer characteristics related to (SS/D) with consumer telemarketing may not be the same characteristics related to CS/D with industrial telemarketing.

The theory regarding the purchase circumstances most appropriate for telemarketing was supported and further clarified through this research. Given customer perceptions of the requirement for product demonstrations versus the appropriateness of telemarketing, the Moncrief et al. (1988) assertion that telemarketing be used in a primary role for routinized selling processes for nontechnical products and a supporting role for unique or technical purchases is partially supported. The rationale behind this partial support is that for firsttime purchases, the research findings do support the belief that telemarketing not be used for technical purchases and used for non-technical purchases. However. for subsequent purchases, the findings showed that customers view all products (i.e. non-technical and technical) as almost equally appropriate for telemarketing.

Similarly, the argument posed by Rudolf (1986), Alexander (1987) and Bailey (1988) that telemarketing can be used to introduce and sell mainline products is partially supported. For instance, when based on the findings alyove, it seems these types of products (also complementary products as the findings 
revealed) can only be introduced and sold over the telephone providing that they are upgrades. Therefore, the important influence affecting the likelihood of mainline and complementary products being introduced and sold over the telephone is the existence of a relationship, the idea put forth by Gilpen (1989). Specifically, it seems that the nature of the relationship must be one which has been established through a previous purchase or product demonstration.

The survey findings gave an indication as to the amount of money industrial customers are willing to spend on telephone purchases. It was discovered that customers could be grouped based on the dollar amounts they are willing to spend over the telephone. These groupings placed limits on telephone purchases ranging from $\$ 2,000$ and under to no dollar limit. Hence, these findings support the Bailey (1988) and Wingis (1981) position that big-ticket items can be sold over the telephone.

In addition, the research provided insight into the rationale behind more expensive telephone purchases by customers. Shipp (1989) believes that the amount of relationship building that has taken place with customers is the main impetus behind more expensive telephone purchases. The emergence of conditions on subsequent dollar limits pertaining to the level of customer commitment to the seller's products and company credibility do suggest that relationship building is a factor that does have an influence on more expensive telephone purchases. However, it is difficult to conclude if relationship building 
is the primary factor influencing more expensive purchases because the results also showed a shift towards a greater need by customers for support, prior information, previous knowledge and product experience with subsecpuent (i.e. more expensive) purchases.

Finally, this research provides additional support to current theories which pertain to CS/D measurement. For instance, the literature states that the confirmation/disconfirmation of expectations approach to CS/D measurement is regarded as the most widely accepted determinant of (S/D (Croslyy, 1989); Dily, 1977). Since this CS/D measure proved to be among the more rigorous of the CS/D measures used in the study (i.e. significant with 15 of the 17 telemarketing service factors), further evidence exists to explain its validity as a ( $S / 1$ ) measurc.

\section{Benefits to Customers}

Finally, customers can benefit from this research through improved telemarketing service. This benefit is indirect, however, because it will only materialize if business telemarketers act on the information that has been presented. For instance, customers will likely be satisfied and continuc to use the service if business telemarketers consider the telemarketing scrvice factors which are more important to customers when planning service and training telemarketers; use the telephone for purchase circumstances deemed appropriate by customers; and monitor their call frequencies so as to avoid becoming 
intrusive. Morcover, widespread responsible use of industrial telemarketing may eventually change negative customer perceptions of telemarketing and hence, benefit the entire industry.

\subsection{FUTURE RESEARCH}

This study has been instrumental in the identification of other areas where further research is warranted. For instunce, it would be interesting to compare and contrast the industrial telemarketing CS/D, service, customer characteristic and usage information from this study to similar information with other types of industrial products or services. From such a comparison, it would te further understood if the results apply across different industries or if they are isolated to computer software products and services.

The barriers to telemarketing satisfaction, acceptance and usage previously discussed should be examined in the future as well. The barriers were identified through the research, however, the reasons behind their existerce were not examined or measured. It appears from the research that companies need to acquire the necessary information, tools and skills to properly plan, coordinate and implement telemarketing. In addition, industrial customers must be educated so that they have an understanding of the advantages of this marketing technique. Consequently, through the identification and measurement of these barriers, telemarketers may be able to determine how to overcome them and use the 
telephone to its full potential without jeopardizing the integrity of the service. This knowledge may also contribute towards a greater understanding of ( $\mathrm{S} / \mathrm{L}$ ) influences and measurement.

Further research should also be completed in the area of relationship building. Information on this area would be timely given telemarketing's past image problems and given there is a need to form these close relationships with customers in order to remain competitive. Specifically, factors which influence close telemarketer-customer relationships could be identified and measured in terms of their importance to CS/D as well as for their effects on telephone purchase spending limits.

Finally, by monitoring CS/D and usage with industrial telemarketing over time, more will be learned about changing perceptions with its use and whether companies are adapting and responding to these trends. This insight will allow researchers and practitioners to better define telemarketing's appropriate sales/marketing role as business practises evolve. 


\section{BIBLIOGRAPHY}

Alexander, Diane M., "Business Leaders' Alert - This is Telemarketing", Telemarketing. The Magazine of Business Telecommunications, Volume 6, Number 3, Technology Marketing Corporation, Norwalk, Connecticut, September, 1987, p. 67-71

Anderson, Rolph E., "Consumer Dissatisfaction: The Effect of Disconfirmed Expectancy on Perceived Product Performance", Journal of Marketing Research, Volume X, February, 1973, p. 38-44

Anderson, Rolph E., and Marvin A Jolson, "Consumer Expectations and the Communications Gap", Business Horizons, Volume 16, April, 1973, p. 1116

Anderson, Robert N., and Robert Rue, "Is a Centralized or Decentralized Telemarketing System Best for You?", Telemarketing. The Magazine of Business Telecommunications, Volume 4, Number 11, Technology Marketing Corporation, Norwalk, Connecticut, May, 1986, p. 66-69

Angus Reid Associates Inc., Telemarketing in Canada: A Profile of Users, Perceptions, and Altitudes, Telecom Canada Education Centre, Ottawa, Ontario, 1988, p. 1-20

Ash. Stephen B., "A Comprehensive Study of Consumer Satisfaction with Durable Products", in H. Keith Hunt (editor), Advances in Consumer Research, Volume V, Association for Consumer Research, Ann Arbor, Michigan, 1978, p. 254-262

AT\&T, Terms of the Times. A Dictionary, Telecommunications Ideas to Grow On (Corporate Literature on Telemarketing), Mt. Prospect, Illinois, 1989a, p. 35

AT\&T, Keeping Customers Satisfied, Telecommunications Ideas to Grow On (Corporate Literature on Telemarketing), Mt. Prospect, Illinois, 1989b, p. 1-11

Bailey, Earl L. (editor), A Growing Role for Business-to-Business Telemarketing, The Conference Board of Canada, Research Report Number 912, Ottawa, Ontario, 1988, p. iv-vi; $1-3 ; 11 ; 28-33$

Bencin, Richard L., "The Trouble with (Some) Telemarketers", Business Marketing, August, 1986, p. 80-82 
Bencin, Ri:hard L., "The Biggest and Most Repetitive Mistakes Telemarketers Make", Telemarketing. The Magazine of Electronic Marketing and Communications. Technology Marketing Corporation, Volume 3. Nunber 5, Norwalk, Connecticut, November, 1984, p. 20-23

Budde, Michael, "Q \& A: Focus on Customer Service". Telemirketing, The Magazine of Business Telecommunications, Volume 8, Number 11, Technology Marketing Corporation, Norwalk, Connecticut, May, 1990), p. 18-21

Bultman, Charles, "How to Define Customer Needs and Expectations: An Overview" (cassette tape), Customer Satisfaction Measurement Conference. Teach'em Inc., American Marketing Association and the American Socicty for Quality Contrcl, Atlanta, Georgia, February 26-28, 1989

Coleman, James S., Introduction to Mathematical Sociology. The Free Press of Glencoe, Collier-Macmillan Canada Ltd., Toronto, Ontario, 1964, p. 189)241

Crosby, Lawrence, "Customer Satisfaction Measurement: An Overview of Methodnlogical Considerations" (cassette tape), Customer Satisfaction Measurement Conference, Teach'em Inc., American Marketing Association and the American Society for Quality Control, Atlanta, Georgia, Fehruary 26-28, 1989

Curran, Gary, "Telemarketing Increases Customer Satisfaction at Ingersoll-Rand". Telemarketing. The Magazine of Business Telecommunications, Volume 5, Number 12, Technology Marketing Corporation, Norwalk, Connecticut, June, 1987 , p. 47,48

Czepiel, John A. and Larry J. Rosenberg, "The Study of Consumer Satisfaction: Addressing the 'So What' Question", in H. Keith Hunt (editor), Conceptualization and Measurement of Consumer Satisfaction and Dissatisfaction, MSI Report Number 77-103, Marketing Science Institutc and National Research Foundation, Cambridge Massachusetts, May, 1977, p. $92-116$

Czepiel, John A. Managing Customer Satisfaction in Consumer Scrvice Businesses, Report No. 80-109, Marketing Science Institute, Cambridge, Massachusett $`$, September, 1980, p. 1,3,11,17

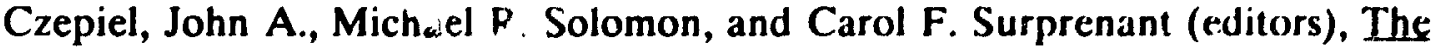
Service Encounter: Managing Employee / Customer Interaction in Service Businesses, Institute of Retail Management, New York University, Lexington Books, D.C. Heath and Company, Toronto, Ontario, 1985, p. 11,268 
Davis, Duane, and Robert M. Cosenza, Business Research for Decision Making, Second Edition, PWS-Kent Publishing Company, Boston, Massachusetts, 1988, p. 108

Day, Ralph L., 'Modeling Choices among Alternative Responses to Dissatisfaction", Advances in Consumer Research, Volume XI, Association for Consumer Research, Chicago, Illinois, 1984, p. 496

Day, Ralph L., "Extending the Concept of Consumer Satisfaction", Advances in Consumer Research, Volume IV, Association for Consumer Research, Atlanta, Georgia, 1977, p. 149-154

Day, Ralph L., "Prescription for the Marketplace-:veryone Listen Better", Business Horizons, Volume 6, December, 1976, p. 57-64

Desatnick, Robert L., Managing to Keep the Customer, Jossey-Bass Publishers, San Francis:o, California, 1987, p. 4

Dillman, Don A., Mail and Telephone Surveys: The Total Design Method, John Wiley \& Sons, Toronto, Ontario, 1977, p. 201-283

Dixon, George, "Keep 'em Satisfied", Marketing News, Volume 23, Number 1, American Marketing Association, Chicago, Illinois, January 2, 1989, p. 1,14

Domine, Jim (Director: Telemarketing, Telecom Canada and Chairman of the Canadian Direct Marketing Association's Telemarketing Council), CDMA Conference, Talisman Hotel, Ottawa, Ontario, January 31, 1989

Driscoll, Linda, "TSRs Tell All: A Landmark Study", Telemarketing. The Magazine of Business Telecom:nunications, Volume 8, Number 3, Technology Marketing Corporation, Norwalk, Connecticut, September, 1989, p. $70-78$

Engledow, Jack L., "Was Customer Satisfaction a Pig in a Poke?", Business Horizons. Volume 20, April, 1977, p. 87-94

Esterhuizen, William, and Angela Poirier, "Telemarketing - The Viable Alternative". Effective Marketing, Dun \& Bradstreet Canada Ltd., Toronto, Ontario. Fall, 1989, p.1-4

Ford executive, Wall Street Journal, December 16, 1985, p. 27

Gilpen, Steve, "Editorial: Telemarketing - From Boilerroom to Boardroom", Canadian Telemarketing News, Volume 2, Issue 2, Telemedia Results Group, Toronto, Ontario, 1989, p. 2 
Greenhalgh, Nile. "Why Telemarketing Didn't Work: A Telemarketer's Point of View". Telemarketing. The Magazine of Electronic Marketing and Communications, Volume 5, Number 3, Technology Marketing Corporation, Norwalk, Connecticut, September, 1986, p. 60,61

Greyser, Stephen A., and S.L. Diamond, "Business is Adapting to Consumerism". Harvard Business Review, Volume 52, September-October, 1974, p. 38-58

Hamilton, Jon T., "Telemarketing To The "Gray Market" ". Telemarketing. The Magazine of Business Telecommunications, Volume 8, Number 4. Technology Marketing Corporation, Norwalk, Connecticut, Octoher, 1989. p. 57-59

Hayes, Michael P., "The Seventh Annual Telemarketing Compensation Update". Telemarketing. The Masazine of Business Telecommunications, Volume 8, Number 5, Technology Marketing Corporation, Norwalk, Connecticut. November, 1989 , p. $46-56$

Hempel, Donald J., and Larry J Rosenberg, "Consumer Satisfaction: A Neg!ected Link?", Advances in Consumer Research, Volume III. Association for Consumer Research, Cincinati, Ohio, 1976, p. 261,262

Howard, John A., and Jagdish N. Sheth, The Theory of Buyer Behiviour, John Wiley \& Sons Inc., Toronto, Ontario, 1969, p. 145-150

Hunt, H. Keith (editor), Conceptualization and Measurement of Consumer Satisfaction and Dissatisfaction, MSI Report Number 77-103, Marketing Science Institute and National Research Foundation, Cambridge Massachusetts, May, 1977a, p. 12,13; 40-42; 155-179; 300,301; 365; 382,383; 412-429; 456-470

Hunt, H. Keith, "CS/D: Bits and Pieces", in Ralph L. Day (editor), Consumer Satisfaction. Dissatisfaction, and Complaining Behaviour, Division of Research, Indiana University, 1977b, p. 38-41

Jackson, Barbara Bund, Winning and Keeping Industrial Customers, Lexingion Books, D.C. Heath and Company, Toronto, 1985, p. 169-171

Kenessey, Mary (editor), Canadian Telemarketing News, Telemedia Results Group, Toronto, Ontario, November, 1988, n. 1

Kennedy, Ann M., "Q \& A: Focus on Telemarketing as a Supplement to Field Sales", Telemarketing. The Magazine of Business Telecommunicalions, Volume 8, Number 10, Technology Marketing Corporation, Norwalk, Connecticut, April, 1990, p. 64-68 
Kidd, Kenneth, "Best companies thrive on complaints, consultant says", The Globe and Mail, September 28, 1989, p. B1,B6

LaTour, Stephen A., and Nancy C. Peat, "Conceptual and Methodological Issues in Consumer Satisfaction Research", Advances in Consumer Research, Volume VI, Association for Consumer Research, Ann Arbor, Michigan, 1979, p. 431-437

Lloyd, Peter A., "Integrated Voice Response - Opportunities and Applications", Telemarketing. The Magazine of Business Telecommunications, Technology Marketing Corporation, Norwalk, Connecticut, May, 1990, p. 40-42

Maister, David H., "Listening to Clients", Business Quarterly, Volume 53, University of Western Ontario, School of Business Administration, London, Ontario, Spring, 1989,p. 70-73

Markham, Vic, Effective Industrial Selling with Total Marketing Communication, George Allen and Unwin Ltd., London, England, 1970, p. 24-37; 38-61; 7083; $90-103$

Marra, Theodore, "Service Must be a Product Attribute", Marketing News, American Marketing Association, Volume 20, Number 21, Chicago, Illinois, October 10, 1986, p. 15

Marshall, Judith J., Innovation Adoption in Industrial Sales Organizations: A Field Study of the Post-Adoption Phase in the Case of Telemarketing, Working Paper Series, Carleton University, School of Business, Ottawa, Ontario, 1986, p. 4

Marshall, Judith J. and Harrie Vredenburg, "Successfully Using Telemarketing in Industrial Sales", Industrial Marketing Management, Volume 17, 1988, p. $8,15-22$

Maynard, Rona, "Getting a Busy Signal", Report on Business Magazine, March, 1986, p. 68-72

McKean, Aldyn, "Telemarketing and Business Communications $\mathbf{Q} \& A$ ", Telemarketing. The Magazine of Business Telecommunications, Volume 5, Number 9. Technology Marketing Corporation, Norwalk, Connecticut, March, 1987, p. 23,24

McNamara, A. J., "How To Make Your Sales Training More Effective", Telemarketing. The Magazine of Business Telecommunications, Volume 4, Number 12, Technology Marketing Corporation, Norwalk, Connecticut, May, 1986, p. 56-70 
Miller, John A., "Studying Satisfaction, Modifying Models, Eliciting Expectations. Posing Problems, and Making Meaningful Measurements", in H. Keith Hunt (editor), Conceptualization and Measurement of Consumer Satisfaction and Dissatisfaction, MSI Report Number 77-103, Marketing Science Institute and National Research Foundation, Cambridge Massachusetts, May, 1977, p. 72-91

Moller, K.E. Kristian, and David T. Wilson, Interaction Perspective in Business Marketiius: An Exploratory Contingency Framework, Report 11-1988, Institute for the Study of Business Markets, College of Business Administration, The Pennsylvania State University, 1988, p. 1-32

Moncrief, William C., Charles W. Lamb Jr., and Terry Dielman, "Developing Telemarketing Support Systems", Journal of Personal \& Silles Management, August, 1986, p. 43-49

Moncrief, William C., Shannon H. Shipp, Charles W Lamb Jr., and David W. Cravens, Examining the Roles of Telemarkiting in Selling Strategy. Working Paper, Texas Christian University, School of Business, July, 1988 , p. $2,4,10-13,16,20,24,45-48$

New Brunswick Department of Commerce and Technology, Telemarketing 1990: A Report on Telemarketing as an Industrial Development Opportunity for New Brunswick, Fredericton, New Brunswick, 1990, p. i, 1, 2

Newman, George, Measuring User Satisfaction with Information Management, Research Report Number 930. The Conference Board of Canada, Otlawa, Ontario, 1989, p. 1-13

Noble, Steie, "High-Tech Says 'YES' to Telemarketing", Telemarketing. The Magazine of Business Telecommunications, Volume 4, Number 12 , Technology Marketing Corporation, Norwalk, Connecticut, June, 1986, p. 26-28

Norusis, Marija J., SPSS Base System User's Guide, SPSS Incorporated, Chicago, Illinois, 1990

Oliver, Richard L., "Measurement and Evaluation of Satisfaction Processes in Retail Settings", Journal of Retailing, Volume 57, Number 3, Fall, 1981. p. 26,27

Paganelli, Mary L., "Telemarketing Industry Matures", Telemarketing. The Magazine of Business Telecommunications, Volume 6, Number 1, Technology Marketing Corporation, Norwalk, Connecticut, July, 1987, p. 45-47 
Parasuraman, A., Valarie Zeithaml, and Leonard L. Berry, Servqual: A MultipleItem Scale for Measuring Customer Perceptions of Service Quality, Report No. 86-108, Marketing Science Institute, Cambridge, Massachusetts, August, 1986, p. $1-5,26$

Parkinson, Stephen T., and Michael J. Baker, with K. Moller, Organizational Buyer Behaviour: Purchasing and Marketing Management Implications, The MacMillan Press Ltd., Houndmills Basingstoke, Hampshire, 1986, p. 1-26

Perruzza, Al, and Grace Bischoff, "Are You Speaking Your Customer's Language", Telemarketing. The Magazine of Business Telecommunications, Volume 7, Number 5, Technology Marketing Corporation, Norwalk, Connecticut, November, 1938, p. 34,35

Peters, Thomas J., and Robert H. Waterman Jr., In Search of Excellence, Harper \& Row Publishers, New York, New York, 1982, p. 156-159

Plakias, Mark, "900 Network Service: The New Math of Inbound Telemarketing", Telemarketing. The Magazine of Business Telecommunications, Technology Marketing Corporation, Norwalk, Connecticut, January, 1990, p. 43-47

Pope, Jeffrey, "What Industrial Telemarketers have that Consumer Telemarketers Don't", Industrial Marketing, Volume 10, August, 1981, p. 80

Ram, S., "A Model of Innovation Resistance", Advances in Consumer Research, Volume XIV, Association for Consumer Research, Provo, Utah, 1987, p. 208-212

Raymond, Corey E., Industrial Marketing: Cases and Concepts, Second Edition, Prentice-Hall Inc., Englewood Cliffs, New Jersey, 1976, p. 1-13; 347-358

Rogers, Everett M., with F.Floyd Shoemaker, Communication of Innovations, Second Edition, The Free Press, New York, New York, 1971, p. 185, 352,353

Roy. Alain (editor), Small Business Ontario: Focusing on Customer Service, Ontario Ministry of Industry, Trade and Technology, Queen's Park, Toronto, Ontario. Spring, 1990, p. 1-6

Rudolf, John, "The Lotus Story: From Order Taking to Account Management to Field Sales", Telemarketing. The Magazine of Business Telecommunications, Volume 5, Number 6, Technology Marketing Corporation, Norwalk, Connecticut, December, 1986, p. 110-114 
Sanchez, Diane, "Telemarketing Skills for Field Sales Reps". Telęmarketing. The Magazine of Electronic Marketing and Communications, Volume 5 . Number 4, Technology Marketing Corporation, Norwalk, Connecticut, October, 1986, p. 56-59

Schneider, Kenneth C., "Telemarketing as a Promotional Tool-Its Effects and Side Effects", The Journal of Consumer Marketing. Volume 2. Number 1, Winter, 1985, p. 29-38

Seon, P. Molley (editor), Canadian Telemarketing News. Telemedial Results Group, Toronto, Ontario, May, 1988, p. 1

Sheth, Jagdish N., "A Model of Industrial Buyer Behaviour", Journal of Marketing, Volume 37, 1973, p. 50-56

Shipp, Shannon H., Associate Professor of Marketing, Texas Christian University. Telephone Interview, October 23, 1989

Smyth, Sandy, "Keeping the Customer Happy: Account Management by Phone". Telemarketing, the Magazine of Business Telecommunications, Volume 4, Number 12, Technology Marketing Corporation, Norwalk, Connecticut, June, 1986, p. 29-31

Steiner Ivan D., and Martin Fishbein, "A Consideration of Beliefs, Attitudes, and their Relationship", Current Studies in Social Psychology, Holt, Rinchart, and Winston Inc., Toronto, Ontario, August, 1966, p. 107-134

Strauss, Marina, "Bad Survice Drives Patrons Away", The Globe \& Mail, March $19,1991$.

Tehrani, Nadji (editor), "Solutions For Success in the '90s" (an interview with AT\&T's William Patchett), Telemarketing. The Magazine of Business Telecommunications, Volume 8, Number 8, Technology Marketing Corporation, Norwalk, Connecticut, February, 1990a, p. 20-23

Tehrani, Nadji (editor), "Zero in on 900 Service - The Fifth Dimension in Marketing", Telemarketing. The Magazine of Business Telecommunications, Volume 8, Number 9, Technology Markcting Corporation, Norwalk, Connecticut, March, 1990b, p. 1

Telecom Canada, Nationwide Communications, various Management Resource Brochures on Phone Power, Ottawa, Ontario, 1989

Tull, Donald S., and Del I. Hawkins, Marketing Research; Mcasurement and Method, Second Edition, MacMillan Publishing Company, New York, New York, 1980, p. 120-130 
Violanti, Michael R., "Telemarketing Development Around the Globe", Telemarketing. The Magazine of Business Teler.ommunications, Volume 7, Number 2, Technology Marketing Corporation, Norwalk, Connecticut, August, i988, p. $42-46$

Voorhees Roy, and John Coppet., "Telemarketing in Distribution Channels", !. $!$, strial Marketing Management, Volume 12, 1983, p. 105-112

Waddell, Garry S, "Facsimile: The Latest Telemarketing Productivity Tool", Telemarketing. The Magazine of Business Telecommunications, Volume 8 , Number 12, Technology Marketing Corporation, Norwalk, Connecticut, June, 1990 , p. $30-34$

Ways, Max, "Business Needs to do a Better Job of Explaining Itself", Fortune, Volume 86, September, 1972, p. 86

Webster, Frederick E., Industrial Marketing Strategy, Second Edition, Ronald Series on Marketing Management, A Ronald Press Publication, John Wiley \& Sons, Toronto, Ontario, 1984, p. 54, 260

Webster, George, Telephone Selling - The Essential Tool for Improving Sales Productivity, Riverview House Publications, Beaufort, South Carolina, 1980 , p. $1-28$

Westhrook, Robert A., "Intrapersonal Affective Infliences on Consumer Satisfaction with Prodicts", Journal of Consumer Research, Volume 7, Number 1, June, 1980, p. 49-54

Westhrook, Robert A. and Joseph W. Newman, "An Analysis of Shopper D'ssatisfaction for Major Household Appliances", Journal of Marketing Research. Volume XV. August, 1978, p. 456-466

Wingis, Chuck, "Telemarketing: A Great Idea Whose Time Has Come", Industrial Marketing, Volume 10, August, 1981, F.71-79

Woodside. Arch G., Jagdish N. Sheth, and Peter D Bennett, (editors), Consumer and Industrial Buying Behaviour, Elsevier North-Holland Inc., New York, New York, 1977, p. 27. 425

'Wotruba, T.R., id P. Duncan, "Are Consumers Really Satisfied?", Rusiness Horizons. Volume 18, February, 1975, p. 85-90 
APPENDICES 


\section{APPENDIX A}

\section{ADVANTAGES / USES OF TELEMARKETING}

\section{Advantages}

*urder convenience/ease of use/fast service

*fficient gathering of competitor information

*time compression/speeits isp sales cycle

* comfort level of customer increases

*allows people less mobile to purchase

*average sale $20 \%$ higher than mail order

* gives customer power to terminate call

*enhance public image

* reduce service/lessen management costs

*differentiates your products

* can make 45 to 50 calls/day

* greater geographic coverage

* easier to train representatives

* sell in all kinds of weather

* time not lost if customer unavailable

* gives ability to meet increasing demand

* many telecommunications products available

"customers can call when interest is greatest

* flexibility: inbound or outbound

*flexibility: main seller or support capecity

*flexibility: full or part-time representatives

* flexibility: scripts can change with each call

* flexibility: consumer or industrial telemarketing

* flexibility: can sell small or big ticket items

* reduced paperwork

* personal contact (second only to personal visits)

* can make dormant clients active again

* training for potential field representatives

*aliows for measurability of ad campaigns

* preve.its losing account if field rep. leaves

* one supervisor for every 5-10 telemarketers

* stronger customer relations

* use human resources to their potential

* ensure customer loyalty

* it grows as your business needs grow

*both targe and small companies can use it

*allows one to target markets

* ficld sales call(\$300); telephone call(\$3.50)

*no expense accounts required

*allows up-to-minute facts on accounts

*not a!fected by postal strikes

*everyone answers tise phone (only 7\% hang up)

*less risk than hiring a field sales force

* reduced turnover of field sales/increased support

*cost affective geographic expansion
Uses

* order processing

* customer service

* sales support

*account management

* promotion management

*qualify/refer leads

* use on marginal accts.

*introduce specials

*increase sales

*introduce new products

*test customer response

* take repair requests

*handle inquiries

* use with ad campaigns

*toll-free 800 *

*helpline

*team selling

* dispense information

*inventory control

* collect receivables

* market research

* credit checks

*allows to upsell

*ailows to cross-sell

* sell old inventory

* handle complaints

* membership drives

* fundraising

* prospect clients

* relationship building

* understand client needs

* secure account data in company records

Sources: Angus Reid Associatcs, 1988; Telecom Canada, 1989

Domine, 1989; Webster, 1980; Maynard. 1986; AT\&T, 1989b

Schneider, 1985; Esterliuizen and Poirier, 1989; Kennedy, 1990 


\section{APPENDIX B}

\section{DISADVANTAGES / LIMITATIONS OF TELEMARKETING}

\section{Disadvantages}

* low compensation for telemarketers

* product not seen (no visual cues)

* more difficult to sell over the telephone

* lose power over the sale (customer controls)

* requires expensive telecommunications equipment

*needs special office arrangements

* often requires new marketing requirements

*lack of face-to-face contact

* may have adverse affect on company image

* lack of career paths for telemarketers

*burnout (4-5 hours/day ceiling for calls)

*little creative work for telemarketers

*high turnover of telemarketers

* requires a person with dynamic personality

* poor attitude of telemarketers towards job

*junk phone calls

* each call still can cost from $\$ 2.50-\$ 10.00$

*best conditions, situations for use unknown

*products most suitec' for unknown

*sensitivity of customers to price unknown

*tension between field sales and telemarketers

* few people know how to manage telemarketers

*telemarketing managers lack authority

* telemarketer must handle a lot of rejections

* customer views on trustworthiness unknown

*telemarketers may lack respect of customers
Limitations/Cause of Piailure

* no cooperation from field siles

*lack of top mgt. support

*ill-clefined responsibilities

* scripting may buther people

* lack of planning/strategy

* motivation of telemarketers

* lack of advertising support

* specialization required

*knowledge of telemarketets

*continual training needed

* immediate results unlike-ly

* poor integration within the business

*lack of planning

* phone used improperly

* poror telephone skills

* lack interpersonal skills

* inadequate training

* poor equipment

* lack of scripts/all guides

*lack of performance measures

* telemarketers lack authorily

*difficult customer response

(i.e. lack 1-800 ")

* didn't use professional help

*lack of follow. up

* no quality control procedures established

Sources: Bencin, 1984; Bencin, 1986; Marshall and Vredenburg, 1988

Schneider, 1985; Greenhalgh, 1986; AT\&T, 1989h:

Maynard, 1986; Moncrief, Lamb, and Dielman, 1986 


\section{APPENDIX C}

\section{DESCRIPTION OF RECENT TECHNOLOGICAL DEVELOPMENTS IMPACTING THE TELEMARKETING INDUSTRY}

1. 900 Network Service: A service to customers, used in conjunction with advertising, whereby potential customers can call into a telemarketing centre and listen to short pre-recorded messages containing more information on the product or service. Its unique feature is that it "pays for itself" as customers are billed for the call. Therefore, it not only allows better pre-qualification of customers but generates revenue as well.

Source: Plakias, 1990; Tehrani, 1990b

2. Inlegrated Voice Response (Audiotex): A stand-alone system that plays pre-recorded messages back to the listener as the person interacts with a computer database using a touch-tone phone pad as the input device. The caller works through menus and responds to the pre-recorded questions to obtain information. This system will free telemarketing representatives from routine and time consuming aspects of their jobs (i.e. placing orders).

Source: Lloyd, 1990

3. Videotex: A technology which enables the exchange of information by computer over pi.one lines. Subscribers of this service will be able to call third party information providers (i.e. brokerage houses for stock quotes). It represents a revenue opportunity for the information providers as they may decide to charge a fee for the service. In addition, it overcomes a telcmarketing disadvantage as it provides customers visua: informati $\eta_{\text {. }}$.

Source: Violanti, 1988

4. Facsimile Machines: This innovation is viewed as the greatest telemarketing advancement in recent years. It allows immediate delivery of hard copy documents to any location around the world via regular telephone lines. The FAX is effective in providing literature as 'followup to sales calls, reducing the sales cycle and resolving billing problems.

5. Integrated Services Digital Network (ISDN): These digital lines are currently replacing analog phone systems. ISDN will offer the capability to speak, transmit a FAX and send compuier data or video simultaneously over one telephone line. This will allow a telemarketing rep to send a F IX while speaking with a prospec', permitting almost instantaneous r esponse to queries. Productivity should increase as this will place several functions at a telemarketer's fingertios.

Source: Waddill, 1990 


\section{APPENDIX D}

\section{DIFFERENCES BETWEEN CONSUMER AND INDUSTRIAL. TELEMARKETING}

\section{Consumer Telemarketing}

* generally part-time telemarketers * must usually close the sale on the first contact

* generally usc one type of telemarketing only

(i.e. selling)

*calls cost less than industrial telemarketing

* generally sales are of low dollar value

* generally sales are lower in volume

* lower margins / lower profits

* eaci, household has an equal potential of being contacted

* no sales force to work with the telemarketers

*no relationship building

* control procedures less elaborate

"utilize "verbatim" scripts (allows for little flexibility)

*telemarketers paid less

* telemarketers do not require extensive product knowledge because they are usually selling only one product line

* must not try as hard to handle objections (have an unlimited number of prospects)

*need less customer information

* call lists usually consist of telephone books or other public sources

* dollar risks are less (lost customer represents insignificant volume potential)

* sell to general public

\section{Industrial Telemarketins}

*generally full-time telemarketers * requires at least fise contacts to close a sale

* uses a variety of telemarketing types (i.e. profiling. prospecting. selling, qualifying. and servicing)

* calis cost more than consumer telemarketing

* generally sales are of high

dollar value

* generally sales are higher in volume

*higher margins / higher profits

*an rank large and small customers by sales potential

*a sales force can work with the telemarketers

* relationship building

* control procedures more elaborale

*use "guided" scripts (allows for flexibility)

*telemarketers paid more

* telemarketers require more extensive product knowledge because usually seliing more than one product line

* must try harder to handle objections (have a limited number of prospects)

* need more customer information

* better call lists of potential customers because they are proprietary in nature

* greater risk (lost customer represents significant volume potential)

* sell to targeted businesses

Source: Pope, 1981

*customers purchase for themselves

*one person involved in the purchase decision only

*old frontier of telemarketing

* customer more willing to be flexible on product specifications
* customers purchase for others * more people usually involved in the purchase decision * new frontier of telemarketing

* customer less willing to be flexible on product specs. 


\section{APPENDIX D (cont.) \\ DIFFERENCES BETWEEN CONSUMER AND INDUSTRIAL TELEMARKETING}

\section{Consumer Telemarketins}

*customers more mobile

*individual selling

*refer technical inquiries elsewhere

* products generally less complex * telemarketers less motivated in their work

*spend less time on an individual

calt ( $1-2$ minutes)

* little career opportunities available

\author{
Industrial Telemarketing \\ * customers less mobile \\ * team selling \\ *handle technical inquiries \\ themselves \\ * products generally more complex \\ *telemarketers show more \\ motivation in their work \\ *spend more time on an individual \\ call (up to 10 minutes or longer) \\ * career opportunities are greater
}

Source: Domine, 1989

*telemarketers generally make outbound calls only *telemarketers generally perform both inbour ${ }^{+}$and outbound telemarketing

Source: Wingis, 1981

*advertise products over radio, T.V. newspapers to a greater extent - $100 \%$ customers make up $100 \%$ sales *no bidding process

* no special characteristics to the orders

* same product/service price for all customers

*negotiation process not long
* do not advertise products over radio, T.V, newspapers often * $20 \%$ customers make up $80 \%$ sales

* may iequire a bidding process "arders inay have unique design. delivery, and quality features * many contracts are individually priced for the customer *may be a long negotiation process

Source: Raymond, 1976

*more turnover; employs financialoriented telemarketer

* conducted, often times, during evenings and weekends *less turnover; employs a more professional, career-oriented telemarketer

*conducted during business hours only 


\section{APPENDIX E}

\section{SAMPLE MAIL QUESTIONNAIRE}

May 1990

Dear (company name) Customer,

On behalf of (company name), I am conducting a survey to measure the appropriateness and level of customer satisfaction with the companys telemarketing service. We want to get your views.

Your opinions are very important to us, therefore, we hope that you will answer every question with complete candor. Most questions can be answered with a checkmark or circle. The survey should take about fifteen minutes to complete. When you are finished, please return the completed questionnaire in the selfaddressed postage-paid envelope provided.

In appreciation of your time and effort, we will be sending a summary of the analysis to all customers who respond by May 31, 1990. Should you have any questions about the survey, please do not hesitate to call me at (613) 2.31-7852 or (613) 788-2395. Thank you for your cooperation.

Sincerely,

John Barton 


\section{TELEMARKETING MAIL QUESTIONNAIRE}

The information we receive from our customers will allow us to continue to enhance the service of our department. Please indicate any changes to your mailing address on the label below.

\section{Section I:}

In this section, we are interested in finding out your views on the usage of our service.

Directions: Please mark your answers to the following questions or fill in the blanks where required.

1. Approximately when were you last contacted by a company telemarketing representative?

$\begin{array}{cccccc}\begin{array}{c}\text { Less than } 2 \\ \text { weeks ago }\end{array} & \begin{array}{c}2 \text { to } 4 \\ \text { weeks ago }\end{array} & \begin{array}{c}4 \text { to } 6 \\ \text { weeks ago }\end{array} & \begin{array}{c}6 \text { to } 8 \\ \text { weeks ago }\end{array} & \begin{array}{c}\text { over } 8 \\ \text { weeks ago }\end{array} & \begin{array}{c}\text { Never } \\ \text { Contacted Before }\end{array} \\ \text { [ ] } & \text { [ ] } & \text { [ ] } & \text { [ ] } & \text { I ] }\end{array}$

2. How often would you like to hear from a company telemarketing representative?

Once every

2 weeks

[ ]

\section{Once a Once every month two months}

Once every three months
Other (please specify) Never

[ ]

\section{[]}

3. How much advarice notice do you require for company seminars and workshops?

One week Two weeks One month Six weeks (please specify) this service

II

$1]$

[]

I]

[ I 
4. Have you been receiving the company's mailings?

[ ] YES [] NO

5. Have you used the company's 1-800\#?

[ ] YES [] NO

If YES, for what reason(s)? (mark all that apply)

1. [1 TO PLACE ORDERS FOR COMPANY PROIDUCTS

2. II TO PLACE ORDERS FOR COMPANY SERVIC TES

3. [] TO GET PRODUCT INFORMATION

4. [i TO GET COURSE INFORMATION

5. [I TO GET PRODUCT RELEASE INFORMATION

6. [I TO ARRANGE FOR DEMONSTRATIONS/TRIAIS

7. I] AS A COMMUNICATION LINK WITH (OTHIER COMPANY PI:RSONNIII.

8. [] OTHER (please specify)

Which reason is most important?

Which reason is least important?

\#

6. Have you purchased any (company) products or services?

[ ] YES [ [ NO

7. Please mark the products or services you and/or your company have purchased and if the purchase was made through our telemarketing de partment.

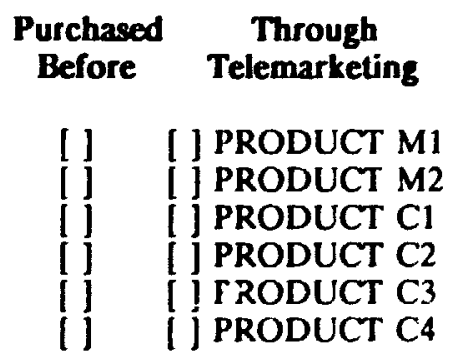

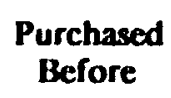

$\left[\begin{array}{l}] \\ {[} \\ \vdots \\ {[} \\ 1\end{array}\right]$

\section{Through \\ Telemarketing}

I I PRODUCT C.5

I ] PRODUCT C6

I I PRODUCT SI

I J PRODUCT S2

I j PRODUCT $\mathrm{S3}$

I OTHIR (please specify) 
8. Are there any company products or services that you would like to have more information about?

I I YES | | NO

If YES. please specify

9. List the top 3 factors that determine whether you would purchase a product or service through our telemarketing department?

1

2.

3.

10. Under what circumstances would you place a dollar limit on a telephone purchase of a (company) product or service? (mark a box and fill in the blanks where applicable)

( ) WOULD NOT PURCHASE COGNOS PRODUCTS OVER THE TELEPHONE

[ ] FIRST-TIME PURCHASES ONLY

Amount S

(] ALL TELEPHONE PURCHASES

Amount $S$

[ ] UNDER NO CIRCUMSTANCES

| / OTHER (please specify) 
Directions: Please circle your responses to the following questions.

11. How important are demonstrations to you for the following (company) products?

PRODUCT MI

- for first-time purchases

- for additional purchases

PRODUCT M2

-for first-time purchases

-for additional purchases

PRODUCT CI

- for first-time purchases

- for additional purchases

PRODUCT C2

-for first-time purchases

-for additional purchases

PRODUCT C3

-for first-time purchases

-for additional purchases

PRODUCT C4

-for first-time purchases

-for additional purchases

PRODUCT C5

- for first-time purchases

-for additional purchases

PRODUCT C6

-for first-tince purchases

-for additional purchases

PRODUCT S1

-for first-time purchases

-for additional purchases

PRODUCT S2

-for first-time purchases

-for additional purchases

PRODUCT S3

-for first-time purchases

-for additional purchases

OTHER (please specify)

Esse

5

Essentia

5

5

5

5

5

5

5

5

5

5

\section{5}

5

5

5

5

5

5
Important

4

4

4

3

3

3

3

3

3

Not

Important

Wate of

Time

$?$

1

2

2

4

2

2

3

3

2

4

4
4

3

3

2

3

3

2

2

3

3

\section{2}

2

3

3

2

3

3

2
2

3

3

2

2

3

3
2

2
- for first-time purchases -for additional purchases 
12. In your opinion, how appropriate is the use of telemarketing for purchases of the following company products?

Not Very

PRODUCT MI

-for first-time purchases

-for additional purchases

PRODUCT M2

- for first-time purchases

- for additional purchases

PRODUCT CI

- for first-time purchases

-for additional purchases

PRODUCT C2

- for first-time purchases

- for additional purchases

PRODUCT C3

- for first-time purchases

- for additional purchases

PRODUCT C4

- for first-time purchases

- for additional purchases

PRODUCT C5

- for first-time purchases

-for additional purchases

PRODUCT C6

-for first-time purchases

-for additional purchases

PRODUCT SI

-for first-time purchases

- for additional purchases

PRODUCT S2

- for first-time purchases

- for additional purchases

PRODUCT S3

- for first-time purchases

- for additional purchases

OTIHER (please specify)

-for first-time purchases - for additional purchases

\section{Appropriate}

Appropriate Indifferent

5

5

4

3

3

5

5

4

3

3

Inappropriate

Inappropriate

5

5

4

3

3

2

1

1

5

5

4

3

3

2

2

4

5

5

4

3

3

2

4

4
4

3

5

5

5

5

5

5

5

5

5

5

5

5

5
4

4
4
4

4
4

4
4

4

4

4

4
3

3
1

1

1

1

1

1

1

1

1

1

1

1

1 


\section{Section II:}

In this section, we are interested in finding out your views aloout the level of service provided. We hope that your perceptions will allow us to assess how well we are doing and identify areas for improvement.

13. Directions: Please rate the telemarketing department on the following service attributes. Circle your importance and satisfaction level (or mark N/A) for each item.

\begin{tabular}{|c|c|c|c|}
\hline & IMPORTANCE & \multicolumn{2}{|l|}{ SATISFACTION } \\
\hline & low high & low high... & $. \mathbf{N} / \mathbf{A}$ \\
\hline 1. Convenience & 012345678910 & 012345678910 & | | \\
\hline 2. Speed filling your requests & 012345678910 & 012345678910 & 11 \\
\hline 3. Ability to speak clearly & 012345678910 & 012345678910 & 11 \\
\hline 4. Listening to your concerns & 012345678910 & 012345678910 & | I \\
\hline 5. Understanding your needs & 012345678910 & 012345678910 & | | \\
\hline $\begin{array}{l}\text { 6. Knowledge of company } \\
\text { products }\end{array}$ & 012345678910 & 012345678910 & 11 \\
\hline $\begin{array}{l}\text { 7. Knowledge of competitive } \\
\text { products }\end{array}$ & 012345678910 & 012345678910 & | | \\
\hline 8. Ability to answer questions & 012345678910 & 012345678910 & I I \\
\hline 9. Quality of advice given & 012345678910 & 012345678910 & | | | \\
\hline 10. Courtesy extended to you & 012345678910 & 012345678910 & | I \\
\hline $\begin{array}{l}\text { 11. Accuracy of shipment } \\
\text { order }\end{array}$ & 012345678910 & 012345678910 & | | \\
\hline 12. Shipment timeliness & 012345678910 & 012345678910 & 11 \\
\hline 13. Updates of order status & 012345678910 & 012345678910 & $|1|$ \\
\hline 14. Regularity of contact & 012345678910 & 012345678910 & 11 \\
\hline $\begin{array}{l}\text { 15. Keeping you informed of } \\
\text { new products and } \\
\text { promotions }\end{array}$ & 012345678910 & 012345678910 & I I \\
\hline $\begin{array}{l}\text { 16. Ability to handle } \\
\text { complaints }\end{array}$ & 012345678910 & 012345678910 & 11 \\
\hline $\begin{array}{l}\text { 17. Communication link to } \\
\text { other company personnel }\end{array}$ & 012345678910 & 012345678910 & 11 \\
\hline
\end{tabular}



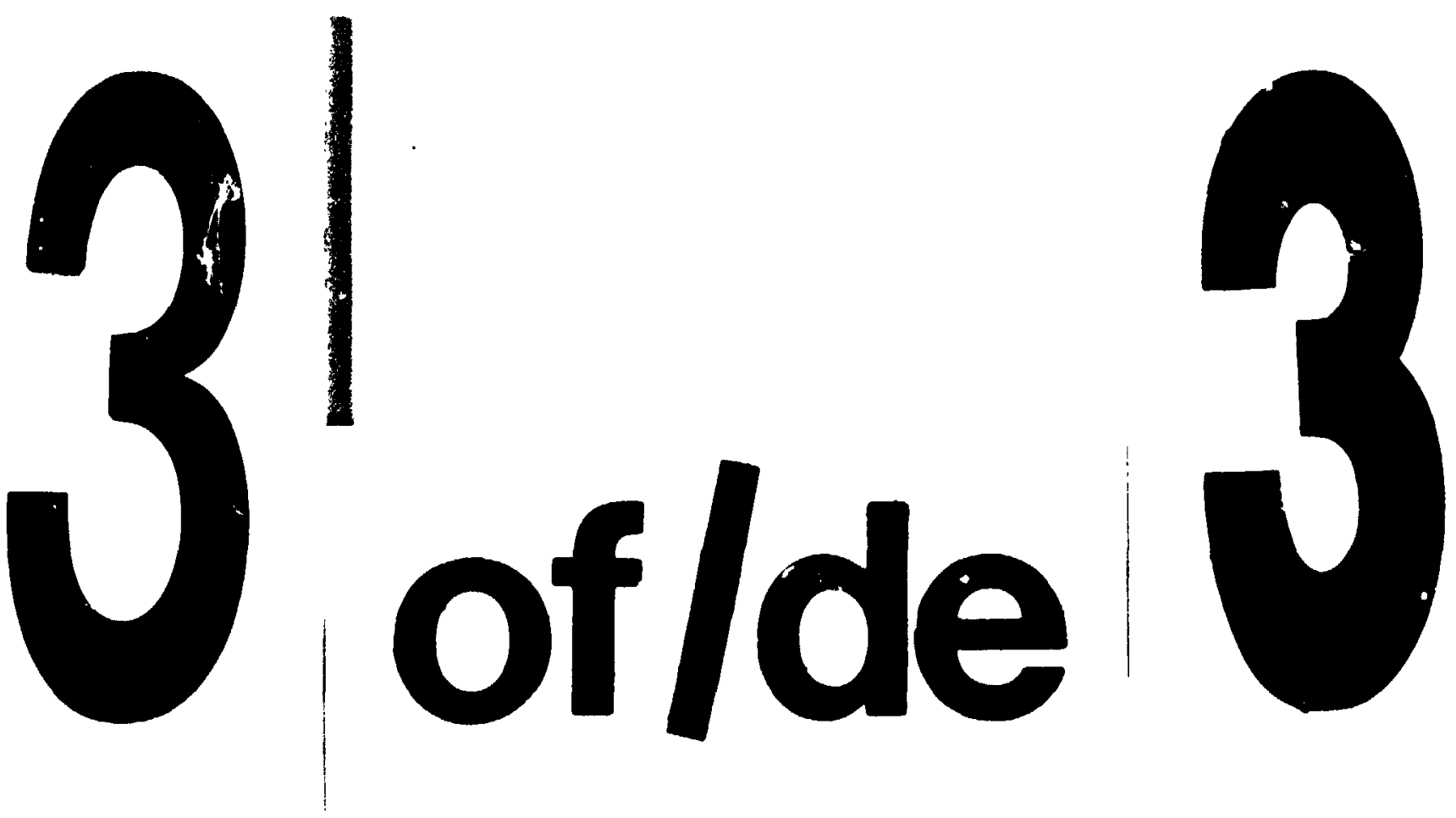

PM-1 31/2"X 4" PHOTOGRAPHIC MICROCOPY TARGET NBS 1010a AMSI/ISO "2 EQUIVALENT

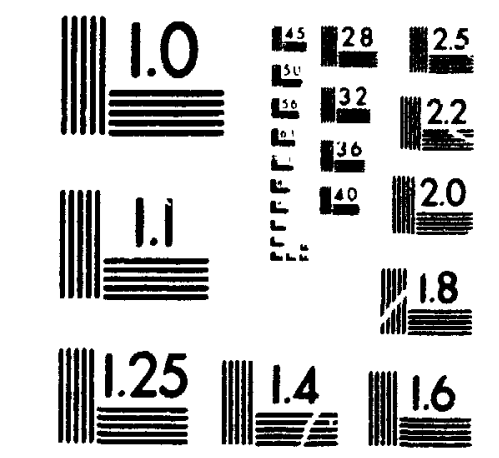

PRECISIONSM RESOLUTION TARGETS

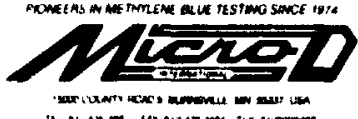


Directions: Please circle your responses to the following questions.

14. Satisfaction with the company's telemarketing department compared to your expectations?

$\begin{array}{ccccc}\begin{array}{c}\text { very } \\ \text { satisfied }\end{array} & \text { satisfied } & \text { indifferent } & \text { dissatisfied } & \begin{array}{c}\text { very } \\ \text { dissatisfiad }\end{array} \\ 5 & 4 & 3 & 2 & 1\end{array}$

15. Willingness to recommend the company's telemarketing department to business associates within your company?

$\begin{array}{ccccc}\begin{array}{c}\text { very } \\ \text { willing }\end{array} & \text { willing } & \text { indifferent } & \text { unwilling } & \begin{array}{c}\text { very } \\ \text { unwilling }\end{array} \\ 5 & 4 & 3 & 2 & 1\end{array}$

16. Willingness to recommend the company's telemarketing department io business associates outside your company?

$\begin{array}{ccccc}\begin{array}{c}\text { very } \\ \text { willing }\end{array} & \text { willing } & \text { indifferent } & \text { unwilling } & \begin{array}{c}\text { very } \\ \text { unwilling }\end{array} \\ 5 & 4 & 3 & 2 & 1\end{array}$

17. Overall satisfaction with the telemarketing department for purchases of the company's products?

$\begin{array}{ccccc}\begin{array}{c}\text { very } \\ \text { satisfied }\end{array} & \text { satisfied } & \text { indifferent } & \text { dissatisfied } & \begin{array}{c}\text { very } \\ \text { dissatisfiud }\end{array} \\ 5 & 4 & 3 & 2 & 1\end{array}$

18. Gverall satisfaction with the telemarketing department for purchases of the company's services?

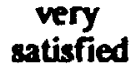

5 satisfied

4 indifferent

3 dissatisfied

2

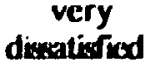




\section{Section III:}

In this section, we are interested in finding out more about our business customers who use our telemarketing service.

Directions: Please mark your answers to the follou :ng questions.

19. What is the nature of your business?

I I AGRICULTURE, FORESTRY, FISHERIES, MINING

[ ] CONSTRUCTION

[] TRANSPORTATION

I EDUCATIONAL, SERVICES

I] ACCOUNTING SERVICES

[ ] NON-PROFIT ORGANIZATION

i ] ELECTRIC, GAS, SANITARY SERVICES

I] RETAIL TRADE

[] INSURANCE/REAL ESTATE

[ ] HEALTH SERVICES

[] MANUFACTURING

[] COMMUNICATIONS

[] GOVERNMENT

[] FINANCE/BANKING

[ ] WHOLESALE TRADE

[ ] OTHER (please specify)

20. Approximately how many people are employed at your company?

I ] UNDER 25 PEOPLE
I $25-50$ PEOPLE
I ] $51-100$ PEOPLE
I ] 101-250 PEOPLE

[1] 251-500 PEOPLE

[] 501-1000 PEOPLE

[] 1001-5000 PEOPLE

[ ] OVER 5000 PEOPLE

21. Which of the following best describes your functional position within your company?
[ ] MIS DIRECTOR
i DP MANAGER
I I PURCHASING AGENT
[ ] SYSTEMS ANALYST
[] SENIOR PROGRAMMER
[ ] OTHER (please specify)

22. How many years have you been in the workforce fulltime?
I I UNDER 5 YEARS
1 5 TO 10 YEARS
I 11 TO 15 YEARS

[] 16 TO 20 YEARS
[] 21 TO 25 YEARS
[] OVER 25 YEARS

23. How many times in the last year have you purchased products or services via telemarketing?
[ ] NONE
[ ] ONCE
[ ] TWICE
[ ] THREE TIMES

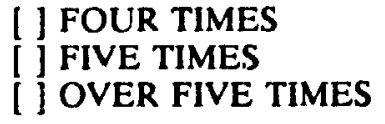




\section{COMMENTS:}

If you would like to make any additional comments about the company's telemarketing department or have any suggestions for improving customer service. please write them in below.

THANK YOU FOR YOUR PARTICIPATION IN THE SURVIEY. YOUR ASSISTANCE IS GREATLY APPRECIATED

Would you like to be contacted by a company representative to further discuss any aspect of this survey?

$$
\text { [ ] YES I] NO }
$$

If you indicated that you would like to be contacted by a company representative, please fill in your phone number below.

Phone Number: $(1$, 


\section{APPENDIX F}

\section{SAMPLE TELEPHONE SURVEY}

Name:

Company:

Region:

Hello Mr. (Ms.) - This is John Barton calling from (company name) in Ottawa. We are conducting brief telephone interviews with our customers to get their views regarding the telemarketing of (company name) products and with the service of our telemarketing department. With this, we hope to better understand how customers feel about purchasing (company name) products and services over the telephone. Since you have spoken with a (company name) telemarketing representative, your comments are of particular interest to us. Therefore, it would be greatly appreciated if you could answer some questions regarding this service. It should take approximately fifteen minutes. If you currently do not have the time, may I call you back at a time which is more convenient.

\section{QUESTIONNAIRE STATUS}




\section{TELEMARKETING TELEPHONE SURVEY}

1. Approximately when did you last speak with a (company name) telemarketing representative?

UNDER TWO WEEKS AGO

ONE MONTH AGO

SIX WEEKS AGO

TWO MONTHS AGO

THREE MONTHS AGO

FOUR MONTHS AGO

SIX MONTHS AGO

ONE YEAR AGO

NEVER

OTHER,

DON'T KNOW/NO OPINION

REFUSAL

1177

MISSING

I 188

1199

2. How often would you like is hear from a (company name) telemarketing representative?

ONCE EVERY TWO WEEKS

| | 01

ONCE EVERY MONTH

ONCE EVERY SIX WEEKS

ONCE EVERY TWO MONTHS

ONCE EVERY THREE MONTHS

I 02

I 0.3

ONCE EVERY FOUR MONTHS

I 04

I 05

ONCE EVERY SIX MONTHS

I (6)

ONCE EVERY YEAR

I 107

NEVER

I 08

WHENEVER NEW INFORMATION

I 09

BECOMES AVAILABLE

I WILL INITIATE THE CALL

OTHER,

1] 10

I) II

12 and up

DON'T KNOW/NO OPINION

[1] 77

REFUSAL

MISSING

I 88

j 99 
3. Which (company name) products or services has your company purchased?

4. Were you directly involved in the purchase(s)?

5. Was it a first-time or subsequent purchase (i.e. upgrade) of the product/service?

6. How was (were) the purchase(s) marle? Was it through a (company name) telemarketing representative (TR) only?; through a sales representative (SR) only?; through a combination (CO) of the two?; or through a third party distributor (D)?

3.

4.

5.

6.

$\begin{array}{lcc}\text { PURCHASED INVGI.VED } & \begin{array}{c}\text { PURCHASE } \\ \text { TYPE }\end{array} & \begin{array}{c}\text { PURCHASE } \\ \text { METHOD }\end{array}\end{array}$

$\begin{array}{lcccccccccccc}\text { Mainline Products } & 1 & 0 & 1 & 0 & 1 & 2 & 7 & 1 & 2 & 3 & 4 & 7 \\ \text { PRODUCT M1 } & \text { YES } & \text { NO } & \text { YES } & \text { NO } & \text { F } & \text { S } & \text { U } & \text { TR } & \text { SR } & \text { CO } & \text { D } & \text { U } \\ \text { PRODUCT M2 } & \text { YES } & \text { NO } & \text { YES } & \text { NO } & \text { F } & \text { S } & \text { U } & \text { TR } & \text { SR } & \text { CO } & \text { D } & \text { U }\end{array}$

Complementary

Products

$\begin{array}{lllllllllllll}\text { PRODUCT C1 } & \text { YES } & \text { NO } & \text { YES } & \text { NO } & \text { F } & \text { S } & \text { U } & \text { TR } & \text { SR } & \text { CO } & \text { D } & \text { U } \\ \text { PRODUCT C2 } & \text { YES } & \text { NO } & \text { YES } & \text { NO } & \text { F } & \text { S } & \text { U } & \text { TR } & \text { SR } & \text { CO } & \text { D } & \text { U } \\ \text { PRODUCT C3 } & \text { YES } & \text { NO } & \text { YES } & \text { NO } & \text { F } & \text { S } & \text { U } & \text { TR } & \text { SR } & \text { CO } & \text { D } & \text { U } \\ \text { PRODUCT C4 } & \text { YES } & \text { NO } & \text { YES } & \text { NO } & \text { F } & \text { S } & \text { U } & \text { TR } & \text { SR } & \text { CO } & \text { D } & \text { U } \\ \text { PRODUCT C5 } & \text { YES } & \text { NO } & \text { YES } & \text { NO } & \text { F } & \text { S } & \text { U } & \text { TR } & \text { SR } & \text { CO } & \text { D } & \text { U } \\ \text { PRODUCT C6 } & \text { YES } & \text { NO } & \text { YES } & \text { NO } & \text { F } & \text { S } & \text { U } & \text { TR } & \text { SR } & \text { CO } & \text { D } & \text { U } \\ \text { PRODUCT C7 } & \text { YES } & \text { NO } & \text { YES } & \text { NO } & \text { F } & \text { S } & \text { U } & \text { TR } & \text { SR } & \text { CO } & \text { D } & \text { U } \\ \text { PRODUCT C8 } & \text { YES } & \text { NO } & \text { YES } & \text { NO } & \text { F } & \text { S } & \text { U } & \text { TR } & \text { SR } & \text { CO } & \text { D } & \text { U }\end{array}$

Service Products:

$\begin{array}{lllllllllllll}\text { PRODUCT SI } & \text { YES NO } & \text { YES NO } & F & S & U & T R & \text { SR } & C O & D & U\end{array}$

$\begin{array}{lllllllllllll}\text { PRODUCT S2 } & \text { YES NO } & \text { YES NO } & \text { F } & S & U & \text { TR } & \text { SR } & C O & D & U\end{array}$

$\begin{array}{lllllllllllll}\text { PRODUCT S3 } & \text { YES NO } & \text { YES } & \text { NO } & F & S & U & \text { TR } & \text { SR } & \text { CO } & \text { D } & U\end{array}$

$\begin{array}{lllllllllllll}\text { PRODUCT S4 } & \text { YES NO } & \text { YES NO } & F & S & U & \text { TR } & \text { SR } & \text { CO } & D & U\end{array}$ 
7. Would you ever consider purchasing (company name) products or services solely over the telephone? (Your answer will not be used for siles purposes)

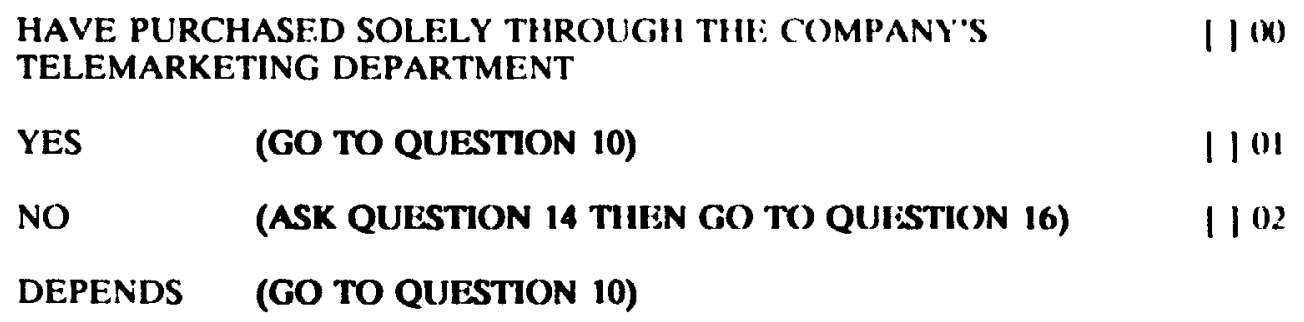

DON'T KNOW/ NO OPINION(GO TO QUIZSTION 10)

REFUSAL

(GO TO QUHSTION 16) 
8. On a scale of one to five where one is very dissatisfied and five is very satisfied, how would you rate your overall satisfaction using telemarketing for purchasing (company name) products? (e.g. products M1, M2 and C1 through C8).

HAVE NEVER HURCHASED ANY (COMPANY NAME) PRODUCTS $[10$ AND SFRVICES OVER THE TELEFHONE

VERY DISSATISFIFD

DISSATISFIED

INIIFFERENT [] 3

SATISFIED 1$] 4$

VERY SATISFIED I] 5

HAVE ONLY PURCHASED̃ (COMPANY NAME) SERVICES OVER THE [ ] 6 TELEPHONE

DON'T KNOW/NO OPINION [] 7

HAVE NOT AND WILL NOT PURCHASE (COMPANY NAME) [ 8

PRODUCTS AND SERVICES OVER THE TELEPHONE

MISSING 1$] 9$

9. On a scale of one to five where one is very dissatistied and five is very satisfied, how would you rate your overall satisfaction usirg telemarketing for purchasing (company name) services? (e.g. products S1 through S4)

HAVE NEVER PURCHASED ANY (COMPANY NAME) PRUDUCTS [ ] 0 AND SERVICES OVER THE TELEPHONE

VERY DISSATISFIED [ ]1

DISSATISFIED [ ] 2

INDIFFERENT [ ] 3

SATISFIED

VERY SATISFIED [] 5

HAVE ONLY PURCHASED (COMPANY NAME) PRODUCTS OVER THE [ ] 6 TELEPHONE

DON'T KNOW/NO OPINION [ ] 7

HAVE NOT AND WILL NOT PURCHASE (COMPANY NAME)

PRODUCTS AND SERVICES OVER THE TELEPHONE

MISSING 
With the next group of questions, we would like to know more about the purchase circumstances you feel the use of the telephone is most appropriate. All that I require is that you answer each que stion with a rating of either low. medium or high.

10a. For first-time purchases of (company name) mainline products such as products $M 1$ and $M 2$, how uould you rate the approprialeness of using telephone sales only?

$\begin{array}{ll}\text { LOW } & \\ \text { MEDIUM } & 1 \\ \text { HIGH } & \\ \text { DON'T KNOW/NO OPINION } & \\ \text { HAVE NOT AND WILI. NOT PURCHASE (COMPANY NAMI:) } \\ \text { PRODUCTS AND SERVICES OVER THE TEIEPHIONI: } \\ \text { MISSING }\end{array}$

10b. Also for first-time purchases of the mainline products, how nould you rate the importance of product demonstrations?

$\begin{array}{ll}\text { LOW } & \\ \text { MEDIUM } & \\ \text { HIGH } & \\ \text { DONT KNOWINO OPINION } & \\ \text { HAVE NOT AND WILL NOT PURCHASE (COMPANY NAMI:) } \\ \text { PRODUCTS AND SERVICIS OVEK TIIE TEI.EPIIONE: } \\ \text { MISSING }\end{array}$

10c. For subsequent purchases (i.e. upgrades) of the mainline products, how would you rate the appropriateness of using telephone sales only?

\begin{tabular}{|c|}
\hline $\begin{array}{l}\text { LOW } \\
\text { MEDIUM } \\
\text { HIGH } \\
\text { DON'T KNOW/NO OPINION } \\
\text { HAVE NOT AND WILL NOT PURCHASE (COMPANY NAMI:) } \\
\text { PRODUCTS AND SERVICES OVER THE TEIIEPIICNI: } \\
\text { MISSING }\end{array}$ \\
\hline
\end{tabular}

10d. Also for subsequent purchases (i.e. upgrades) of the mainline products, how would you rate the importance of product demonstrations?

\begin{tabular}{ll} 
LOW & 1 \\
MEDIUM & 1 \\
HIGH & 1 \\
DON'T KNOW/NO OPINION & 1 \\
HAVE NOT AND WILL NOT PURCHASE (COMPANY NAME) & \\
PRODUCTS AND SERVICES OVER TIE TELEPIONE & 1 \\
MISSING & $1 \%$ \\
\hline
\end{tabular}


11a. For first-time purchases of (company name) add-on or complementary products such as products $\mathrm{C} 1$ through $\mathrm{C8}$, how would you rate the appropriateness of usine telephone sales only?

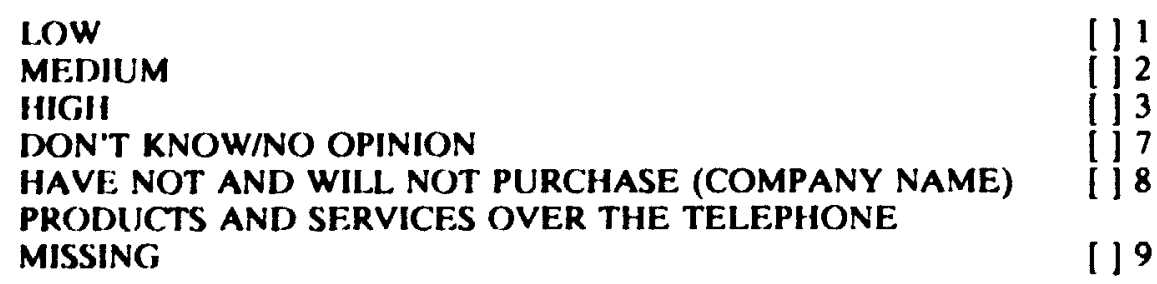

11h. Also for first-time purchases of add-on or complementary products, how would you rate the importance of product demonstrations?

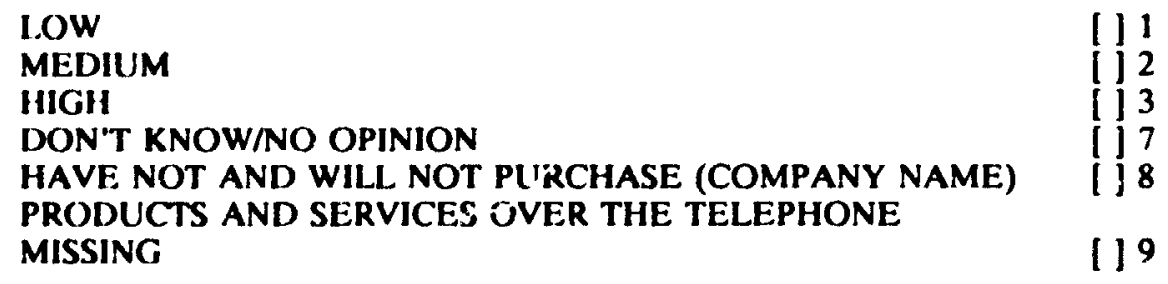

11c. For subequent purchases (i.e. upgrades) of add-on or complementary products, how would you rate the appropriateness of using telephone sales only?

L.OW

MEDIUM

HIGH

DON'T KINOW/NO OPINION

[] 2

KNOW/NO OPINION

HAVE NOT AND WILL NOT PURCHASE (COMPANY NAME) I j 8

PRODUCTS AND SERVICES OVER THE TELEPHONE

MISSING

[ ] 9

11d. Also for subsequent purchases (i.e. upgrades) of the add-on or complementary products, how would you rate the importance of product úcmonstrations?

$\begin{array}{ll}\text { L.OW } & {\left[\begin{array}{l}1 \\ \text { MEDIUM }\end{array}\right.} \\ \text { HIGH } & 1] 2 \\ \text { DON'T KNOW/NO OPINION } & 1] 3 \\ \text { HAVE NOT AND WILL NOT PURCHASE (COMPANY NAME) } & 1] 7 \\ \text { PRODUCTS AND SERVICES OVER THE TELEPHONE } & 1] 8 \\ \text { MISSING } & 119\end{array}$ 
12a. For first-time purchases of (company name) service products such as products $\mathrm{S} 1$ through $\mathrm{S4}$, how would you rate the appropratteness of using telephone sales only?

$\begin{array}{ll}\text { LOW } & \\ \text { MEDIUM } & 1 \\ \text { HIGH } & \\ \text { DON'T KNOW/NO OPINION } & \\ \text { HAVE NOT AND WILL NOT PURCHIASE (COMPANY NAMII) } \\ \text { PRODUCTS AND SERVICES OVIER THIE TEILPIIONI: } \\ \text { MISSING }\end{array}$

12b. Also for first-time purchases of service products, how would you ralle the importance of product demonstrations?

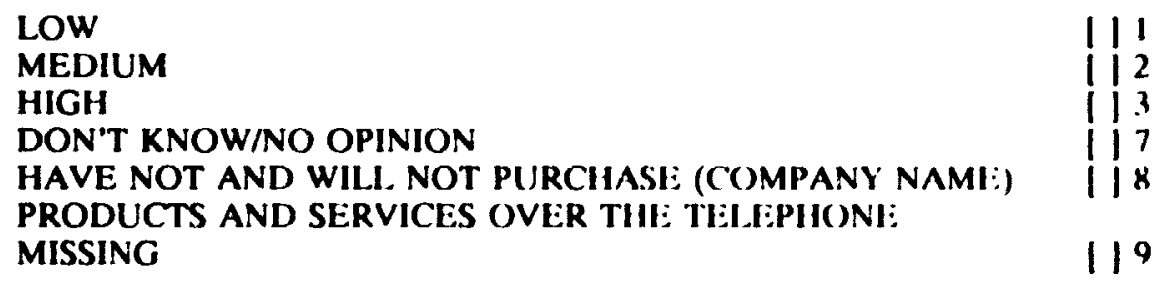

12c. For subsequent purchases (i.e. upgrades) of service products, how would you rate the appropriateness of using telephone sales only?

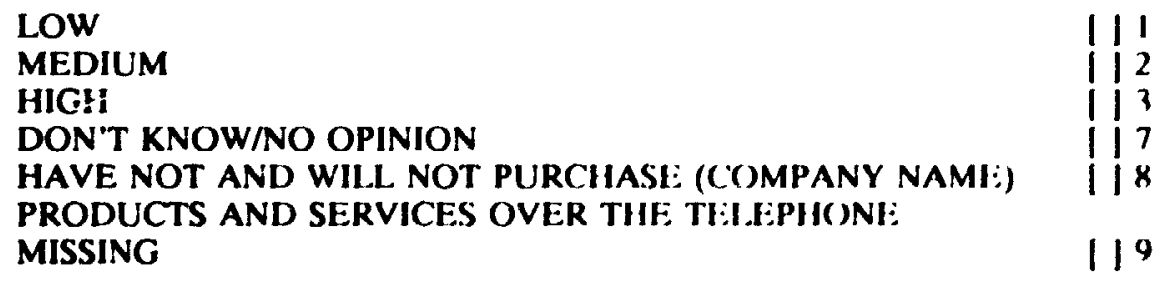

12d. Also for subsequent purchases (i.e. upgrades) of service products, how would you rate the importance of product demonstrations?

LOW

MEDIUM

HIGH

DON'T KNOW/NO OPINION

HAVE NOT AND WILL NOT PURCHASE (COMPANY NAMI:)

PRODUCTS AND SERVICES OVER THE TEIIEPIIONE.

MISSING
111
1) 2
1) 3
117
II 8 
13. What do you see as the most important reason for purchasing (company name) products or services over the telephone?

PRODUCT IS NOT TOO COMPLEX (e.g. a service)

[ ] 0:

PRODUCT PRICE IS NOT TOO HIGH

HAVE PREVIOUS KNOWLEDGE/EXPERIENCE WITH PRODUCT

FAST SERVICE/DELIVERY

PRODUCT REQUIRES NO DEMONSTRATION OR TEST

THE CREDIBILITY OF THE TELESALES REPRESENTATIVE

COMPANY IS STABLE AND CREDIBLE

DON'T HAVE TIME TO SEE A SALES REPRESENTATIVE

NOT AVAILABLE THROUGH LOCAL SALES REPRESENTATIVE

QUALITY SERVICE FROM TELESALES REPS.

EASE OF USE/CONVENIENCE

LIBERAL RETURN/EXCHANGE/MONEY-BACK POLICIES EXIST

PERSONAI. AND FRIENDLY WAY TO DO BUSINESS

OTHER,

DON'T KNOW/NO OPINION

HAVE NOT AND WILL NOT PURCHASE (COMPANY NAME)

PRODUCTS AND SERVICES OVER THE TELEPHONE

MISSING

14. What do you see as the most important reason for not purchasing (company name) products or services over the telephone?

PRODUCT IS TOO COMPLEX (e.g. mainline product)

HIGH PRODUCT PRICE WARRANTS A SALES CALL

NO PREVIOUS EXPERIENCE/KNOWLEDGE WITH PRODUCT

SI,OW SERVICE/DELIVERY

'PRODUCT REQUIRES A DEMONSTRATION OR TEST

[] 03

[ ] 04

TELESALES REPS. ARE NOT VERY CREDIBLE

COMPANY HAS A POOR RE.PUTATION

HAVE THE TIME TO SEE A SALES REPRESENTATIVE

PRODUCT IS AVAILABLE THROUGH LOCAL SALES

[ ] 05

[1] 06

[ ] 07

[ ] 08

REPRESFNTATIVE

[ ] 09

POOR SERVICE FROM TELESALES REPRESENTATIVES

DIFFICULTT TO CONTACT REPRESENTATIVES/INCONVENIENT

[ ] 10

[ ] 11

RETURN/EXCHANGE/MONEY-BACK POLICIES DON'T EXIST

SEEN AS IMPERSONAL WAY TO DO BUSINESS

[ ] 12

OTHER. 
15a. What is the highest dollar amount that you would pay on a first-time telephone purchase of a (company name) product or service?

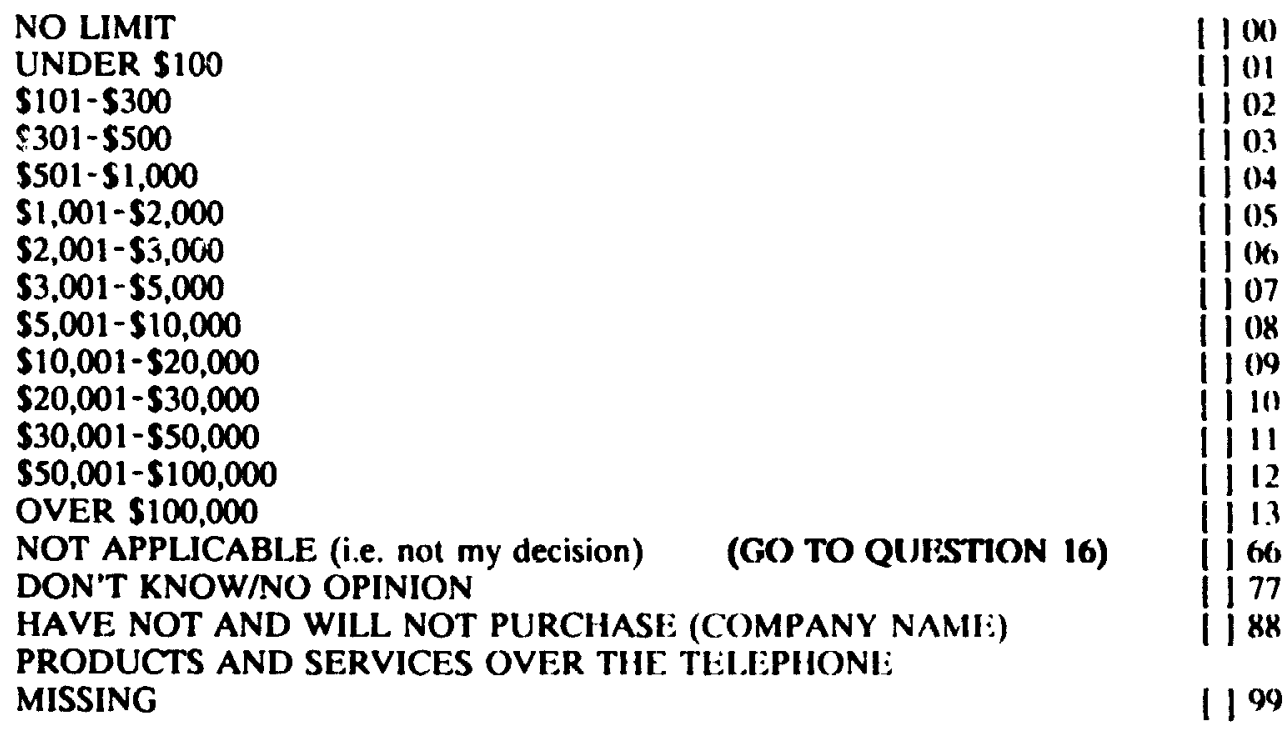

15b. Does this dollar limit depend on any factors?

NO

YES

NOT APPLICABLE (i.e. not my decision)

DON'T KNOW/NO OPINION

HAVE NOT AND WILL NOT PURCIIASE: (COMPANY NAMI:)

PRODUCTS OR SERVICES OVER THE TELEPIIONI:

MISSING

110

11

116

117

II 8

$1 / 9$

15c. What factors does this first-time limit depend on?

DID NOT ANSWER DEPENDS

...ON THE AVAILABLE BUDGET

...ON THE CREDIBILITY OF THE COMPANY

...OUR NEED FOR THE PRODUCT/SERVICE

...ON THE COST OF THE PRODUCT/SERVICE

...ON THE EXPERIENCE WITH (COMPANY NAMł:)

TELEMARKETING

...ON THE EXPERIENCE WITH THE PRODUCT

OR SERVICE

...OTHER,

1 03

1 04

Ijo5

I 106

07 and up

NOT APPLICABLE (i.e. not my decision)

DON'T KNOW/NO OPINION

HAVE NOT AND WILL NOT PURCHASE (COMPANY NAME)

PRODUCTS AND SERVICES OVER THE TELEPHONE

MISSING

1160

I) 77

1188

1199 
15d. What is the highest dollar amount that you would pay on a subsequent telephone purchase ;..e. upgrade) of a (company name) product or service?

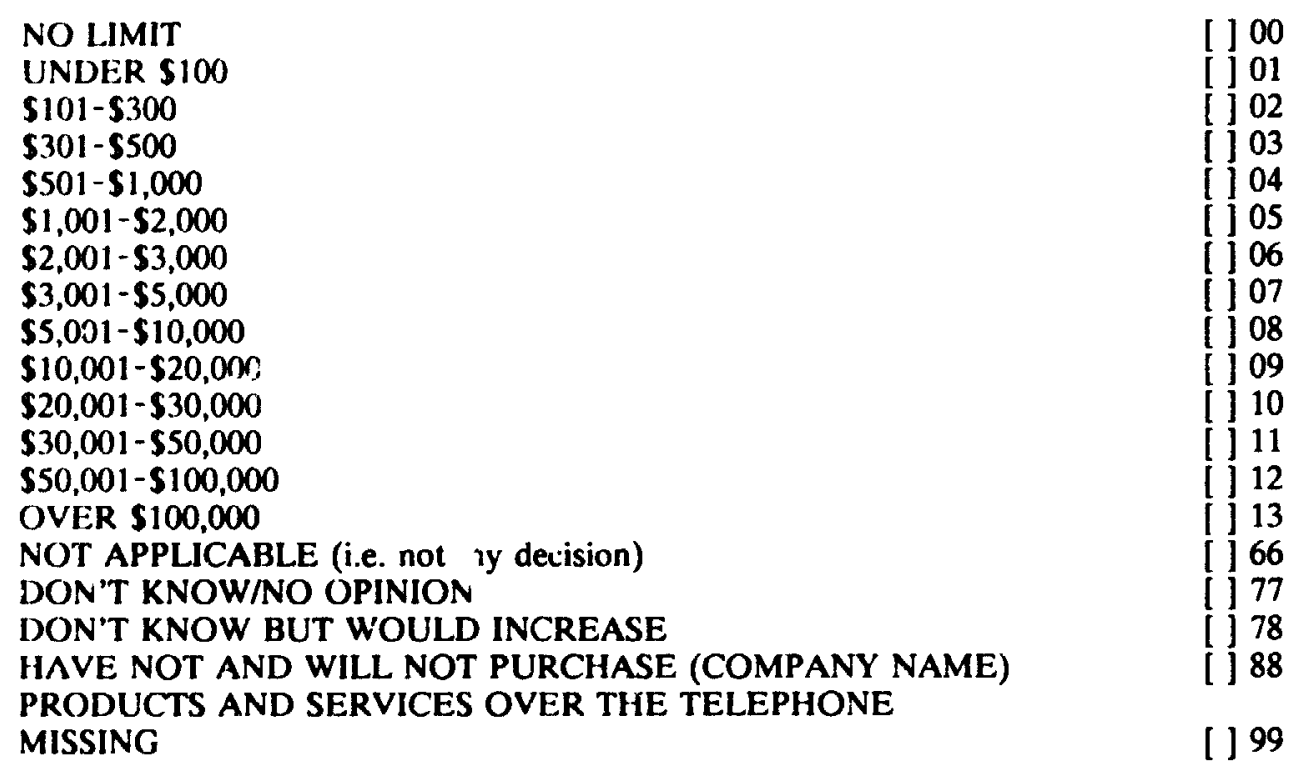

15c. Does this dollar limit depend on any factors?

NO

YES

NOT APPLICABLE (i.e. not my decision)

DON'T KNOW/NO OPINION

HAVE NOT AND WILL NOT PURCHASE (COMPANY NAME) [ ] 8

PRODUCTS OR SERVICES OVER THE TELEPHONE

MISSING

[1]0

[ ] 1

[] 6

[ ] 7

[ ] 9

15f. What factors does the subsequent limit depend on?

DID NOT ANSWER DEPENDS

...ON THE Al'AILABLE BUDGET

...ON THE CREDIBILITY OF THE COMPANY

...OUR NEED FOR THE PRODUCT

...ON THE COST OF THE PRODUCT

.... ON THE EXPERIENCE WITH (COMPANY NAME)

TELEMARKETING

...ON THE EXPERIENCE WITH THE PRODUCT

OR SERVICE

...OTHER,

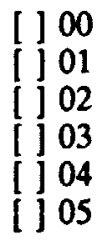

[] 06

07 and up

NOT APPLICABLE (i.e. not my decision)

DON'T KNOW/NO OPINION

HAVE NOT AND WILL NOT PURCHASE (COMPANY NAME)

PRODUCTS AND SERVICES OVER THE TELEPHONE

MISSING 
16. We are interested in finding out your views about the scrvice (company name) telemarketing provides. In doing so, I am going to read a list of service attributes and ask that you rate your satisfaction level with each on a scale of one to five where one is very dissatisfied and five is very satisfied.

\section{SATISFACTION}
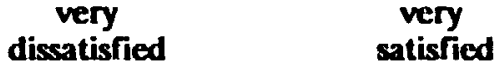

N/A U R $M$

1. Convenience

2. Speed filling your request

$\begin{array}{lll}1 & 2 & 3\end{array}$

45

$\begin{array}{llll}6 & 7 & 8 & 9\end{array}$

$$
1
$$

2

3. Ability to speak clearly

4. Listening to your concerns

5. Understanding your needs

6. Knowledge of (company name) products

7. Knowledge of competitive products

8. Ability to answer questions

9. Quality of advice given

10. Courtesy extended to you

11. Accuracy of shipment order

12. Shipment timeliness

13. Updates of order status

14. Regularity 'ff contact

15. Keeping you informed of new products and promotions

$\begin{array}{lllllllll}\text { 16. Ability to handle complaints } & 1 & 2 & 3 & 4 & 5 & 6 & 7 & 9 \\ \text { 17. } & \begin{array}{l}\text { Communication link to other } \\ \text { (company name) departments } \\ \text { or personnel }\end{array} & 1 & 3 & 4 & 5 & 6 & 7 & 8 \\ \end{array}$

17. What three service attributes are most important to you? I can read the list for you again if you like. 
18. With the same five point scale, would you ple ise rate your satisfaction with the (company name) telemarketing service compared to your expectations?

VERY DISSATISFIED

[1]

DISSATISFIED

[ ] 2

INDIFFERENT

[] 3

SATISFIED

[ ] 4

VERY SATISFIED

[ ] 5

NOT APPLICABLE

[] 6

DON'T KNOW/NO OPINION

[ ] 7

REFUSAL

[ ] 8

MISSING

[ ] 9

19. On a five point scale where one is very unwilling and five is very willing, how would you rate your willingness to recommend (company name) telemarketing to business associates?

VERY UNWILLING

[ ] 1

UNWILLING

[ ] 2

INDIFFEREN:

[ ] 3

WILLING

[] 4

VERY WILLING

[1] 5

NOT APPLICABLE

[] 6

DON'T KNOW/NO OPINION

[ ] 7

REFUSAL

[] 8

MISSING

[] 9 
I have five general questions left to ask. They will help us find out more about our business customers who use (company name) telemarketing.

20. What is the nature of your business?

\begin{tabular}{|c|c|}
\hline D & \\
\hline HEALTH SERVICES & \\
\hline MANUFACTURING & \\
\hline CATIONS & \\
\hline GO & \\
\hline NKING & \\
\hline ION SERVIC & 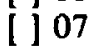 \\
\hline & \\
\hline UTIL & \\
\hline INSI & 05 \\
\hline WHOLESALE, RE & 10 \\
\hline DED RESELI & \\
\hline $\begin{array}{l}\text { CULTURAL } \\
\text { ENTERTAINME }\end{array}$ & \\
\hline
\end{tabular}

\begin{tabular}{|c|c|}
\hline $\begin{array}{l}\text { REALI. ESTATLI } \\
\text { CONSTRUCTION }\end{array}$ & 1112 \\
\hline TRANSPORTATION & 1.3 \\
\hline $\begin{array}{l}\text { EDUCATIONAI. } \\
\text { SERVICES }\end{array}$ & \\
\hline NON-PROFIT & 1115 \\
\hline ORGANIZATION & \\
\hline TOURISM & 1116 \\
\hline & \\
\hline DON'T KNOW & 184 \\
\hline $\begin{array}{l}\text { REFUSAI } \\
\text { MISSING }\end{array}$ & $\left\{\begin{array}{l}88 \\
99\end{array}\right.$ \\
\hline
\end{tabular}

21. Approximately how many people are employed at your company?

$\begin{array}{ll}\text { UNDER 25 PEOPLE } & \text { [ ] } 01 \\ \text { 25-50 PEOPLE } & \text { [ ] } 02 \\ 51-100 \text { PEOPLE } & \text { [ } 03 \\ 101-250 \text { PEOPLE } & \text { [ ] } 04 \\ 251-500 \text { PEOPLE } & \text { [ ] } 05\end{array}$

\begin{tabular}{|c|c|}
\hline & \\
\hline $\begin{array}{l}501-1000 \text { PEOT TE } \\
\text { 1MO1-5000 PI:OPIIE }\end{array}$ & $\begin{array}{l}06 \\
07\end{array}$ \\
\hline OVER 5000 PIXOPI.I: & 08 \\
\hline DON'T KNOW & 77 \\
\hline REFUSAL, & 88 \\
\hline MISSING & \\
\hline
\end{tabular}

22. What was your company's gross dollar revenue for 199()?

$\$$

23. How would you describe your functional position within your company?

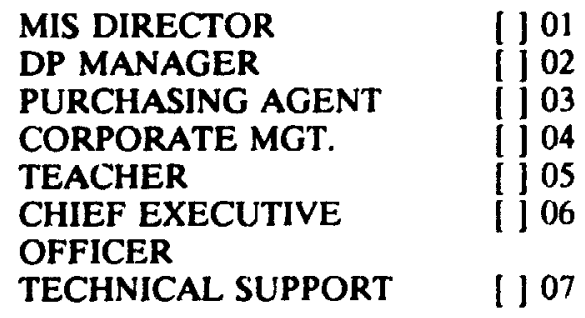

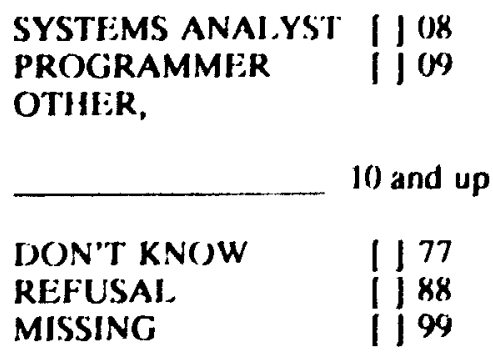


24. How many years have you been in the workforce fulltime excluding school?

$\begin{array}{llll}\text { UNDER 5 YEARS } & {[1]} & \text { 21 TO 25 YEARS } & {[15} \\ \text { 5 TO } 10 \text { YEARS } & {[12} & \text { OVER 25 YEARS } & {[] 6} \\ 11 \text { TO } 15 \text { YEARS } & {[3]} & \text { DON'T KNOW } & {[37} \\ 16 \text { TO } 20 \text { YEARS } & {[] 4} & \text { REFUSAL } & {[38} \\ & & \text { MISSING } & {[] 9}\end{array}$

25. How many times in the last year have you purchased products or services via telemarketing?

$\begin{array}{llll}\text { NONE } & {[1] 0} & \text { FIVE TIMES } & {[1] 5} \\ \text { ONCE } & {[1] 1} & \text { OVER FIVE TIMES } & {[1] 6} \\ \text { TWICE } & {[] 2} & \text { DON'T KNOW } & {[1] 7} \\ \text { THREE TIMES } & {[1] 3} & \text { REFUSAL } & {[] 8} \\ \text { FOUR TIMES } & {[] 4} & \text { MISSING } & {[1] 9}\end{array}$




\section{APPENDIX G \\ LINKAGE OF RESEARCH QUESTIONS, TELEPHONE SURVEY AND DATA ANALYSIS}

I. Research Objective: To document CS/D with industrial telemarketing and determine what factors are related to this satisfaction/dissatisfaction.

\begin{tabular}{l} 
RESEARCH \\
QUESTIONS \\
\hline \\
1) Are business-to-business \\
customers satisfied with the \\
telemarketing of computer \\
software products and \\
services?
\end{tabular}

2) Which telemarketing service factors are most highly associated with CS/D? Which telemarketing service factors are most important to customers when they purchase computer software products and services over the telephone? How similar are these two groups of factors?

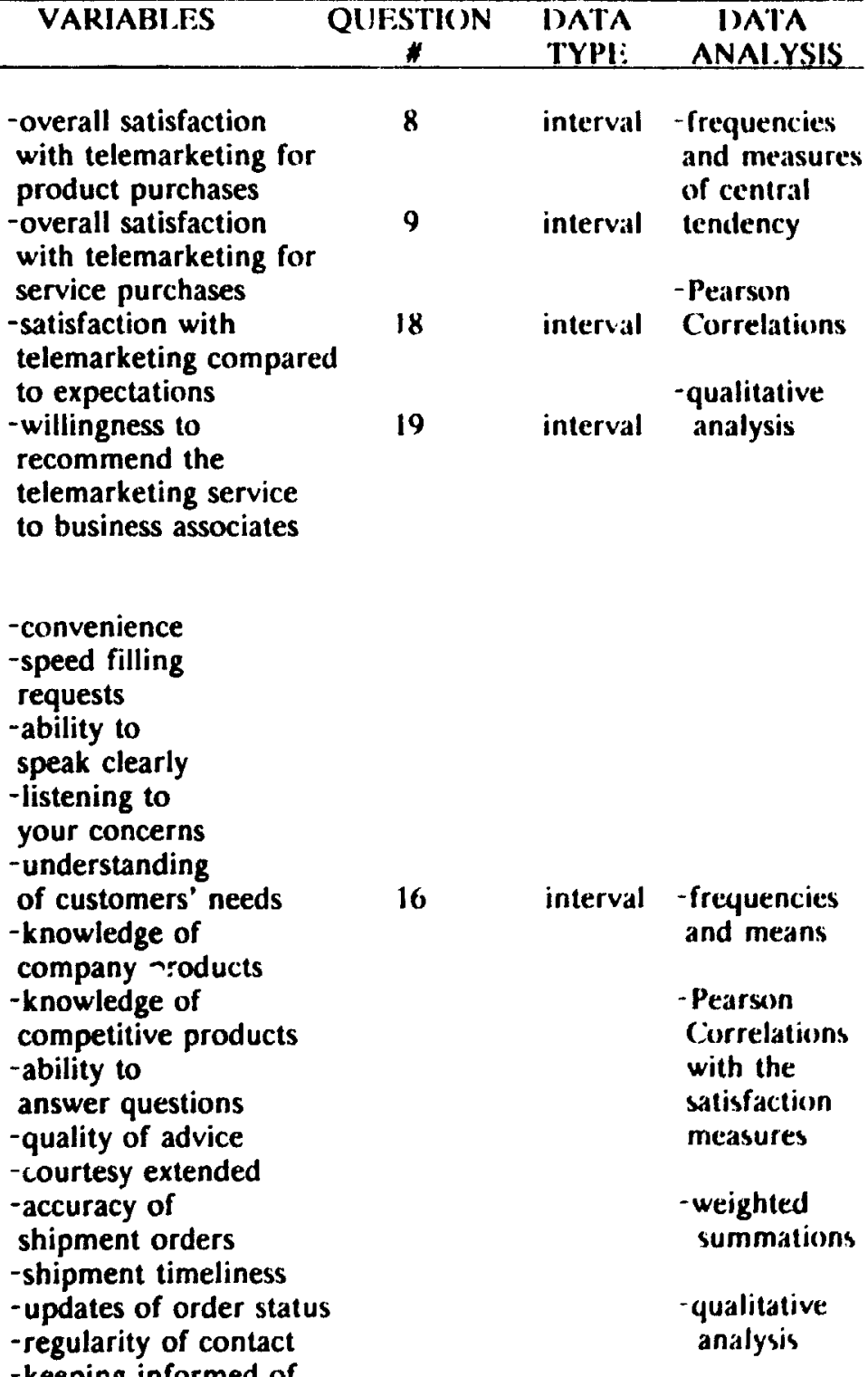

new products and promotions -complaint handling -communication link 


\section{APPENDIX G (cont.) \\ LINKAGE OP RESEARCH QUESTIONS, TELEPHONE SURVEY AND DATA ANALYSIS}

\begin{tabular}{|c|c|c|c|c|}
\hline $\begin{array}{l}\text { RESEA.RCH } \\
\text { OUES:IONS }\end{array}$ & VARIABLES & $\begin{array}{c}\text { QUESTION } \\
\#\end{array}$ & $\begin{array}{l}\text { DATA } \\
\text { TYPE }\end{array}$ & $\begin{array}{c}\text { DATA } \\
\text { ANALYSIS } \\
\end{array}$ \\
\hline $\begin{array}{l}\text { 3) What effect do } \\
\text { customer characteristics } \\
\text { have on overall CS/D with } \\
\text { the telemarketing of } \\
\text { iomputer software products } \\
\text { and services? }\end{array}$ & $\begin{array}{l}\text {-size of the } \\
\text { customer company } \\
\text {-age of the } \\
\text { customer } \\
\text {-experience } \\
\text { purchasing } \\
\text { products and } \\
\text { services over } \\
\text { tise telephone }\end{array}$ & $\begin{array}{l}21 \\
24 \\
25\end{array}$ & $\begin{array}{l}\text { nominal } \\
\text { nominal } \\
\text { nominal }\end{array}$ & $\begin{array}{l}\text {-frequencies } \\
\text { - Coleman } \\
\text { Analysis } \\
\text { using the } \\
\text { satisfaction } \\
\text { measures }\end{array}$ \\
\hline
\end{tabular}

II. Research Objective: To collect customer perceptions regarding the appropriate usage of industrial telemarketing.

RESEARCH
QUESTIONS
4) What are the most
important factors which
determine whether
customers would purchase
and would not purchase
computer software products
and services over the
telephone?

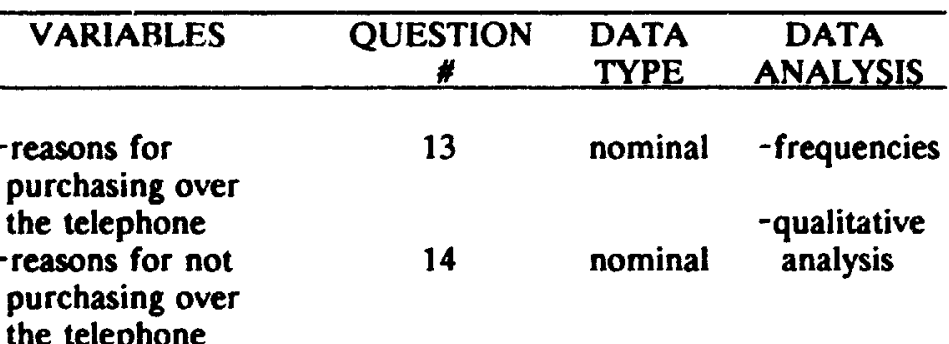

5) Are certain software product types more apt to be purchased over the telephone?

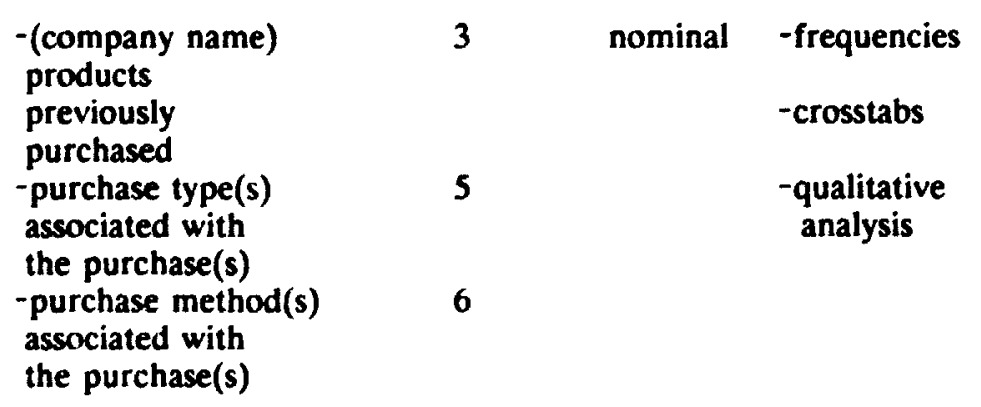


APPENDIX G (cont.)

\section{LINKAGE OF RESEARCH OUESTIONS, TELEPHONE SURVEY AND DATA ANALYSIS}

\begin{tabular}{l}
\multicolumn{1}{c}{ RESEARCH } \\
OUESTIONS \\
\hline 6) For first-time purchases, \\
how is the requirement for \\
product demonstrations by \\
product type related to the \\
appropriateness of \\
telemarketing by \\
product type?
\end{tabular}

7) For subsequent purchases, how is the requirement for product demonstrations by product type related to the appropriateness of telemarketing by product type?

\author{
VARIABLES \\ VARIABLES \\ -appropriateness \\ of telemarketing \\ by product type \\ for first-time \\ purchases \\ -importance of \\ demonstrations \\ by product type \\ for first-time \\ purchases
}

-appropriateness of telemarketing by product type for subsequent purchases

-importance of demonstrations by product type for subsequent purchases

\footnotetext{
-highest price willing to pay on first-time and subsequent telephone purchases

- conditionality of the first-time and subsequent purchase dollar limits

-factors the first-time and subsequent purchase dollar limits depend upon
}

\begin{tabular}{|c|c|c|}
\hline $\begin{array}{c}\text { QUESTION } \\
\end{array}$ & $\begin{array}{l}\text { DATA } \\
\text { TYPE: }\end{array}$ & $\begin{array}{c}\text { DATA } \\
\text { ANAIYSIS }\end{array}$ \\
\hline $\begin{array}{l}10 a \\
11 a \\
12 a\end{array}$ & $\begin{array}{l}\text { ordinal } \\
\text { ordinal } \\
\text { ordinal }\end{array}$ & $\begin{array}{l}\text {-frequencies } \\
\text { and medians } \\
\text {-crosstabs }\end{array}$ \\
\hline $\begin{array}{l}10 b \\
11 b \\
12 b\end{array}$ & $\begin{array}{l}\text { ordinal } \\
\text { ordinal } \\
\text { ordinal }\end{array}$ & $\begin{array}{l}\text {-Spearman } \\
\text { Rank Order } \\
\text { Correlations } \\
\text {-qualitative } \\
\text { analysis }\end{array}$ \\
\hline
\end{tabular}

\begin{tabular}{|c|c|c|}
\hline $\begin{array}{l}10 c \\
11 \mathrm{c} \\
12 \mathrm{c}\end{array}$ & $\begin{array}{l}\text { ordinal } \\
\text { ordinal } \\
\text { ordinal }\end{array}$ & $\begin{array}{l}\text {-frequencies } \\
\text { and medians } \\
\text {-crosstabs }\end{array}$ \\
\hline $\begin{array}{l}10 d \\
11 d \\
12 d\end{array}$ & $\begin{array}{l}\text { ordinal } \\
\text { ordinal } \\
\text { ordinal }\end{array}$ & $\begin{array}{l}\text {-Spearman } \\
\text { Rank Order } \\
\text { Correlations } \\
\text {-qualitative } \\
\text { analysis }\end{array}$ \\
\hline
\end{tabular}

15a nominal -frequencies

15d nominal

$$
\begin{aligned}
& \text {-qualitative } \\
& \text { analysis }
\end{aligned}
$$

If yes, what factors do the limits depend upon? Do these limits and conditions and subsequent purchases? vary between first-time encompass all product types?

customers would pay on a telephone purchase of a computer software product or service? Do these limits 


\section{APPENDIX H}

\section{SAMPLE CGLEMAN ANALYSIS CALCULATIONS}

Coleman (1964) provided the basis for the procedures and calculations used to determine the effect sizes that demographic factors have on customer satisfaction. These procedures are listed and described below and are further illustrated with sample calculations.

\section{PROCEDURES:}

1. Derivation of the Effect Equations:

i) Specify variables;

ii) Partition transition rates; and

iii) Estimate proportions by standardizing the parameters and using the method of least squares to generate the equations.

II. Calculation of the Effect Parameters:

i) Put data into tabular form using crosstabulations;

ii) Substitute percentage figures into the equations and calculate the effect sizes; and

iii) Analyze the residuals.

III. Test the Hypothesis:

i) Specify null and alternate hypothesis;

ii) Calculate the variance;

iii) Calculate an estimate of the variance and the standard deviation; and

iv) Calculate the probability that each effect might be zero in the population; and

v) Identify the corresponding significance level from the tables of cumulative normal distribution. 


\section{APPENDIX H (cont.)}

\section{SAMPLE COLEMAN ANALYSIS CALCULATIONS}

\section{Derivation of the Effect Equations:}

i) supecify variables

Three demographic factors were examined in this thesis. They include the amount of experience the customer has purcihasing products through industrial telemarketing, the age of the customer and the size of his/her respective company.

$$
\begin{array}{ll}
x_{0}=\text { less experienced } & x_{1}=\text { more experienced } \\
y_{0}=\text { younger } & y_{1}=\text { older } \\
z_{0}=\text { small company } & z_{1}=\text { large company }
\end{array}
$$

State $0=$ dissatisfied

State $1=$ satisfied

* Assume a two way effect where:

$\mathrm{q}_{01}=$ transition rate from state 0 to 1

$q_{10}=$ transition rate from state 1 to 0

$\alpha_{x}=$ effect of experience using telemarketing

$\alpha_{y}=$ effect of age

$\alpha_{z}=$ effect of company size

$\epsilon_{1}=$ random shock due to other variables in the direction of satisfaction

$\epsilon_{2}=$ random shock due to other variables in the direction of dissatisfaction

\section{ii) Partition transition rates}

There are three effect parameters and two random shocks in the direction of satisfaction and dissatisfaction and eight resulting transition rates whose differences lie in the direction in which the effect parameter operates.

1. Cell 000: less experienced, younger, small company

$$
\begin{aligned}
& \mathrm{q}_{10}=\alpha_{x}+\alpha_{y}+\alpha_{2}+\epsilon_{2} \\
& \mathrm{q}_{01}=
\end{aligned}
$$


APPENDIX $\mathrm{H}$ (cont.)

SAMPLE COLEMAN ANALYSIS CALCULATIONS

2. Cell 100: more experienced, younger, small company

$$
\begin{aligned}
& q_{10}=\alpha_{x}+\alpha_{y}+\alpha_{z}+\epsilon_{2} \\
& q_{01}=\epsilon_{1}
\end{aligned}
$$

3. Cell 010: less experienced, older, small company

$$
\begin{aligned}
& q_{10}=\alpha_{x}+\alpha_{y}+\alpha_{z}+\epsilon_{2} \\
& q_{01}=\epsilon_{1}
\end{aligned}
$$

4. Cell 110: more experienced, older, small company

$$
\begin{aligned}
& q_{10}= \\
& q_{01}=\alpha_{x}+\alpha_{y}+\alpha_{z}+\epsilon_{2} \\
& \epsilon_{1}
\end{aligned}
$$

5. Cell 001: less experienced, younger, large company

$$
\begin{aligned}
& q_{10}=\alpha_{x}+\alpha_{y}+\epsilon_{z}+\epsilon_{2} \\
& q_{01}=\epsilon_{1}
\end{aligned}
$$

6. Cell 101: more experienced, younger, large company

$$
\begin{aligned}
& q_{10}=\alpha_{x}+\alpha_{y}+\epsilon_{z}+\epsilon_{2} \\
& q_{01}=\epsilon_{1}
\end{aligned}
$$

7. Cell 011: less experienced, older, large company

$$
\begin{aligned}
& q_{10}=\alpha_{x}+\alpha_{y}+\alpha_{z}+\epsilon_{2} \\
& q_{01}=\epsilon_{1}
\end{aligned}
$$

8. Cell 111: more experienced, older, large company

$$
\begin{aligned}
& q_{10}= \\
& q_{01}=a_{x}+a_{y}+a_{z}+\epsilon_{2} \\
& \epsilon_{1}
\end{aligned}
$$




\section{APPENDIX H (cont.)}

\section{SAMPLE COLEMAN ANALYSIS CALCILATIONS}

iii) Estimate Proportions

* Assume statistical equilibrium: $n_{1} q_{10}=n_{11} l_{111}$

$$
\begin{aligned}
& \text { or } n_{1}=q_{01} \text { where } n_{1} / n_{1}+n_{11} \text { is } \\
& \text { the proportion in } \\
& n_{1}+n_{0} \quad q_{01}+q_{10} \quad \text { variable. }
\end{aligned}
$$

To estimate the parameters by use of the observed proportions in state 1 (i.e. satisfaction) for each classification, it is necessary (o) relate or compare the transition rates to the proportions. With three demographic factors, the estimated proportions are $P^{*}, P_{1}^{*}, P_{2}^{*}, P_{12} *$. $P_{3}{ }^{*}, P_{13}{ }^{*}, P_{23}^{*}$ and $P_{123}{ }^{*}$.

$$
\begin{aligned}
& P^{*}= \\
& \epsilon_{1} \\
& \mathbf{P}_{3}^{*}=\boldsymbol{\alpha}_{1}+\mathbf{\epsilon}_{1} \\
& \overline{\alpha_{x}+\alpha_{y}+\alpha_{z}+\epsilon_{1}+\epsilon_{2}} \\
& a_{x}+a_{y}+a_{2}+c_{1}+c_{2} \\
& P_{1}^{*}=\alpha_{x}+\epsilon_{1} \\
& P_{13}{ }^{*}=\alpha_{x}+\alpha_{1}+\epsilon_{1} \\
& \overline{\alpha_{x}+\alpha_{y}+\alpha_{z}+\epsilon_{1}+\epsilon_{2}} \\
& a_{x}+a_{y}+\alpha_{1}+c_{1}+c_{2} \\
& \mathrm{P}_{2}^{*}= \\
& \alpha_{y}+\epsilon_{1} \\
& P_{23}{ }^{*}=\alpha_{y}+\alpha_{1}+\epsilon_{1} \\
& \overline{\alpha_{x}+\alpha_{y}+\alpha_{z}+\epsilon_{1}+\epsilon_{z}} \\
& \alpha_{x}+\alpha_{y}+\alpha_{1}+c_{1}+c_{2} \\
& P_{12}{ }^{*}=\alpha_{x}+\alpha_{y}+\epsilon_{1} \\
& \overline{\alpha_{x}+\alpha_{y}+\alpha_{z}+\epsilon_{1}+\epsilon_{2}} \\
& P_{123}=\frac{\alpha_{x}+\alpha_{y}+\alpha_{1}+\epsilon_{1}}{\alpha_{x}+\alpha_{y}+\alpha_{1}+\epsilon_{1}+\epsilon_{2}}
\end{aligned}
$$




\section{APPENDIX H (cont.)}

\section{SAMPLE COLEMAN ANALYSIS CALCULATIONS}

This technique analyzes the relations of $x, y$ and $z$ by estimating five parameters (i.e. $\alpha_{x}, \alpha_{y}, \alpha_{z}, \epsilon_{1}$ and $\epsilon_{2}$ ), four of which are independent, with eight pieces of information. Therefore, there is an excess of data. The method of least squares is used so that a set of parameters whose sum of squared deviations are a minimum can be generated. The notation can be simplified by dividing through by the denominators to get standardized parameters which add up to 1.0. These are called $a_{1}, a_{2}, a_{3}, r$ and $s$ in place of $\alpha_{x}, \alpha_{y}, \alpha_{2}, \epsilon_{1}$ and $\epsilon_{2}$ respectively.

Therefore,

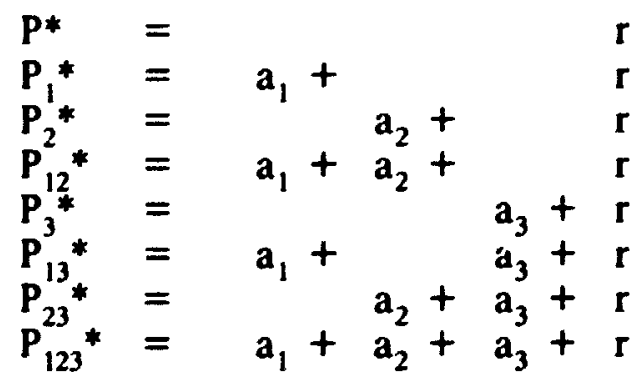

The next step is to calculate values for $a_{1}, a_{2}, a_{3}, r$ and $s$ (i.e. the empirical estimates in the model) so the actual proportions can be estimated.

The method of least squares consists of finding the minimum summation of the squared differences between the actuals and the estimates or $\Sigma\left(P_{i}-P_{i}{ }^{*}\right)^{2}$. The following equations were derived by adding the $P_{i}$ 's where this parameter contributes and subtracting the $P_{i}$ 's where it does not and dividing by four (i.e. four differences).

$$
\begin{aligned}
& a_{1}=1 / 4\left(P_{1}+P_{12}+P_{13}+P_{123}-P-P_{2}-P_{3}-P_{23}\right) \\
& a_{2}=1 / 4\left(P_{2}+P_{12}+P_{23}+P_{123}-P-P_{1}-P_{3}-P_{13}\right) \\
& a_{3}=1 / 4\left(P_{3}+P_{13}+P_{23}+P_{123}-P-P_{1}-P_{2}-P_{12}\right) \\
& r=1 / 4\left(2 P+P_{1}+P_{2}+P_{3}-P_{123}\right) \\
& s=1-a_{1}-a_{2}-a_{3}-r
\end{aligned}
$$




\section{APPENDIX H (cont.)}

\section{SAMPLE COLEMAN ANALYSIS CALCULATIONS}

$a_{1}, a_{2}$ and $a_{3}$ can be rewritten as:

$$
\begin{aligned}
& a_{1}=1 / 4\left[\left(P_{1}-P\right)+\left(P_{12}-P_{2}\right)+\left(P_{13}-P_{3}\right)+\left(P_{123}-P_{23}\right)\right] \\
& a_{2}=1 / 4\left[\left(P_{2}-P\right)+\left(P_{12}-P_{1}\right)+\left(P_{23}-P_{3}\right)+\left(P_{123}-P_{13}\right)\right] \\
& a_{3}=1 / 4\left[\left(P_{3}-P\right)+\left(P_{13}-P_{1}\right)+\left(P_{23}-P_{2}\right)+\left(P_{123}-P_{12}\right)\right]
\end{aligned}
$$

II. Calculation of the Effect Parameters:

\begin{tabular}{|c|c|c|c|c|c|c|c|c|}
\hline & \multicolumn{4}{|c|}{ Small Company } & \multicolumn{4}{|c|}{ Large Company } \\
\hline & & nger & & & & ger & () & \\
\hline & Less & More & Less & More & Less & More & less & More \\
\hline $\mathbf{s}$ & $\begin{array}{c}.22 \\
9 \\
(\mathrm{P})\end{array}$ & $\begin{array}{c}.10 \\
10 \\
\left(P_{1}\right)\end{array}$ & $\begin{array}{c}.30 \\
10 \\
\left(\mathbf{P}_{2}\right)\end{array}$ & $\begin{array}{c}.07 \\
14 \\
\left(P_{12}\right)\end{array}$ & $\begin{array}{c}.13 \\
8 \\
\left(\mathbf{P}_{3}\right)\end{array}$ & $\begin{array}{c}.17 \\
18 \\
\left(P_{13}\right)\end{array}$ & $\begin{array}{c}.22 \\
18 \\
\left(P_{23}\right)\end{array}$ & $\begin{array}{c}.23 \\
13 \\
\left(P_{13}\right)\end{array}$ \\
\hline
\end{tabular}

i) Put data into tabular form using crosstabulations

$$
\begin{aligned}
& \text { RELATION OF COMPANY SIZE, AGE AND AMOUNT OF IXXPISRIENCI! } \\
& \text { USING TELEMARKETING TO SATISFACTION USING TBI JMARKIYTING } \\
& \text { FOR PURCHASING COMPUTER SOFTWARE PRODUCTS (PRODSAT) }
\end{aligned}
$$

ii) Substitute percentage figures into the equations and calculate the effect sizes

$$
\begin{aligned}
\mathrm{a}_{1} & \left.=1 / 4\left[\mathrm{P}_{1}-\mathrm{P}\right)+\left(\mathrm{P}_{12}-\mathbf{P}_{2}\right)+\left(\mathrm{P}_{13}-\mathbf{P}_{3}\right)+\left(\mathrm{P}_{123}-\mathbf{P}_{23}\right)\right] \\
& =1 / 4[(.10-.22)+(.07-.30)+(.17-.13)+(.23-.22)] \\
& =1 / 4[-.12-.23+.04+.01] \\
& =1 / 4[-.30] \\
& =-.075 \text { effect of experience using telemarketing } \\
\mathrm{a}_{2} & =1 / 4\left[\left(\mathrm{P}_{2}-\mathrm{P}\right)+\left(\mathrm{P}_{12}-\mathrm{P}_{1}\right)+\left(\mathrm{P}_{23}-\mathrm{P}_{3}\right)+\left(\mathrm{P}_{123}-\mathrm{P}_{13}\right)\right] \\
& =1 / 4[(.3-.22)+(.07-.10)+(.22-.13)+(.23-.17)] \\
& =1 / 4[.08-.03+.08+.06] \\
& =1 / 4[.19] \\
& =.048 \text { effect of age }
\end{aligned}
$$




\section{APPENDIX H (cont.)}

\section{SAMPLE COLEMAN ANALYSIS CALCULATIONS}

$$
\begin{aligned}
\mathrm{a}_{3} & =1 / 4\left[\left(\mathrm{P}_{3}-\mathrm{P}\right)+\left(\mathrm{P}_{13}-\mathrm{P}_{1}\right)+\left(\mathrm{P}_{23}-\mathrm{P}_{2}\right)+\left(\mathrm{P}_{123}-\mathrm{P}_{12}\right)\right] \\
& =1 / 4[(.13-.22)+(.17-.10)+(.22-.30)+(.23-.07)] \\
& =1 / 4[-.09+.07-.08+.16] \\
& =1 / 4[.06] \\
& =.015 \quad \text { effect of company size } \\
\mathbf{r} & =1 / 4\left[\left(2 \mathrm{P}+\mathrm{P}_{1}+\mathrm{P}_{2}+\mathrm{P}_{3}-\mathrm{P}_{123}\right)\right] \\
& =1 / 4[(2 \times .22)+.10+.30+.13-.23] \\
& =1 / 4[.44+.10+.30+.13-.23] \\
& =1 / 4[.74] \\
& =.185 \quad \text { random shock due to other variables in the } \\
& \quad \text { direction of satisfaction } \\
\mathbf{s} & =1-\mathrm{a}_{1}-\mathrm{a}_{2}-\mathrm{a}_{3}-\mathrm{r} \\
& =1-(-.075)-(.048)-.015-.185 \\
& =1+.075-.048-.015-.185 \\
& =.827 \quad \frac{\text { random shock due to other variables in the }}{\text { direction of dissatisfaction }}
\end{aligned}
$$

iii) Analyze the residuals

$\begin{array}{lllllllll}\text { Proportions } & \mathbf{P} & \mathbf{P}_{1} & \mathbf{P}_{2} & \mathbf{P}_{12} & \mathbf{P}_{3} & \mathbf{P}_{13} & \mathbf{P}_{23} & \mathbf{P}_{123} \\ \mathbf{P}_{\mathrm{i}} \text { (actual) } & .22 & .10 & .30 & .07 & .13 & .17 & .22 & .23 \\ \mathbf{P}_{\mathrm{i}}^{*} \text { (est.) } & .19 & .11 & .23 & .16 & .20 & .13 & .25 & .17 \\ & - & - & - & - & - & - & - & - \\ \mathbf{P}_{\mathrm{i}}{ }^{-\mathbf{r}_{\mathrm{i}}^{*}} & .03 & -.01 & .07 & -.09 & -.07 & .04 & -.03 & .06 \\ & - & - & - & - & - & - & - & -\end{array}$

The deviations of the estimated values from the actual values are small and do not show any consistent pattern. Therefore, the estimates from the model provide a good fit to the data. 


\section{APPENDIX H (cont.)}

\section{SAMPLE COLEMAN ANALYSIS CALCULATIONS}

\section{Test the Hypothesis:}

i) Specify null and alternate hypotheses

$$
\begin{aligned}
& H_{0}: \quad \operatorname{pr}\left\{a_{1}{ }^{*}=0 \quad H_{a}: \quad \operatorname{pr}\left\{a_{1}{ }^{*} \neq 0\right.\right. \\
& \text { pr }\left\{a _ { 2 } { } ^ { * } = 0 \quad \text { pr } \left\{a_{2}^{*} \neq 0\right.\right. \\
& \text { pr }\left\{a _ { 3 } { } ^ { * } = 0 \quad \text { pr } \left\{a_{3}{ }^{*} \neq 0\right.\right.
\end{aligned}
$$

$\mathrm{H}_{0}$ : Experience using telemarketing, age and company size have no effect on customer satisfaction/dissatisfaction.

$\mathrm{H}_{\mathrm{a}}$ : Experience using telemarketing, age and company size have an effect on customer satisfaction/dissatisfaction.

ii) Calculate the variance

The variance is calculated using the following formula

$$
\begin{aligned}
& \hat{\sigma P}_{j}^{2}=\underline{P_{j}\left(1-P_{j}\right)} \\
& \mathbf{r}_{\mathrm{j}} \\
& \text { where } \mathrm{j}=\text { the } \\
& \text { independent attribute } \\
& \text { groupings } \\
& \hat{\sigma^{2}}=\frac{.22-.78}{9}=.019 \\
& \hat{\sigma}_{3}{ }^{2}=\frac{.13-.87}{8}=.014 \\
& \hat{\sigma}_{1}{ }^{2}=\frac{.10-.90}{10}=.009 \\
& \sigma_{13}{ }^{2}=\frac{.17-.83}{18}=.008 \\
& \sigma_{2}^{2}=\frac{.30-.70}{10}=.021 \\
& \hat{\sigma}_{23}{ }^{2}=\frac{.22-.78}{18}=.010 \\
& \hat{\sigma}_{12}{ }^{2}=\frac{.07-.93}{14}=.005 \\
& \sigma_{123}{ }^{2}=\frac{23 \cdot .77}{13}=.014
\end{aligned}
$$




\section{APPENDIX H (cont.) \\ SAMPLE COLEMAN ANALYSIS CALCULATIONS}

iii) Calculate an estimate of the variance and the standard deviation

The following formula is used to calculate an estimate of the variance:

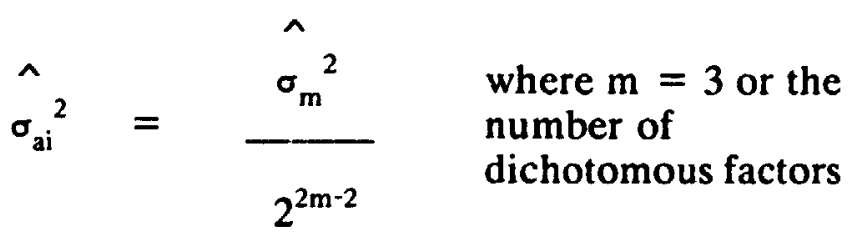

$$
\begin{aligned}
& =1 / 16(\text { sum of the variances }) \\
& =1 / 16(.019+.009+.021+.005+.014+.008+.010+.014) \\
& =1 / 16(.1) \\
& =.00625
\end{aligned}
$$

The standard deviation can be calculated by taking the square root of the variance.

$$
\hat{\sigma_{\mathrm{ai}}} \quad=.079
$$

iv) Calculate the probability that each effect might be zero in the population

This probability can be calculated using the following formula:

$$
\begin{aligned}
& u_{\mathrm{i}}=\frac{\mathrm{a}_{\mathrm{i}}-0}{\frac{\sigma_{\mathrm{ai}}}{\hat{N}}}=\begin{array}{l}
\text { where } \mathrm{u}_{\mathrm{i}} \text { is } \\
\text { the standardized } \\
\text { normal deviate. }
\end{array} \\
& \mathrm{u}_{1}=\frac{.075}{.079}=-.949 \\
& \mathrm{u}_{2}=\frac{.048}{.079}=.608 \\
& \mathrm{u}_{3}=\frac{.015}{.079}=.190
\end{aligned}
$$




\section{APPENDIX H (cont.)}

\section{SAMPLE COLEMAN ANALYSIS CALCULATIONS}

v) Identify the corresponding significance level from the tables of cumulative normal distribution

$$
\begin{array}{lll}
\mathrm{H}_{\mathrm{a}}: & \operatorname{pr}\left\{\mathrm{a}_{1}{ }^{*} \neq 0=0\right. & .1736 \\
\operatorname{pr}\left\{\mathrm{a}_{2}{ }^{*} \neq 0=\right. & .2743 \\
\operatorname{pr}\left\{\mathrm{a}_{3}{ }^{*} \neq 0=\right. & .4246
\end{array}
$$

Therefore, at $a=.10, \mathrm{H}_{0}$ cannot be rejected because there is a probability that these effects are a consequence of chance. 


$$
\begin{aligned}
& \text { END } \\
& 2405.93 \\
& \text { FIN }
\end{aligned}
$$

